\title{
Estratégias de teste e validação no contexto de decompilação
}

\author{
Percy Antonio Pari Salas
}

Orientador:

Prof. Dr. José Carlos Maldonado

Dissertação apresentada ao Instituto de (iênuas Matemáticas e de Compuaçĩo ICMC-ISP. como parte des rapuisitos fara oblenção do titulo de Mestre em Ciencias de Computaçăo e Matemática Computacional.

\section{USP - São Carlos \\ $M a r c o / 2002$}

\begin{tabular}{l|ll} 
Revisada) & $18 / 03 / 2002$ \\
Visto do Orientador:
\end{tabular}


Aos meus pais,

Alfonso e Nilda 


\section{Agradecimentos}

A Deus por estar sempre comigo.

Ao meu orientador, Prof. Dr. José Carlos Maldonado, pelo esforço, dedicação e amizade. Especialmente pela troca de idéias e pelo apoio nos momentos certos.

À minha família porque, ainda que longe, souberam ajudar-me a superar os diversos obstáculos e demonstraram-me sempre muito carinho.

À Rita pelo amor, dedicação e compreensão, que fizeram com que se acrescentasse em mim o desejo de melhorar cada dia, tanto pessoal quanto profissionalmente.

Aos colegas e compatriotas, Alex, Carlos, Charlie, Pastor, César, Eduardo, com os quais morei junto na minha estada em São Carlos e que souberam compreender-me e suportar-me. A todos os demais, que não menciono porque seria uma lista longa, mas que, com certeza, sempre levarei no meu coração.

Ao pessoal do Labes, especialmente Adenilso e Auri, por todo o apoio e amizade que sempre me brindaram.

Ao pessoal administrativo do ICMC, em especial à Beth, Laura, Ana Paula e Marília, pela disposição e atenção que sempre demonstraram.

Aos novos amigos que fiz em São Carlos e que ajudaram a sentir-me como se estivesse em casa.

À CAPES pelo apóio financeiro. 
Numa realidade em que a maioria das atividades desenvolvidas por nós são realizadas com apoio de sistemas computacionais, torna-se ainda mais relevante a atividade de validação desses sistemas. A decompilação é uma das atividades, dentro do processo de desenvolvimento desses sistemas, que está sendo muito difundida atualmente. Assim, torna-se necessária a existência de técnicas e estratégias que visem a aumentar a confiança na corretitude tanto das ferramentas que sc usam quanto dos produtos que se geram. Este trabalho propõe uma estratégia incremental de aplicação de diversas técnicas e critérios para o teste e validação de ferramentas de decompilação e, conseqüentemente, dos produtos gerados por um decompilador. Para ilustrar o emprego da estratégia definida foram realizados dois estudos de caso, usando os decompiladores Dcc(para a linguagem alvo C) e JAD (para a linguagem alvo Java). 
Most of our activities are carried out with the assistance of computational systems, which makes even more relevant the validation activity of such systems. Decompilation is one of the activities of the software development process that is being very much difussed nowadays. Thus, the existence of testing and validation techniques and strategies that aim at incrementing confidence on decompilation tools and products becomes a necessity. This work proposes an incremental strategy composed of various techniques and testing criteria for testing and validating decompilation tools and related products. To illustrate that strategy two case studies were used, one case study using Dcc (a decompiler for C language) and another one using JAD (a decompiler for Java language). 
1 Introdução 1

1.1 Considerações iniciais . . . . . . . . . . . . . . . . . . 1

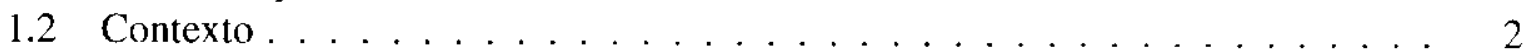

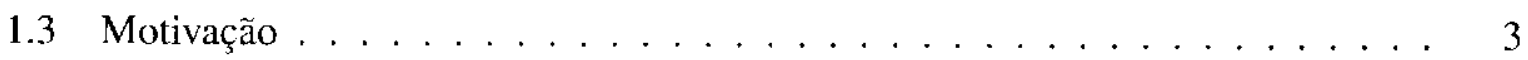

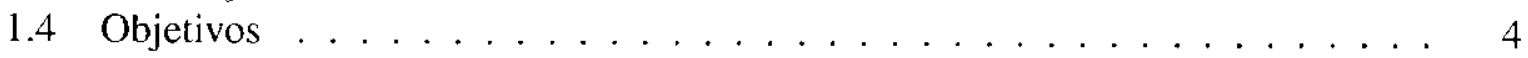

1.5 Estrutura da monografia . . . . . . . . . . . . . . 5

2 Decompilação de software 6

2.1 Considerações inicias . . . . . . . . . . . . . . . . . . 6

2.2 Um processo de decompilação de arquivos binários . . . . . . . . . . . . 6

2.2 .1 Loader . . . . . . . . . . . . . . . . . . . . . . 8

2.2 .2 Gerador de assinaturas . . . . . . . . . . . . . . . . 8

2.2 .3 Gerador de protótipos . . . . . . . . . . . . . . . . 8

2.2 .4 Desassembler . . . . . . . . . . . . . . . . . . 9

2.2 .5 Decompilador . . . . . . . . . . . . . . . . . . 9

2.2 .6 Correspondência entre bibliotecas . . . . . . . . . . . 11

2.2 .7 Pós-processador . . . . . . . . . . . . . . . . . . 11

2.3 Ferramentas de decompilação . . . . . . . . . . . . . . . . . 11

2.4 Considerações finais . . . . . . . . . . . . . . . . . . 12

3 Teste de Software 14

3.1 Considerações iniciais . . . . . . . . . . . . . . . . . . . 14

3.2 Terminologia e conceitos básicos . . . . . . . . . . . . . . . . 14

3.3 Técnicas e critérios de teste . . . . . . . . . . . . . 15

3.3 .1 Técnicas e critérios funcionais . . . . . . . . . . . 16

3.3 .2 Técnicas e critérios estruturais . . . . . . . . . . . . . 17

3.3 .3 Técnicas baseadas em erros . . . . . . . . . . . . . . . . . . . . . . . . . . . .

3.4 Ferramentas de apoio ao teste e validação . . . . . . . . . . . . . . 21

3.4 .1 A ferramenta de teste Poke-Tool . . . . . . . . . . . . . . 22

3.4 .2 A ferramenta de teste Proteum . . . . . . . . . . . . . 23

3.4 .3 A ferramenta JCover . . . . . . . . . . . . . . . . . . . . . . . 24

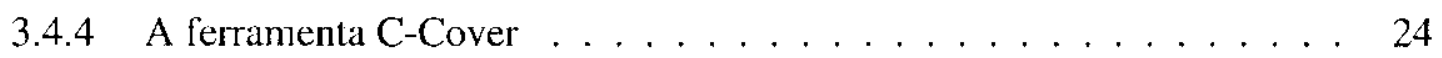

3.4.5 As ferramentas JUnit e Jester . . . . . . . . . . . . . . 25 


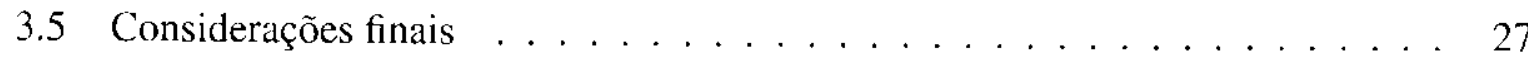

4 Teste de Software no contexto de decompilação 28

4.1 Considerações iniciais . . . . . . . . . . . . . . . . . . 28

4.2 Considerações para as atividades de teste e validação . . . . . . . . . . . . . . . 29

4.3 Procedimento para teste e validação . . . . . . . . . . . . . . . 30

4.4 Estudo de caso - Linguagem C . . . . . . . . . . . . . . . . . . 36

4.4.1 Ambiente de decompilação e configuração . . . . . . . . . . . . 36

4.4.2 Passo 1. Determinação do conjunto de casos de teste para o decompilador Dcc . . . . . . . . . . . . . . . . . . . . . 38

4.4.3 Passo2. Teste e validação dos programas decompilados pelo decompilador Dcc . . . . . . . . . . . . . . . . . . . . . 43

4.4 Resultados . . . . . . . . . . . . . . . . . . . . 48

4.5 Estudo de caso - Linguagem Java . . . . . . . . . . . . . . . . . . . . . 51

4.5.1 Ambiente de decompilação e configuração . . . . . . . . . . . . 51

4.5.2 Passo 1. Determinação do conjunto de casos de teste para o decompilador JAD . . . . . . . . . . . . . . . . . . . . . 52

4.5.3 Passo 2. Teste e validação das classes Java geradas . . . . . . . . . . . . 54

4.5 .4 Resultados . . . . . . . . . . . . . . . . . 59

4.6 Considerações finais . . . . . . . . . . . . . . . . . . 60

5 Conclusões e Trabalhos Futuros $\quad 63$

5.1 Considerações iniciais . . . . . . . . . . . . . . . . 63

5.2 Conclusões e contribuições . . . . . . . . . . . . . . . 63

5.2 .1 Trabalhos futuros . . . . . . . . . . . . . . . 65

$\begin{array}{lr}\text { Referências Bibliográficas } & 65\end{array}$

A Código fonte de programas $\quad 71$

A.1 O programa fact . . . . . . . . . . . . . . . . . 71

A.2 A classe SimpleTestHarness . . . . . . . . . . . . . . 74 


\section{Lista de Figuras}

2.1 O processo de decompilação . . . . . . . . . . . . . . . . 7

2.2 Fases de um decompilador . . . . . . . . . . . . . . . . . 10

3.1 Uma vista simplificada do framework JUnit . . . . . . . . . . . . 26

4.1 Procedimento para teste e validação de ferramentas de decompilação . . . . . . 31

4.2 Programas com erros detectados em cada etapa do Passo 2 - Estudo de caso C . 49

4.3 Porcentagem de programas errados detectados em cada etapa do Passo 2 - Estudo de caso C . . . . . . . . . . . . . . . . . . . . 50

4.4 Classes com erros detectados em cada etapa do Passo 2 - Estudo de caso Java . 60

4.5 Porcentagem de classes erradas detectadas em cada etapa do Passo 2 - Estudo de caso Java . . . . . . . . . . . . . . . . . . . . . . . . 61 


\section{Lista de Tabelas}

2.1 Resumo de características dos decompiladores Dcc, JAD e REC . . . . . . 13

4.1 Evolução do benchmark para validar o decompilador Dcc - Estudo de caso C . 39

4.2 Resultados da inspeção do código fonte do decompilador Dec - Estudo de caso C 41

4.3 Programas .EXE decompilados - Estudo de caso C . . . . . . . . . . . . . 42

4.4 Programas .EXE decompilados e recompilados com sucesso-Estudo de caso C 43

4.5 Resultados da verificação de funcionalidade com teste aleatório - Estudo de caso C 44

4.6 Porcentagens de adequação a critérios de teste estrutural - Estudo de caso C . . 46

4.7 Resultados da verificação de funcionalidade com casos de teste adequados a critério(s) de teste estrutural - Estudo de caso C . . . . . . . . . . . . . . . . 47

4.8 Resultados da aplicação do critério Análise de Mutantes - Estudo de caso C . . 48

4.9 Resumo da evolução do benchmark para o teste e validação do decompilador Dcc 48

4.10 Arquivos binários .CLASS a serem decompilados - Estudo de caso Java . . . . 53

4.11 Classes não recompiladas - Estudo de caso Java . . . . . . . . . . . . . 55

4.12 Classes decompiladas do projeto Mauve que apresentaram erros funcionais . . 56

4.13 Resultados do teste aleatório - Estudo de caso Java . . . . . . . . . . . . 56

4.14 Porcentagens de adequação a critérios estruturais - Estudo de caso Java . . . . 58

4.15 Resultados da aplicação do critério Análise de Mutantes - Estudo de caso Java . 59

A.1 Código fonte original do programa fact $\ldots \ldots \ldots \ldots . \ldots 72$

A.2 Código fonte decompilado do programa fact . . . . . . . . . . . . 73 


\subsection{Considerações iniciais}

O processo de desenvolvimento de software é composto por diversas atividades, entre elas, atividades de garantia de qualidade, que envolve VV\&T - Verificação, Validação c Teste. A atividade de validação dos processos computacionais torna-se muito importante nos tempos atuais, nos quais a maioria das atividades desenvolvidas no cotidiano são auxiliadas por sistemas de computador.

Dentro do processo de desenvolvimento de software, em permanente evolução, a Engenharia Reversa tem-se tornado cada vez mais importante $c$ tem recebido importantes aportes de pesquisas acadêmicas e bastante apoio da industria. A decompilação, sendo parte complementar da Engenharia Reversa, é uma atividade ligada ao processo de desenvolvimento de software, que visa a gerar, a partir do código objeto de um programa de computador, uma versão em código fonte, escrito em alguma linguagem de alto nível, funcionalmente equivalente ao programa que the deu origem. A decompilação está ganhando cada vez mais espaço tanto no ambiente acadêmico quanto no ambiente industrial/comercial com a realização de diversas pesquisas, algumas patrocinadas por empresas de desenvolvimento de software e, inclusive, com a criação e comercialização de ferramentas e serviços de decompilação. 
Neste capítulo são discutidos o contexto, as motivações, a relevância do tema da Dissertação dentro da área da Engenharia de Software e os objetivos específicos a serem atingidos. A organização da Dissertação é apresentada na última seção deste capítulo.

\subsection{Contexto}

A decompilação é o processo que visa a converter o código objeto (exccutável) de um programa de computador para uma versão, semanticamente compatível, em código fonte escrito em alguma linguagem de alto nível. No cntanto, vale a pena destacar que a decompilação é um processo incompleto e que, em muitos casos, requer a intervenção do usuário, dada a quantidade de informação "perdida" durante o processo de compilação (Cifuentes, 1994; Housel III, 1973).

A decompilação de arquivos binários é um conceito que existe desde o início dos anos 60 . Desde aquela época tentou-se incluir a decompilação como uma parte do processo de software, como fez Halstead (1977). Halstead é considerado o pai da decompilação, pois foi o primeiro a usar o termo para designar o processo no seu livro "Machine Independent Computer Programming", publicado em 1962.

A decompilação tem crescido muito nesses últimos anos, tanto dentro da área acadêmica quanto dentro da área comercial. Muitas empresas relacionadas ao desenvolvimento de software têm começado a oferecer serviços de decompilação para aquelas empresas que ainda usam sistemas antigos (sistemas legados), especialmente sistemas da IBM como o 360, o 370, entre outros, que apresentam pouca compatibilidade e pobre competitividade com sistemas modernos. A decompilação desses sistemas é fcita para linguagens como Cobol e C.

Existem duas grandes subáreas (Cifuentes, 1994) nas quais a decompilação é usada: manutenção de software e segurança.

Dentro da área de manutenção de software identificam-se usos tais como (Cifuentes, 1994; O'Gorman, 1991):

- Facilitar a migração de um programa binário escrito numa linguagem ou para uma arquitetura de hardware já obsoletas para alguma outra linguagem ou arquitetura. Cabe destacar que esta é a motivação sob a qual foram desenvolvidos a maioria dos esforços de decompilação já publicados.

- Recuperar ou regenerar o código fonte perdido ou inacessível.

- Depurar programas binários com erros conhecidos quando o código fonte não esteja disponível. 
- Produzir uma versão revisada do programa original logo após um processo de otimização.

Observa-se que os dois primeiros usos mencionados encontram-se relacionados dirctamente à Engenharia Reversa.

$\mathrm{Na}$ área de segurança podem-se encontrar usos tais como:

- Desenvolvimento de mélodos para fazer auditoria. Os decompiladores poderiam ajudar a determinar se o código binário de um programa, de contabilidade por exemplo, corresponde realmente ao código fonte entregue para o auditor.

- Em sistemas críticos, quando não se possa confiar completamente num determinado compilador, verificar que o código objeto produzido por ele seja cquivalente à especificação.

- Detecção e eliminação de código indesejável como vírus de software e outros.

Assim sendo, a decompilação tem provocado avanços e pesquisas tanto diretamente na sua área específica, quanto em outras áreas como otimização de compiladores, criptografia, verificação de software, tradução binária, entre outras.

No aspecto legal, alguns países como os Estados Unidos, a Austrália e os países da Comunidade Européia, têm desenvolvido legislações que contemplam o processo de decompilação como um ato lícito sempre que esteja restringido a certos usos, especialmente no caso de atingir interoperabilidade entre sistemas de software, $\mathrm{c}$ aqueles usos relacionados com a pesquisa sobre criptografia e segurança. O Japão também se apresenta como um país onde, ainda que não tenha na sua legislação menção específica para casos de decompilação, a posição das cortes sustenta a afirmação de que cla é permitida e é considerada um ato lícito sempre que não se produza uma cópia substancialmente similar em expressão ao programa original (Mishra, 1997).

\subsection{Motivação}

A decompilação, como parte do processo de desenvolvimento de software, é uma atividade que requer métodos $\mathrm{e}$ tćcnicas que forneçam às pessoas envolvidas a possibilidade de validar c verificar as ferramentas que utilizam $\mathfrak{c}$ os resultados que elas produzem. Porém, ainda não existe dentro da literatura da área nenhuma menção específica sobre tais métodos e técnicas. Os pesquisadores da área têm efetuado alguns tipos de testes sobre as ferramentas existentes, mas sem contar com procedimentos estruturados, nem seguindo padrões que assegurem um alto grau de efetividade de tais testes. Poder-se-ia dizer que o conhecimento que se tem sobre a verificação e validação dessas ferramentas de decompilação é ainda empírico, ou, se existe pelo 
menos uma heurística, ela existe isoladamente. Além disso, em relação ao testc c validação dos produtos gerados, não se obscrva a existência de métodos sistemáticos para a validação desses produtos.

A inclusão da decompilação como um processo lcgalmente aceito sob detcrminadas restrições vai requerer também técnicas e métodos que possam garantir que o processo ć realizado segundo cstabelecido, e que os resultados são concordantes com a legislação e critérios técnicos.

Por outro lado, na área de teste e validação de software muitas pesquisas apresentam como resultados diversas técnicas e critérios de teste que visam a medir quão adequado a um programa $P$ ć um determinado conjunto de casos de teste $T$. Outras pesquisas têm demonstrado que algumas dessas técnicas são mais rigorosas do que outras na detecção de erros, entretanto algumas são incomparáveis entre si. De fato, se forem levados em consideração os resultados e as pesquisas dessa área, os testes realizados em ferramentas de decompilação foram feitos usando os critérios mínimos exigidos e considerados entre os mais fracos na sua habilidade de detectar erros.

Portanto, motiva-se investigar a adequação do conhecimento da área de teste e validação de software para validar as ferramentas de decompilação e os produtos por elas gerados (programas decompilados), aumentando assim a confiança nas ferramentas e nos produtos.

\subsection{Objetivos}

No presente trabalho de pesquisa objetiva-se investigar uma estratégia incremental de teste e validação para ser usada no contexto de decompilação de software.

Esse objetivo geral contém dois objetivos específicos a serem atingidos:

1. estabelecer uma estratégia para validar um decompilador, com um critério de teste $C$, que contribua para avaliar a sua corretitude, para logo gerar um conjunto de casos de teste $T$ que cumpra os requisitos daquele critério $\left(T_{C \text {-adequado }}\right)$ formado por pares de programas $\left(P_{O}, P_{L}\right) ; \mathrm{e}$

2. supondo correto o decompilador, determinar uma estratégia que indique quais critérios de teste utilizar para a validação de programas $P_{L}$ (programas na linguagem alvo do decompilador) gerado pelo decompilador a partir de programas executáveis $P_{O}$ (programas originais). Com base no conjunto de casos de teste $T$ obtidos a partir dos critérios sclecionados, avaliar o comportamento, em relação a $T$, dos programas $P_{L}\left(P_{L}{ }^{*}(T)\right)$ e $P_{O}\left(P_{O}{ }^{*}(T)\right)$, considerando correto o processo de decompilação se o comportamento de ambos os programas for o mesmo em relação a $T\left(P_{L}^{*}(T) \equiv P_{O}{ }^{*}(T)\right)$. 


\subsection{Estrutura da monografia}

Este capítulo apresentou o contex to no qual este trabalho está inserido, a motivação para realizá-lo e os objetivos principais a serem atingidos.

Assim, o restante da monografia encontra-se estruturado da seguinte forma: o Capítulo 2 apresenta os aspectos teóricos básicos do processo de decompilação e algumas ferramentas que apóiam e automatizam esse processo; o Capítulo 3 apresenta os aspectos teóricos básicos do teste e validação de software, assim como algumas das técnicas e ferramentas usadas nessa atividade; o Capítulo 4 apresenta a definição de um procedimento para teste e validação de decompiladores e de software decompilado e dois estudos de caso que aplicam esse procedimento para dois decompiladores diferentes; e o Capítulo 5 apresenta as conclusões, as contribuições deste trabalho e perspectivas de trabalhos futuros. No Apêndice A são fornecidos os códigos fonte, originais e decompilados, de um programa na linguagem $\mathrm{C}$ e outro na linguagem Java. 


$-5$

\section{Decompilação de software}

\subsection{Considerações inicias}

Neste capítulo, apresentam-se conceitos básicos referentes à área de decompilação de arquivos binários, uma descrição geral do processo de decompilação e algumas ferramentas que se encontram disponíveis para a comunidade acadêmica. Dentre as diversas perspectivas ao se abordar a decompilação, apresenta-se um processo de decompilação mais tradicional, para efeitos didáticos.

\subsection{Um processo de decompilação de arquivos binários}

Um decompilador é escrito para traduzir programas na linguagem de máquina específica da máquina $M$ para uma linguagem específica $L$. Assim, dado qualquer programa objeto da máquina $M(P(M))$, o decompilador $D(M, L)$ deveria traduzi-lo num programa fonte equivalente $\left(I^{P}(L)\right.$ ) (Housel III, 1973). Este processo pode envolver uma substancial recriação ou reprodução do código fonte do programa original (Cifuentes e Fitzgerald, 1995).

Conceitualmente, um decompilador está estruturado da mesma forma que um compilador, contendo uma série de fases que transformam o programa que serve como cntrada de uma representação para outra. Ainda assim, é necessário notar que, segundo Housel III (1973), 


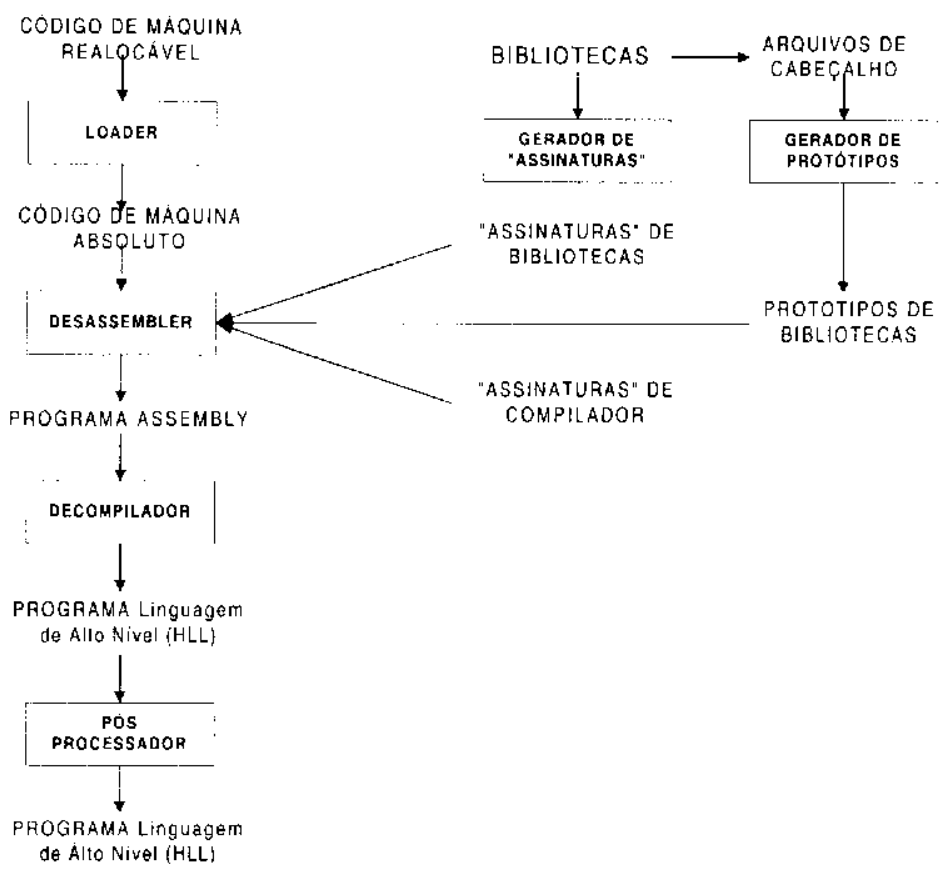

Figura 2.1: O processo de decompilação (adaptada de Cifuentes (1994))

na prática a decompilação é um processo incompleto, dada a quantidade de informação que é "perdida" no processo de compilação, como complementa Cifuentes (1999).

Com base na Figura 2.1, que mostra as diferentes fases c o contexto de um processo de decompilação segundo Cifuentes (1995), descreve-se o processo de uma forma geral para logo abordar cada um dos componentes ou partes deste processo de forma particular.

Como pode-se observar na Figura 2.1, são muitos os subprocessos ou programas (se automatizados) que são utilizados pelo decompilador para conseguir gerar o código de alto nível desejado a partir do código executável. Para começar, todos os programas têm uma tabela de endereços de memória as quais têm que ser realocadas com a finalidade de carregar o programa na mcmória física do computador, esta tarefa é executada pelo loader. Uma vez que o código se encontra na memória, produz-se uma representação dele na linguagem assembly. Como pode-se supor, esta tarefa é realizada por um desassembler. Este desassembler pode-se apoiar nos programas geradores de assinaturas (signatures) do compilador e das bibliotecas originais que produziram ou compilaram o código executável que está sendo decompilado. Essas assinaturas vão lhe permitir descartar o código que não deve ser "traduzido" para a linguagem assembly dado que são sub-rotinas proprietárias da linguagem, do compilador ou das respectivas bibliotecas. Então, esse código assembly é utilizado como entrada para o decompilador, o qual devolverá como saída o código escrito na Linguagem de Alto Nível (HLL) objeto. Fi- 
nalmente, e de forma opcional, esse código pode ser transformado por um pós-processador que poderá fazer mudanças menores, na sintaxe por exemplo.

Na seqüência, cada um dos componentes deste processo será abordado com mais detalhe.

\subsubsection{Loader}

O módulo loader é um programa que, dada a informação típica que se encontra num outro programa executável (cabeçalho, tabela de realocação, scgmento de código e segmento de dados), lê a informação do cabeçalho do programa executável, determina a quantidade de memória necessária para carregar uma imagem binária do programa (incluindo "dados" e "código"), separa a memória, a preenche e realiza a realocação dos elementos de "dados" encontrados. Tambćm determina o início de execução do programa.

\subsubsection{Gerador de assinaturas}

O gerador de assinaturas é um programa que automaticamente determina um padrão binário que identifica unicamente cada compilador ou cada sub-rotina. Esses padrões são chamados de "assinaturas" e são usados para tentar reverter o que foi realizado pelo linker durante o processo de compilação. $O$ uso dessas "assinaturas" tem por objetivo que as sub-rotinas do programa que são analisadas pelo decompilador (ou então o desassembler) sejam somente as sub-rotinas do usuário, aquelas que foram criadas por ele, enquanto todas as outras são climinadas da análise ou substituídas por chamadas a elas.

O uso de um gerador de assinaturas não somente reduz o número de sub-rotinas que têm que ser analisadas, mas também incrementa a documentação dos programas usando os nomes reais das bibliotecas no lugar de usar nomes de sub-rotinas arbitrárias. Segundo Cifuentes (1995), a procura dessas assinaturas pode ser feita com um simples algoritmo de hashing mínimo $\mathfrak{c}$ perfeito, atingindo uma ordem constante $O(1)$ para determinar se a sub-rotina bate com alguma sub-rotina conhecida. Um método automático para gerar as assinaturas de diferentes bibliotecas e compiladores é descrito no trabalho de Emmerik (1994).

\subsubsection{Gerador de protótipos}

O gerador de protótipos é um programa que reconhece automaticamente os tipos de argumentos das sub-rotinas das bibliotecas e o tipo de valor de retorno no caso das funções (Cifuentes, 1995). Essa informação, geralmente obtida a partir de arquivos de cabeçalho, quando eles existirem, é usada pelo decompilador para determinar os tipos de argumentos passados para as 
sub-rotinas das bibliotecas, o número de argumentos (sempre que possível) e o tipo do valor de retorno das funções.

\subsubsection{Desassembler}

O desassembler é um programa que analisa a imagem binária de um programa para transformá-la numa representação equivalente na linguagem assembly. O desassembler, com a assistência das assinaturas de compilador, pode determinar se o programa carregado na memória pelo loader foi compilado por um compilador conhecido, caso no qual o ponto de início da função principal pode ser determinado e o proccsso começará por esse ponto. No caso de não poder reconhecer o compilador usado para criar aquele programa, o processo começa no endereço de memória indicado inicialmente pelo loader. Geralmente, antes do código do programa propriamente dito o loader carrega na memória instruções pertencentes ao código de inicialização do compilador (como instruções que colocam na pilha os argumentos passados ao programa desde linha de comandos, no caso de programas na linguagem C), código esse que não deveria ser decompilado. Assim sendo, a desvantagem de não reconhecer o compilador que gerou o programa binário reside no fato de que esse código de inicialização é considerado pelo desassembler como sendo parte das rotinas de usuário do programa, produzindo erros no próprio processo de decompilação ou após ele, quando se tenta compilar novamente o código fonte decompilado.

O maior problema que o desassembler tem que enfrentar ć o fato de ter que determinar quais bytes ou palavras são instruções e quais bytes ou palavras são dados. Realiza-se a análise percorrendo todos os caminhos a partir do início de execução do programa; novos caminhos são adicionados sempre que houver uma transferência de controle para outra porção do código e o algoritmo pára quando todos os caminhos identificados foram percorridos. Mesmo assim é importante notar que nem sempre todas as instruções podem ser representadas na linguagem assembly, isto é, poderiam ficar caminhos parcialmente percorridos porque alguma instrução no meio deles não foi "traduzida".

Um desassembler por si só gera somente a representação do programa na linguagem assembly, mas se usado como parte de um decompilador ele precisa gerar também o grafo de fluxo de controle, indispensável para realizar as análises de fluxo de controle c de fluxo de dados que o decompilador faz.

\subsubsection{Decompilador}

Um decompilador é um programa que transforma uma representação de um programa em baixo nível numa representação do mesmo programa numa linguagem de alto nível. Existem di- 


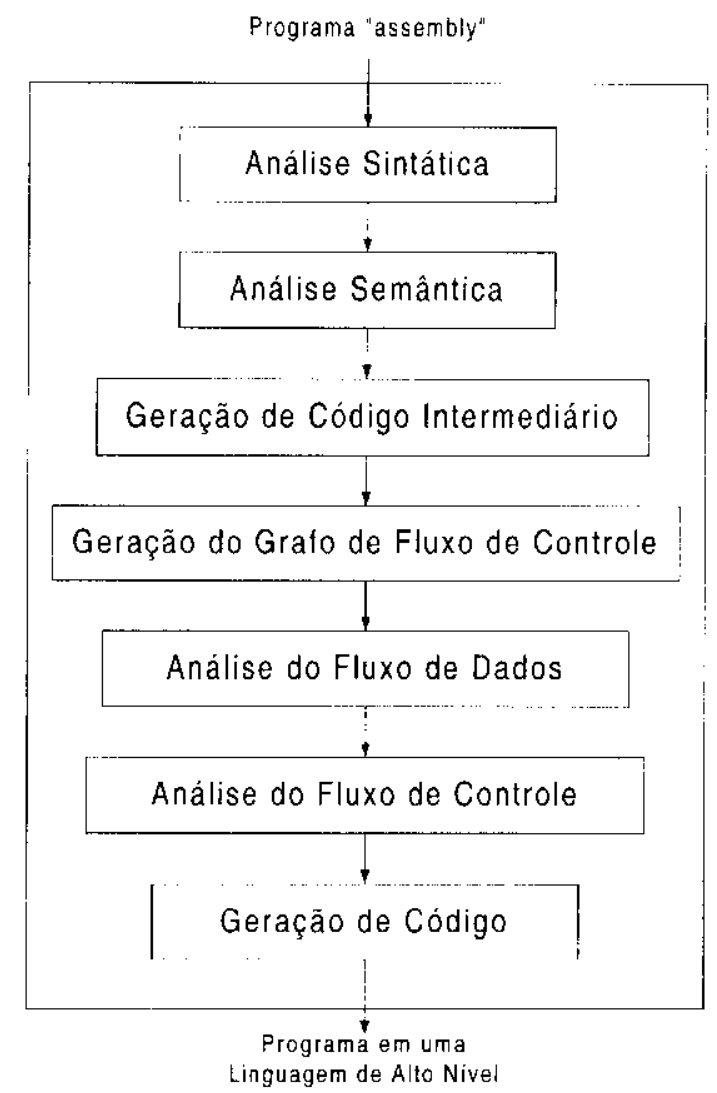

Figura 2.2: Fases de um decompilador (adaptada de Cifuentes (1994))

versas abordagens que tratam da construção e da estrutura do decompilador (Cifuentes, 1994; O'Gorman, 1991), mas para efeitos de estrutura vai se usar como guia a abordagem de Cifuentes. Na implementação do Dcc (Cifuentes, 1994), o desassembler faz parte do (ou está embutido no) decompilador, e a linguagem assembly é usada como uma linguagem intermediária que é analisada e transformada pelo decompilador.

A Figura 2.2 (Cifuentes, 1994) mostra as fases ou partes do decompilador propriamente dito. É importante notar a similaridade com um processo de compilação e, também em comparação com o compilador, a ausência da fase de análise léxica da entrada no decompilador, isto devido à simplicidade da linguagem de máquina.

Uma descrição mais detalhada, algoritmos e exemplos sobre a estrutura de um decompilador podem ser encontrados em (Cifuentes, 1994). 


\subsubsection{Correspondência entre bibliotecas}

Aqui faz-se referência a um conceito que nasce a partir da procura da universalidade das linguagens. Desse modo, sempre que a Linguagem de Alto Nível (HLL) objeto do decompilador for diferente da HLL original na qual foi compilado o programa, se o programa faz uso de chamadas a bibliotecas ele não poderá ser recompilado a partir do programa gerado na HLL objeto, dado que esta última não usa ou possui as mesmas bibliotecas. Exemplificando, considerando o seguinte código decompilado a partir de um programa binário originalmente escrito na linguagem Pascal (extraído de Cifuentes (1994))

Writestring("Hello Pascal");

CrLf;

o decompilador reconheceu o compilador usado e fazendo uso das assinaturas de bibliotecas gerou chamadas às bibliotecas cm Pascal. Mas dado que a linguagem alvo é C, esse código não pode ser recompilado exceto se se trocassem essas instruções pela equivalente em $\mathrm{C}$

writeln("Hello Pascal");

A introdução de enlaces entre bibliotecas resolve o problema, ligando as bibliotecas de uma linguagem com as bibliotecas equivalentes numa outra. Esses enlaces podem ser indicados num arquivo que seria usado pelo decompilador quando for requerido.

\subsubsection{Pós-processador}

O pós-processador é um programa que transforma um programa numa linguagem de alto nível para um programa semanticamente equivalente escrito na mesma linguagem de alto nível. Cabe ressaltar que determinar a equivalência semântica entre dois programas é em geral um problema indecidível, mas existem estudos (Offutt e Craft, 1994; Offutt e Pan, 1997) que visam a aproximar uma solução automatizada próxima ao ótimo.

\subsection{Ferramentas de decompilação}

As ferramentas de decompilação existentes atualmente visam a automatizar o processo de decompilação para diversos tipos de arquivos binários (EXE, CLASS, COFF, entre outros) e de linguagens alvo (C, Java, Visual Basic, FoxPro, entre outros). Na seqüência são apresentadas, em síntese, descrições das ferramentas de decompilação Dcc e REC, para a linguagem alvo C, e JAD, para a linguagem alvo Java. 
Dcc é um protótipo de decompilador escrito na linguagem C por Cifuentes (1994) que gera código fonte na linguagem $\mathrm{C}$ a partir de arquivos binários executáveis que lhe são fornecidos como entrada. Dcc foi desenvolvido inicialmente numa DecStation 3000 com o sistema opcracional Ultrix e logo foi transferido para a arquitetura PC com sistema operacional DOS. A entrada fornecida para este compilador é um arquivo executável - exe ou .com - com o formato da arquitetura i 80286 da Intel.

JAD (Kouznetsov, 1997) é um decompilador, desenvolvido na linguagem $\mathrm{C}++$, que decompila arquivos. CLASS para código fonte escrito na linguagem Java. Foi criado por Pavel Kouznetsov cm 1997, e a sua última versão, criada em meados de 2001, está disponível para uso não comercial e em varias plataformas (Linux, HP-Ux e Windows). JAD não é resultado de pesquisa acadêmica e talvez por isso não existem publicações que tratem sobre ele. Entretanto, trata-se de uma boa ferramenta, visto que muitos decompiladores comerciais já fizeram uso dele como motor de decompilação, acrescentando algumas funcionalidades extras. Além disso, numa avaliação preliminar realizada como parte do presente trabalho de pesquisa, JAD mostrou melhor desempenho ( $\mathrm{cm}$ termos de geração de código recompilável) e apresentou menos erros do que Mocha (van Vliet, 1997). Esse último decompilador destacou-se num estudo empírico (Dyer, 1997) que apresentava uma comparação entre três decompiladores para a linguagem Java.

REC (Reverse Engineering Compiler) (Caprino, 1997) é um decompilador de uso livre, escrito por Giampicro Caprino, mas que não disponibiliza informação sobre as técnicas que utiliza, nem sobre o projeto da sua construção. REC pode ser usado de diversas formas segundo o tipo de arquivo que pretende-se decompilar, isto ć, cle suporta vários tipos de arquivos binários (COFF, Windows PE, ELF, AOUT) de diversas plataformas c/ou arquiteturas como MIPS R3000, Intel i386, 68000 e PowerPC. A saída desse decompilador é um código "C-like" do programa original, além do programa na linguagem assembly se requisitado pelo usuário. $\mathrm{O}$ código "C-like", que contém instruções numa linguagem de baixo nível, dificilmente pode ser compilado com o objetivo de gerar um novo executável. Isso ocorre pois, o principal objetivo do REC é facilitar ao usuário a compreensão da estrutura do programa.

\subsection{Considerações finais}

Neste capítulo foram apresentados conceitos tcóricos básicos sobre a decompilação, assim como o processo de decompilação de arquivos binários segundo descrito por Cifuentes. Também apresentaram-se breves descrições das ferramentas de decompilação Dcc, JAD e REC. Na Tabela 2.1 apresenta-se um resumo das características (linguagem na qual foi desenvolvida, linguagem alvo, entre outras) dos decompiladores descritos neste capítulo. 
Tabela 2.1: Resumo de características dos decompiladores Dcc, JAD e REC

\begin{tabular}{|c|c|c|c|c|c|}
\hline \multirow[b]{2}{*}{ Decompilador } & \multicolumn{5}{|c|}{ Características } \\
\hline & Ling. alvo & Decompila & Linguagem & $\begin{array}{l}\text { Código } \\
\text { fonte }\end{array}$ & Plataformas \\
\hline Dec & $\mathrm{C}$ & $\begin{array}{l}\text { Exe } \\
\text { Com }\end{array}$ & $\mathrm{C}$ & Sim & $\begin{array}{l}\text { Windos/DOS } \\
\text { Unix }\end{array}$ \\
\hline JAD & Java & Class & $\mathrm{C}$ & Não & $\begin{array}{l}\text { Linux } \\
\text { HP-Ux } \\
\text { Windows } \\
\text { MacOS X } \\
\text { Solaris } 7\end{array}$ \\
\hline $\mathrm{REC}$ & "C-like" & $\begin{array}{l}\text { Coff, Elf } \\
\text { Aout } \\
\text { EXE(PE) }\end{array}$ & - & Não & $\begin{array}{l}\text { Linux } \\
\text { Solaris } \\
\text { Windows } \\
\text { SunOS }\end{array}$ \\
\hline
\end{tabular}

Essas ferramentas descritas, particularmente Dcc e JAD, serão úteis para observar a aplicação prática do procedimento de teste e validação que se objetiva obter como resultado do presente trabalho.

No contexto do presente trabalho, técnicas e critérios de teste e validação apresentadas no seguinte capítulo serão aplicadas para testar algumas das ferramentas antes descritas e validar os produtos por elas gerados. 


-2.2Átulo

\section{Teste de Software}

\subsection{Considerações iniciais}

Neste capítulo são abordadas algumas técnicas e critérios de teste de software, tais como, técnicas e critérios de teste funcional, cstrutural - baseados em fluxo de controle e em fluxo de dados - e baseados em mutação, sendo apresentados conceitos pertinentes e ferramentas de apoio.

Essas técnicas e critérios de teste, especialmente critérios estruturais e critérios baseados em mutação, serão utilizados, com o apoio das diversas ferramentas aqui descritas, na aplicação do procedimento de teste e validação que objetiva-se desenvolver no presente trabalho de pesquisa.

\subsection{Terminologia e conceitos básicos}

Esforços para padronizar a terminologia utilizada no contexto de Engenharia de Software têm sido realizados pela IEEE. No padrão IEEE número 610.12-1990, adotado neste trabalho, diferenciam-se os termos:

defeito (fault): Passo, processo ou definição de dados incorreto, como por exemplo, uma instrução ou comando incorreto; 
engano (mistake): Ação humana que produz um resultado incorreto, como por exemplo, uma ação incorreta tomada pelo programador;

erro (error): Diferença entre o valor obtido e o valor esperado, ou seja, qualquer estado intermediário incorreto ou resultado inesperado na execução do programa constitui um erro;

falha (failure): Produção de uma saída incorreta com relação à especificação.

Diz-se que um programa $P$ com domínio de entrada $D$ é correto com respeito a uma especificação $S$ se $S(d)=P(d)$ para qualquer item $d \in D$, ou seja, se o comportamento do programa está de acordo com o comportamento esperado para todos os dados de entrada. No teste de software, pressupõe-se a existência de um "oráculo" que possa determinar, para qualquer item $d \in D$, se $S(d)=P(d)$, dentro de limites de tempo e esforço razoáveis.

As técnicas e critérios de teste visam a medir o nível de adequação de um determinado conjunto de dados de teste para um programa (software) determinado. A adequação dos dados de teste refere-se à habilidade dos dados de assegurar a ausência de determinados erros no programa que está sendo testado. Poder-se-ia dizer, citando DeMillo et al. (1987), que um conjunto de dados de teste $T$ é adequado em relação a um programa $P$ se $P$ executa corretamente com $T$ e todos os programas incorretos executam incorretamente.

Ressalta-se que a atividade de teste é permeada por uma série de limitações. Em geral, os scguintes problemas são indecidíveis (Maldonado et al., 1998): dados dois programas, sc eles são equivalentes; dadas duas sequiências de comandos (caminhos) de um programa, ou de programas diferentes, se eles computam a mesma função; e dado um caminho, se ele é exccutável ou não. Esses aspectos impactam inclusive a automatização das atividades de teste.

\subsection{Técnicas e critérios de teste}

As atividades de VV\&T - Verificação, Validação e Teste - inseridas dentro do processo de desenvolvimento de software procuram minimizar a ocorrência de erros e riscos associados com o objetivo de aumentar a confiança no software que está sendo testado, e numa última análise, verificar a corretitude.

Em se tratando de critérios de teste e de métodos de seleção de casos de teste, as propricdades mínimas que devem ser preenchidas por um critério de teste são (Maldonado et al., 1992):

1. garantir, do ponto de vista de fluxo de controle, a cobertura de todos os desvios condicionais: 
2. requerer, do ponto de vista de fluxo de dados, ao menos um uso de todo resultado computacional; e

3. requerer um conjunto de casos de teste finito.

Na sequiência, apresentam-se as diferentes técnicas e critérios de teste (funcionais, estruturais $\mathrm{c}$ baseadas em erros). Sobre as técnicas e critérios funcionais, descreve-se qual o objetivo delas, apresentam-se alguns exemplos dessas técnicas, $\mathrm{e}$ apontam-se alguns problemas e limitações que se apresentam na sua aplicação. Sobre as técnicas c critérios estruturais, apresenta-se o uso do Grafo de Fluxo de Controle (GFC) e descreve-se brevemente a forma de representar um programa como um GFC. Seguidamente, trata-se de alguns desses critérios, com ênfase nos critérios bascados em fluxo de controle e fluxo de dados. Finalmente, sobre as técnicas e critérios bascados $\mathrm{cm}$ crros descrevem-se as categorias de erros e apresentam-se dois critérios, fazendo ênfase no critério Análise de Mutantes.

\subsubsection{Técnicas e critérios funcionais}

O teste funcional também é conhecido como teste de caixa preta (DeMillo et al., 1987) pelo fato de tratar o software como uma caixa cujo conteúdo é desconhecido $\mathrm{e}$ da qual só é possível visualizar o lado externo, isto é, os dados de entrada fornecidos e as respostas produzidas como saída.

O teste funcional concentra-se nos requisitos funcionais do software sem considerar a estrutura interna do programa e, segundo Pressman (2000), procura descobrir erros nas seguintes categorias: (1) funções incorretas ou ausentes; (2) erros de interface; (3) erros nas estruturas de dados ou no acesso a bancos de dados externos; (4) erros de desempenho; e (5) erros de inicialização e término.

O teste funcional envolve dois passos principais: identificar as funçōes que o software deve realizar e criar casos de teste capazes de checar se essas funções estão sendo realizadas pelo software (Pressman, 2000). As funções que o software deve possuir, assim como os casos de teste a serem utilizados são identificados a partir da sua especificação.

Alguns exemplos de teste funcional (DeMillo et al., 1987; Pressman, 2000):

1. Particionamento em classes de equivalência. Com o objetivo de minimizar o númcro de casos de teste, dividi-se o domínio de entrada do programa em classes de equivalência válidas e inválidas com base nas condições de entrada de dados identificadas na especificação. Em seguida, selecionam-se os casos de teste, baseando-se na hipótese de que um elemento de uma dada classe seria representativo da classe toda, sendo que para cada uma 
das classes de equivalência inválidas deve ser gerado um caso de teste distinto. A identificação das classes de cquivalência na maioria dos casos requer a utilização de heurísticas.

2. Análise do valor limite. É uma extensão do critério Particionamento em Classes de Equivalência, sendo que os limites associados às condições de entrada são exercitados de forma mais rigorosa; ao invés de selecionar-se qualquer elemento de uma classe, os casos de teste são escolhidos nas fronteiras das classes, pois, por razões que não são completamente claras, nesses pontos concentra-se um grande númcro de crros (Pressman, 2000). O espaço de saída do programa também é particionado e são exigidos casos de teste que produzam resultados nos limites dessas classes de saída.

3. Grafo de causa-efeito. Oferece uma representação concisa das condições lógicas e das ações correspondentes, estabelecendo requisitos de teste baseados nas possíveis combinações das condições de entrada. O uso deste critério segue os seguintes passos:

- São levantadas as possíveis condições de entrada (causas) e as possíveis ações (efeitos) do programa, atribuindo-se um identificador para cada uma delas;

- é construído um grafo de causa-efeito relacionando as causas e os efeitos levantados; $\mathrm{e}$

- o grafo é convertido em uma tabela de decisão a partir da qual são derivados os casos de teste.

Os maiores problemas do teste funcional são a sua dependência a respeito da corretitude da especificação do software e a necessidade de usar cada entrada possível para o programa como caso de teste para assegurar a corretitude do módulo (DeMillo et al., 1987). A respeito da especificação do programa, muitas vezes ela é feita de modo descritivo e não formal, de maneira que os requisitos de teste derivados daquela são também, de certa forma, imprecisos e informais. Quanto a testar todas as possíveis entradas, todos os programas operam sobre um número finito de cntradas, mas qualquer coisa que essas entradas signifiquem elas sempre podem ser representadas como uma cadeia de valores binários, assim, para realizar um teste funcional completo deveria-se fornecer como entrada todas as combinações de cadcias binárias possíveis, o qual resulta ccrta c claramente impraticável (Beizer, 1990).

\subsubsection{Técnicas e critérios estruturais}

O teste estrutural, também conhecido como teste de caixa branca, é visto como complementar à técnica funcional (Pressman, 2000). Nesta técnica de teste a estrutura do programa é examinada 
e os casos de teste são derivados da lógica do programa, sendo fundamentais os aspectos de implementação.

Em geral, a maioria dos critérios dessa técnica utiliza uma representação de programa conhecida como Grafo de Fluxo de Controle (GFC) ou grafo de programa '.

Para a construção do GFC, um programa $P$ pode ser decomposto em um conjunto de blocos disjuntos de comandos; a execução do primeiro comando de um bloco acarreta a execução de todos os outros comandos desse bloco, na ordem dada. Todos os comandos de um bloco, possivelmente com exceção do primeiro, têm um único predecessor e exatamente um único succssor, exceto possivelmente o último comando. A representação de um programa $P$ como um GFC $G=(N, E, s)$ consiste, então, em estabelecer uma correspondência entre nós e blocos $\mathrm{e} \mathrm{cm}$ indicar possíveis fluxos de controle entre blocos com o uso de arcos. Um GFC é portanto um grafo orientado, com um único nó de entrada $s \in N$ e um único nó de saída, no qual cada vértice representa um bloco indivisível de comandos e cada aresta representa um possível desvio de um bloco para outro.

Em se tratando dos critérios de teste estrutural em si, eles são, em geral, classificados em (Barbosa et al., 2000):

1. Critérios baseados em fluxo de controle. Utilizam as características de controle da execução do programa, como comandos ou desvios, para determinar quais estruturas são necessárias. Os critérios mais conhecidos dessa classe são:

- Todos-Nós - exige que a execução do programa passe, ao menos uma vez, em cada vértice do grafo de fluxo, isto é, que cada comando do programa seja executado pelo menos uma vez. Também é referenciado na literatura como critério de Cobertura de Sentenças.

- Todos-Arcos - requer que cada aresta do grafo, ou seja, cada desvio do fluxo de controle, seja exercitada pelo menos uma vez. Também é referenciado na literatura como critério de Cobertura de Decisões.

- Todos-Caminhos - requer que todos os caminhos possíveis do programa sejam executados.

Outros critérios dessa categoria são: cobertura de condição; cobertura de condições múltiplas; LCSAJ (Linear Code Sequence and IJump); o critério Boundary-Interior; e a familia de critérios K-tuplas requeridas de Ntafos.

\footnotetext{
'Housel III (1973) e Cifuentes (1994) fazem referência a essa forma de representação dentro do processo de decompilação
} 
A utilização dessa classe de critérios tem demonstrado que eles não são cfetivos para indicar a presença de erros nos programas, especialmente erros computacionais. Sendo essa uma das motivações para o desenvolvimento dos critérios que utilizam o fluxo de dados ao invés do fluxo de controle.

2. Critérios baseados em fluxo de dados. Estes critérios, surgidos em meados da década de 70 (Herman, 1976), utilizam informações do fluxo de dados do programa para determinar os requisitos de teste. Esses critérios exploram as interações que envolvem definições de variáveis c refcrências a tais definições para estabclccer os requisitos de teste. Exemplos dessa classe de critérios são: os Critérios de Rapps e Weyuker (Rapps e Weyuker, 1982), e os Critérios Potenciais-Usos (Maldonado, 1991). Dentre esses critérios, no presente trabalho de pesquisa foi utilizado o critério:

- Todos-Usos - que requer que todas as associações $(i, j$, var $)$ ou $(i,(j, k)$, var $)$ entre uma definição da variável var num nó $i$ e seus subseqüentes usos (no nó $j$ ou no arco $(j, k))$ sejam exercitadas através de pelo menos um caminho livre de definição, com respeito à variável var, do nó $i$ ao nó $j$ ou ao arco $(j, k)$. Um caminho é livre de definição em relação à variável var se var é definida no nó $i$ c não é redefinida em nenhum outro nó do caminho até o nó $j$ ou o arco $(j, k)$.

3. Critérios baseados na complexidade. Utilizam informações sobre a complexidade do programa para derivar os requisitos de teste. Um critério bastante conhecido dessa classe é o Critério de McCabe, que utiliza a complexidade ciclomática do grafo de programa para derivar os requisitos de teste.

\subsubsection{Técnicas baseadas em erros}

Em (Budd, 1981), definem-se duas grandes categorias de erros de programa chamadas erros de domínio e erros computacionais. Um erro de domínio ocorre quando uma cntrada específica segue um caminho errado devido a um defeito num comando de controle. Um erro computacional ocorre quando os dados de entrada seguem o caminho correto ou esperado, mas devido a um defeito nos comandos que realizam computações é aplicada uma função ou computação errada.

Dentro dessa classificação existe um grande número de erros. No teste baseado em crros, são coletadas informações sobre os erros mais freqüentes no processo de desenvolvimento com o objetivo de derivar os requisitos de teste (Barbosa et al., 2000). Dois critérios típicos que se concentram em erros são: 
1. Semeadura de erros Consiste em gerar ou adicionar defeitos que provocarão erros (conhecidos como erros artificiais) num programa supostamente correto com o objetivo de verificar a porcentagem de erros que um caso de teste determinado revela. Supõe-se que a porcentagem de erros artificiais revelados é equivalente à porcentagem de erros desconhecidos que esse caso de teste revela.

2. Análise de mutantes Consiste em gerar mutantes de um programa supostamente correto e determinar os casos de teste que conseguem identificar esses mutantes. Surgiu na década dos 70 na Yale University e Georgia Institute of Technology derivado de um método clássico para deteç̧ão de erros lógicos em circuitos digitais.

A análise de mutantes é um critério para medir a adequação dos casos de teste para um determinado programa. Alguns dos primeiros artigos sobre a análise de mutantes (Budd ct al., 1979; DeMillo et al., 1978) apresentam uma descrição do método assim como duas hipóteses nas quais se baseia. A idćia básica apresentada por DeMillo é conhecida como hipótese do programador competente (Competent Programmer Assumption) e assume que os programadores criam programas, que se não corretos, são muito próximos do correto. A outra hipótese explorada na aplicação do critério Análise de Mutantes é o princípio empírico chamado efeito de acoplamento (coupling effect) (Budd et al., 1979; DeMillo et al., 1978, 1987), o qual assume que os dados de teste que distinguem todos os programas que diferem do correto apenas em erros simples são tão sensíveis que, de maneira implícita, distinguem também erros mais complexos, isto é, erros complexos estão relacionados a crros simples.

Partindo das duas hipóteses assinaladas, a princípio, o testador deve fornecer um programa $P$ a ser testado, e um conjunto $T$ de casos de teste para os quais deseja-se avaliar sua adequação. Um conjunto de mutantes de $P$, que consiste em um conjunto de programas os quais diferem de $I^{p}$ apenas pela ocorrência de erros simples, é gerado submetendo-se o programa a uma série de operadores de mutação. Por exemplo, se $I=I+1$ é uma sentença de $P$, então

$$
\begin{aligned}
& I=I-1 \\
& I=I+2 \\
& I=J+1
\end{aligned}
$$

são alterações simples que geram três mutantes de $P$.

O conjunto de mutantes gerados é chamado de $M(P)$. Alguns dos mutantes em $M(P)$ são funcionalmente equivalentes ao programa $P$, e serão chamados Mutantes Equivalentes e denotados por $E(P)$. Para qualquer caso de teste, esses mutantes equivalentes apresentam o mesmo comportamento que o programa original. 
Finalmente, quando o programa $P$ e os mutantes no conjunto $M(P)$ são executados sob o mesmo conjunto de casos de teste $T$, alguns dos mutantes em $M(P)$ produzem resultados diferentes daqueles produzidos por $P$. Esse conjunto de mutantes são identificados $\mathrm{c}$ chamados de mutantes mortos, e denotados por $D M(P, T)$.

Na análise de mutantes define-se uma medida objetiva do nível de confiança da adequação dos casos de teste analisados, o escore de mutação (mutation score), como a fração dos mutantes não equivalentes de $P$ que são distinguíveis pelo conjunto de casos de teste $T$. Para o cálculo do escore de mutação é usada a scguinte fórmula:

$$
m s(P, T)=\frac{|D M(P)|}{|M(P)| \cdots|E(P)|}
$$

O escore de mutação ć um número que varia no intervalo entre 0 e 1 , sendo que, um alto escore, próximo a 1, indica que o conjunto de casos de teste é próximo ao adequado para o programa que está sendo testado.

Um dos maiores problemas para a aplicação do critério Análise de Mutantes está relacionado ao seu alto custo, uma vez que o número de mutantes gerados, mesmo para pequenos programas, pode ser muito grande, exigindo um tempo de execução muito alto.

Várias estratégias têm sido propostas para fazer uso da análise de mutantes de maneira mais eficiente, como diminuir o tempo de execução dos mutantes perante o uso de arquiteturas de hardware mais avançadas, ou o uso da análise estática de anomalias de fluxo de dados para reduzir o número de mutantes gerados. Além disso, critérios alternativos derivados da análise de mutantes também foram criados com o objetivo de reduzir os custos associados a ela, selecionando um subconjunto do total de mutantes gerados, mas com a expectativa de não reduzir a eficácia. Tais critérios alternativos são: Mutação aleatória (Randomly Selected X\% Mutation) (Wong, 1993), Mutação restrita (Constrained Mutation) e Mutação seletiva (Selective Mutation) (Mathur, 1991).

\subsection{Ferramentas de apoio ao teste e validação}

Devido a sua natureza, a aplicação de critérios de teste, em geral, não é possível sem o auxílio de ferramentas automatizadas. A seguir dá-se uma visão geral sobre as ferramentas de apoio para a aplicação de critérios baseados em fluxo de dados e do critério Análise de Mutantes, pois são esses os critérios sob os quais se têm realizado muitas pesquisas recentes, com resultados promissores. 
Muitas ferramentas foram criadas para a aplicação dos diferentes critérios de teste estrutural baseados em fluxo de dados. O primeiro desses critérios, proposto no trabalho de Herman (1976), dispunha de uma ferramenta de apoio à sua aplicação. Rapps e Weyuker, junto com a definição de sua família de critérios baseados em fluxo de dados propuseram uma ferramenta de apoio para uma linguagem muito simples (Rapps e Weyuker, 1985); Frankl c Weyuker implementaram, posteriormente, a ferramenta ASSET para um subconjunto da linguagem Pascal; Laski e Korel, definiram o critério contexto ordenado em (Laski e Korel, 1983), e a ferramenta SADT para apoiar a sua aplicação; Ostrand e Weyuker, redefinem os critérios de Rapps e Weyuker considerando o uso de ponteiros e desenvolvem a ferramenta TACTIC; Chaim. na sua dissertação de mestrado (Chaim, 1991), descreve o desenvolvimento da ferramenta Poke-Tool, ferramenta de apoio à aplicação dos critérios Potenciais Usos (Maldonado, 1991), desenvolvida na Faculdade de Engenharia Elétrica da Universidade Estadual de Campinas - UNICAMP e amplamente tratada e usada em diversos artigos da área (Barbosa et al., 2000; Chaim et al., 1998, 1991; Maldonado et al., 1998).

Várias outras são as iniciativas de desenvolvimento de ferramentas de apoio à aplicação do critério Análise de Mutantes. A Mohtra, a Proteum (Delamaro, 1993) e as variações dela, Protcum/FSM para máquinas de estados finitos c Proteum/IM (Delamaro et al., 1997) para mutação de interface.

Em seguida descrevem-se com mais detalhe as firramentas Poke-Tool (Chaim et al., 1998) e Proteum (Delamaro, 1993), dada a importância do seu uso e a sua disponibilidade na linguagem e plataformas nas quais vai se desenvolver o presente trabalho de pesquisa. Também são apresentadas as ferramentas Jester e JUnit que trabalham em conjunto para automatizar a aplicação do critério Análise de Mutantes, e com um pouco menos de detalhe a ferramentas comerciais JCover e CCover.

\subsubsection{A ferramenta de teste Poke-Tool}

Poke-Tool é uma ferramenta de teste de software que apóia a aplicação dos critérios Potenciais Usos (PU) - critérios estruturais de teste de software baseados em fluxo de dados. A Poke-Tool é uma ferramenta configurável que suporta diversas linguagens e encontra-se disponível para ambientes DOS e Unix (Chaim et al., 1998).

A Poke-Tool é uma ferramenta interativa cuja operação é orientada a sessão de trabalho ou de teste na qual o usuário realiza todas as tarefas de teste (Chaim et al., 1991). Na Poke-Tool a sessão de trabalho é dividida em duas fases: uma estática e outra dinâmica.

$\mathrm{Na}$ fase estática, basicamente, o usuário entra com o programa a ser testado, com o conjunto de casos de teste e seleciona todos ou alguns dos critérios disponíveis (Todos-Potenciais-Usos, 
Todos-Potenciais-Usos/DU, Todos-Potenciais-Du-Caminhos, Todos-Nós e Todos-Arcos). A ferramenta analisa o código fonte, obtém as informações necessárias para a aplicação dos critérios c instrumenta (insere "pontas de prova" que produzem um trace do caminho executado) produzindo a versão instrumentada do programa em teste.

A fase dinâmica consiste no processo de execução e avaliação dos casos de teste. A ferramenta, após a execução dos casos de teste, realiza a avaliação desses segundo os critérios de teste estrutural selecionados.

As saídas fornecidas pela ferramenta são: os conjuntos de nós e arcos primitivos (arcos que uma vez executados garantem a execução de todos os demais arcos do grafo do programa), o Grafo Def (grafo de fluxo de controle no qual é associado a cada nó o conjunto de variáveis definidas nele) obtido do programa em teste, o programa instrumentado, o conjunto de caminhos ou associações requeridas pelos critérios selecionados e o conjunto de caminhos executados pelo caso de teste sendo avaliado.

\subsubsection{A ferramenta de teste Proteum}

A Proteum (Delamaro, 1993) é uma ferramenta de apoio à aplicação do critério Análise de Mutantes desenvolvida no ICMC/USP. É a única ferramenta que apóia o teste de mutação para programas C existente atualmente (Barbosa et al., 2000). Além disso, esta ferramenta está disponível para os sistemas operacionais SunOS, Solaris e Linux, e pode ser configurada para o teste de programas escritos $\mathrm{cm}$ outras linguagens.

Basicamente, a ferramenta Proteum oferece ao testador recursos, por meio da aplicação do critério Análise de Mutantes, para avaliar a adequação de um conjunto de casos de teste, ou para gerar um conjunto mais adequado de casos de teste $T$ para determinado programa $P$. A seleção de casos de teste, ainda que não automatizada, é apoiada pela ferramenta Proteum quando o testador faz uso dos resultados da avaliação para melhorar os casos de teste.

Os recursos oferecidos pela ferramenta permitem a execução das seguintes operações: definição dos casos de teste, execução do programa em teste, seleção dos operadores de mutação a serem utilizados, geração dos mutantes, execução dos mutantes com os casos de teste definidos, análise dos mutantes vivos e cálculo do escore de mutação.

Um dos pontos essenciais para a aplicação do critério Análise de Mutantes é a definição dos operadores de mutação. A Proteum conta com 71 operadores de mutação divididos em quatro classes: mutação de comandos (statement mutations), mutação de operadores (operator mutations), mutação de variáveis (variable mutations) e mutação de constantes (constant mutations). 


\subsubsection{A ferramenta JCover}

JCover é uma ferramenta comercial. criada pela empresa Man Machine Systems, que apóia a aplicação de vários critćrios de teste estrutural baseados em fluxo de controle para programas escritos na linguagem Java. Os critérios que a ferramenta apóia são:

- Todos-Nós;

- Todos-Arcos;

- cobertura de Métodos; e

- cobertura de Classes.

JCover instrumenta os programas a serem testados de modo que quando executados deixem um "rasto" no caminho que seguiram na sua execução. Após a execução dos programas com os casos de teste cuja adequação aos critérios que a ferramenta apóia está sendo avaliada, JCover lê os dados produzidos e gera relatórios em diversos formatos.

A interface visual de JCover facilita ao usuário a análise dos resultados da avaliação de cobertura dos casos de teste, permitindo, inclusive, identificar porções de código não testado ou executado, o que é muito útil para o aprimoramento do conjunto de casos de teste.

Essa ferramenta não possui nem compilador nem uma máquina virtual de Java próprios, de modo que utiliza o toolkit de desenvolvimento JDK (versões 1.2 e posteriores). Essa característica permite que a execução dos programas instrumentados possa ser realizada em qualquer computador com o toolkit JDK instalado.

\subsubsection{A ferramenta C-Cover}

C-Cover é uma ferramenta comercial, criada pela empresa Bullseye Testing Technology, que apóia alguns critérios de análise de cobertura para programas escritos em $\mathrm{C} / \mathrm{C}++$. Os critérios que esta ferramenta apóia são (Wlodarski, 2001):

- cobertura de decisão;

- cobertura de condição/decisão; e

- cobcrtura de funções

Essa ferramenta trabalha em conjunto com diversos compiladores e/ou ambientes de programação $\mathrm{C} / \mathrm{C}++$, tais como Microsoft Visual $\mathrm{C}++$, GNU gcc e g++, Borland $\mathrm{C}++$ Builder, entre outros. 
C-Cover instrumenta, em tempo de compilação, o código dos programas sendo testados, de modo que quando executados gcram um relatório de execução num arquivo previamente estabclecido. Após a execução dos programas com um ou mais casos de teste, o arquivo que contém o relatório de execução é lido pelo módulo "Coverage Browser", permitindo analisar os dados. Esse módulo não possui características muito flexíveis: permite visualizar um relatório mais ou menos detalhado mas não permite exportar os dados para outras aplicações.

\subsubsection{As ferramentas JUnit e Jester}

JUnit (Beck e Gamma, 1998; Schneider, 2000) é uma ferramenta, na verdade é um framework, de uso livre, escrito em Java, para a realização de testes de unidade de programas escritos na linguagem Java.

JUnit oferece uma coleção de classes úteis para o teste de outras classes escritas em Java. Podem-se criar casos de teste para classes individuais ou conjuntos de casos de teste para packages inteiros, que contenham os casos individuais.

JUnit está projetada com base em dois modelos (Command e Composite) segundo os quais os casos de teste ou os conjuntos de casos de teste tornam-se classes, tal e como se observa na Figura 3.1 .

Seguindo o primeiro modelo tem-se a classe TestCase. Qualquer classe que contenha casos de teste deve ser sub-classe da classe TestCase. Dentro da sub-classe de TestCase pode-se definir um ou vários métodos test $x \times x \times()$ dentro dos quais realiza-se a comparação entre os resultados da execução dos métodos testados com os resultados esperados mediante o uso de uma variação do método assert().

Seguindo o segundo modelo, as instâncias da classe TestCase podem compor uma hierarquia TestSuite que executará automaticamente todos os métodos testxxxx() contidos em cada uma das instâncias de TestCase. A definição da classe TestSuite permite a criação recursiva de hierarquias até o nível que o usuário considere conveniente.

Jester (Moore, 2001) é uma ferramenta de teste para programas escritos na linguagem Java, que usa o critério Análise de Mutantes modificando o código fonte das classes e verificando se aquelas classes modificadas produzem saídas erradas com relação às esperadas para algum caso ou conjunto de casos de teste. Essa ferramenta faz uma modificação por vez para cada um dos arquivos com código fonte contidos numa determinada árvore de diretórios.

Jester trabalha junto com o framework JUnit (versões 3.2, 3.5 e 3.7). As classes criadas com base no JUnit, e que são usadas por Jester, contêm casos de teste para executar e "matar" os mutantes gerados. Além disso, Jester modifica o código fonte da classe que está sendo testada 


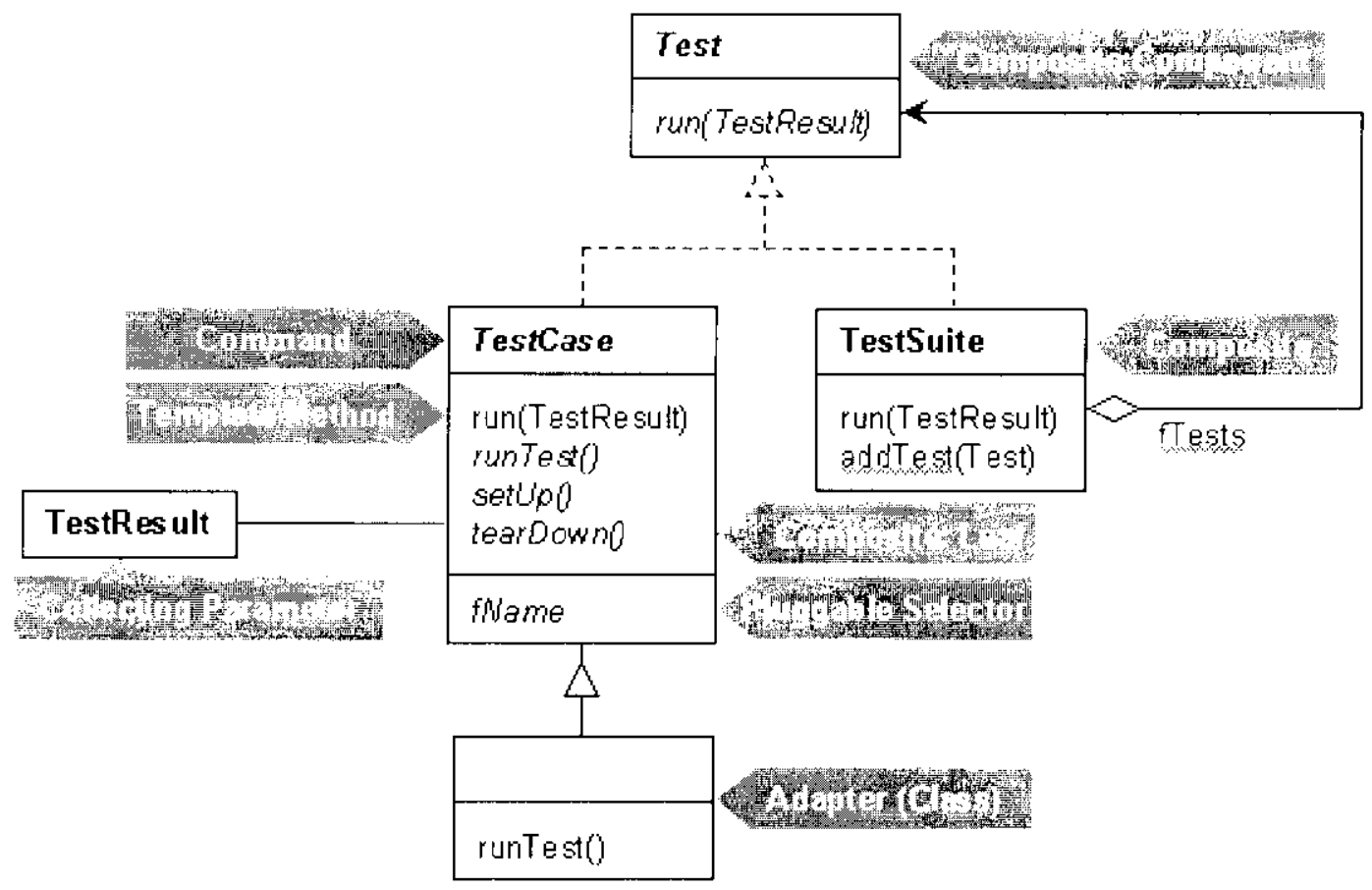

Figura 3.1: Uma vista simplificada do framework JUnit (extraída de (Beck e Gamma, 2001))

e o recompila, de modo que precisa de um ambiente de desenvolvimento Java (foi testado junto com o JDK 1.4 e JDK 1.3).

O conjunto de operadores de mutação que Jester implementa é bem reduzido, mas segundo Moore (2001) eles mostraram ser suficientes para revelar casos de teste não adequados para programas simples. As modificações (operadores de mutaçăo) que Jester introduz no código fonte atualmente são:

- modificação de constantes; ex. trocar o número 0 pelo 1.

- trocar valores booleanos true por false e vice-versa.

- trocar as sentenças iff por ifftrue \|l (o que força que o resultado desses comandos seja sempre true).

- trocar as sentenças iff por ifffalse \&\&(o que força que o resultado desses comandos seja scmpre false).

Mas pela construção da ferramenta não é difícil analisar e incluir novos operadores de mutação, os quais também são planejados para versões posteriores. 


\subsection{Considerações finais}

Neste capítulo foram apresentados os conceitos básicos $\mathrm{c}$ a terminologia usados na área de Teste e Validação de Software. Foram apresentadas também técnicas e critérios de teste (técnica funcional, técnica estrutural e baseada $\mathrm{cm}$ erros) com ênfase nos critérios estruturais baseados em Fluxo de Controle e Fluxo de Dados, e no critério Análise de Mutantes, por sua relevância no presente trabalho de pesquisa. Finalmente, apresentaram-se ferramentas de apoio ao teste e validação de software.

Em se tratando as ferramentas, fez-se ênfase nas ferramentas Poke-Tool (teste estrutural) e Proteum (análise de mutantes) dados o scu amplo uso e a sua disponibilidade em ambientes e linguagens a screm usadas no desenvolvimento desta pesquisa. Também fez-se uma breve descrição das ferramentas JUnit e Jester, e as comerciais JCover e CCover, usadas para teste de programas.

Dentre essas últimas ferramentas observou-se que JCover e CCover apóiam somente a aplicação de critérios de teste estrutural baseados em fluxo de controle, e Jester, sendo a única ferramenta disponível que apóia a aplicação do critério Análise de Mutantes para programas escritos na linguagem Java, é uma ferramenta ainda em processo de desenvolvimento que apresenta algumas limitações.

No capítulo a seguir, os critérios e técnicas descritos serão usados como parte de uma estratégia de teste e validação de ferramentas de decompilação e de software decompilado, e as fcrramentas descritas servirão para apoiar a aplicação desses critérios em estudos de caso. 


\section{Teste de Software no contexto de decompilação}

\subsection{Considerações iniciais}

A atividade de teste de software decompilado deveria, em princípio, ser igual à atividade de teste de qualquer outro software, exceto pelo fato de que ela se insere num contex to muito especial, no qual o código "fonte" do software não é produto de um processo de software tradicional, mas de um processo de engenharia reversa $\mathrm{c}$, portanto, pode carecer de documentação (documentos de análise, projeto, entre outros).

Além disso, são poucos os artigos e publicações que apresentam informações sobre o testc c validação de software decompilado e de ferramentas de decompilação de forma específica. Dc fato, os artigos que tratam sobre as ferramentas como o decompilador Dec (Cifuentes, 1994), e o NJCM Toolkit (Ramsey e Fernández, 1997), apresentam somente exemplos e casos de uso que, de alguma mancira, demonstram o seu funcionamento. Poder-sc-ia dizer que esses exemplos e casos de uso são casos de teste para aquelas ferramentas, mas eles não garantem uma alta confiabilidade desde que não foram planejados de forma sistemática nem fazem uso de técnicas e critérios consolidados. 
Neste capítulo investiga-se um procedimento sistemático para o teste e validação de ferramentas de decompilação e de software decompilado. Além disso, os diferentes critérios e técnicas de teste são avaliados nesse contexto.

\subsection{Considerações para as atividades de teste e validação no contexto de decompilação}

Analisando a definição de decompilação (Cifuentes, 1994; Housel III, 1973), nota-se que o objetivo principal de um processo automatizado de decompilação é a geração de uma versão, semanticamente compatível, do código fonte de um determinado programa cxecutável $P_{O}$.

Por outro lado, sabe-se que as atividades de teste são geralmente caras em termos computacionais, de recursos humanos, entre outros, representando em alguns casos até $40 \%$ do custo de desenvolvimento de software. Assim sendo, é recomendável levar em consideração a aplicação de uma estratégia incremental de teste que permita detectar erros aplicando primeiro os critérios menos onerosos e aumentar a confiabilidade dos testes aplicando, na seqüencia, critérios mais rigorosos se assim for requerido.

Em se tratando de testar e validar um software qualquer, primeiro determina-se um conjunto de casos de teste que serve como entrada para tal software. Esse conjunto pode ser determinado segundo diversos critérios (funcionais, estruturais, baseados em erros). Posteriormente, o software é exccutado com csses casos de teste e compara-se a saída (ou resultado) de tal execução com a saída esperada, previamente determinada.

No contexto de decompilação, apresentam-se duas perspectivas: a perspectiva do desenvolvedor de um decompilador, e a perspectiva do usuário do decompilador.

Na perspectiva do desenvolvedor, o conjunto de casos de teste $T$ é formado por pares de programas $\left(P_{O}, P_{L}\right)$, onde $P_{O}$ ć o código binário (cxecutável) de um programa e $P_{L}$ é o código fonte decompilado a partir de $P_{O}$. A adequação desse conjunto também pode ser avaliada segundo diversos critérios (quanto mais rigoroso o critério, maior a confiança no decompilador). A saída esperada está representada pela definição do comportamento que se espera que o programa $P_{L}$ apresente quando compilado novamente, ou seja, o comportamento de $P_{O}$. Para verificar a equivalência funcional dos programas $P_{U}$ e $P_{L}$ requer-se de um novo processo de teste, esta vez, do programa decompilado $P_{L}$.

Do ponto de vista do usuário, a preocupação concentra-se na ultima parte do processo requerido pelo desenvolvedor, isto é, em verificar a equivalência funcional dos programas decompilados $P_{L}$ com relação aos programas originais $P_{O}$. 


\subsection{Procedimento para teste e validação de ferramentas de decompilação}

O procedimento proposto consiste de dois passos: 1)determinar um conjunto de casos de teste para o decompilador $\left(T_{\text {Decomp }}\right.$ ), e 2 ) validar as saídas do decompilador (programas decompilados). Na Figura 4.1 ilustra-se o procedimento e mostra-se a terminologia usada. Observa-se que o Passo 2 deste procedimento pode ser aplicado isoladamente para cobrir os requisitos da perspectiva do usuário (validar unicamente o software decompilado) se assim for requerido.

Como resultado do procedimento, caracteriza-se um benchmark composto pelo conjunto de casos de teste do decompilador $\left(T_{\text {Decomp }}\right)$ e pelos conjuntos de casos de teste de cada um dos programas decompilados $P_{L}$ que pertencen a $T_{\text {Decomp }}$.

A seguir detalham-se cada uma das etapas do procedimento:

\section{- Passo 1. Determinação de um conjunto de casos de teste para o decompilador.}

Para determinar um conjunto de programas binários que sirvam como casos de teste para testar e validar um decompilador, propõe-se seguir as seguintes etapas:

\section{Procurar um benchmark para o decompilador.}

Idealmente, o benchmark deveria ter sido projetado especificamente para o decompilador que está sendo testado, mas caso não esteja disponível, pode-se procurar um benchmark projetado para um decompilador similar, isto é, um decompilador que aceite como entrada os mesmo tipos de arquivos binários e que tenha a mesma linguagem alvo que o decompilador que pretende-se testar.

No caso da não disponibilidade de benchmarks nem específicos nem similares, pode-se constituir um benchmark inicial aplicando:

- Uso de benchmarks para teste de compiladores da linguagem alvo. Quando disponíveis, o uso desses benchmarks pode aumentar a confiança no teste $\mathfrak{e}$ validação do decompilador. Sendo que esses benchmarks são projetados para testar o processo de compilação de, se não todas, a maioria de produções da gramática, os produtos executáveis deles contem também o código binário correspondente a todas essas produções.

- Geração automática de programas a partir da gramática da linguagem. Embora a literatura da área apresente esforços nessa área desde inícios dos anos 70, não se tem relatórios de ferramentas que auxiliem essa tarefa.

- Técnicas de teste funcional ou seleção aleatória de casos de teste. 


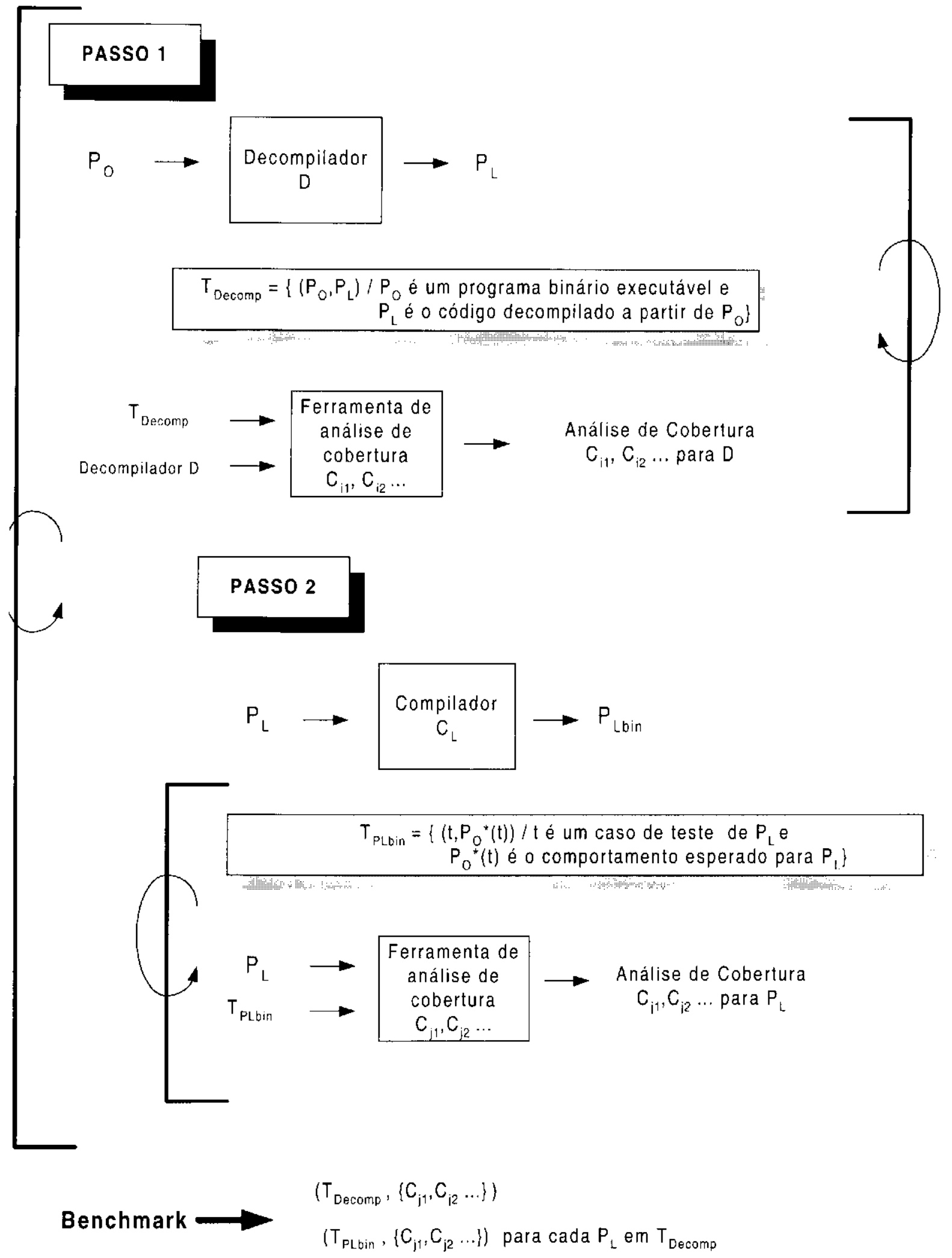

Figura 4.1: Procedimento para teste e validação de ferramentas de decompilação 


\section{Medir a adequação do benchmark.}

Após determinado o benchmark inicial, elegc-se um critério $C$ de teste para medir a adequação dos casos de teste (pares de programas $\left(P_{O}, P_{L}\right)$ ) que compõem essc benchmark e procede-se a avaliar a adequação executando o decompilador com cada um dos programas $P_{O}$. Como resultado desta etapa obtém-se um conjunto de casos de teste $T$ formado por pares de programas $\left(P_{O}, P_{L}\right)$ com o correspondente nível de adequação em relação ao critério $C$. Se a medida de adequação obtida é suficiente, procede-se então a avaliar se os programas $P_{O}$ e $P_{L}$ são funcionalmente equivalentes, seguindo o Passo 2. Caso a medida de adequação obtida não seja suficiente, pode-se melhorar o conjunto de casos de teste segundo se descreve no passo seguinte, scmpre levando em consideração a medida de adequação que se deseja atingir como critério de parada.

Cabe ressaltar que, quanto mais rigoroso o critério de teste selecionado, maior a confiança nos resultados do teste dos programas decompilados. Dentre os critérios de teste que podem ser aplicados encontram-se:

(a) Critérios de Teste Estrutural

Os critérios de teste estrutural são diversos e existem muitas ferramentas que auxiliam a sua aplicação. A escolha de qual critério aplicar não é trivial pois depende de fatores como o grau de confiança no decompilador que se deseja atingir, a disponibilidade de ferramentas que apóiem esse critério, cntre outros. Outro ponto a ser levado em consideração é o critério de parada que vai indicar até quando continuar testando.

Em se tratando do critério de parada para os critérios de teste funcional, no trabalho de Cornett (1998), que apresenta uma análise dos critérios de cobertura, recomenda-se como critério mínimo de parada uma cobertura de $80 \%$ para os critérios cobertura de Condição/Decisão, Todos-Nós e Todos-Arcos. O trabalho de Horgan et al. apud Menzies c Cukic (2000) apresenta uma síntese de dados de sistemas em produção que mostram que ainda sistemas com muito tempo de uso conseguem, com os seus casos de uso diários, uma cobertura menor que $80 \%$ em critérios como Todos-Arcos, e uma cobertura media de $50 \%$ para o critério Todos-Usos. Enfim, cmbora a literatura não apresente um consenso, todos apontam o fato de que pode-se parar de procurar novos casos de teste quando o custo de gerar casos de teste que consigam detectar novos erros não é mais aceitável.

(b) Critério Análise de Mutantes

Este critério é um dos mais efetivos na detecção de erros, mas também um dos mais custosos em termos computacionais (Mathur e Wong, 1993). 
Para determinar atć quando continuar testando em relação a este critério, a literatura não determina um critério de parada. Para o critério Semeadura de Erros (também baseado em erros) um critério de parada considerado bom é quando consegue-se detectar mais do que $80 \%$ dos erros artificiais (Menzies e Cukic, 2000).

Para a aplicação desta ctapa, com os critérios mencionados, fixa-se como pré-requisito a disponibilidade do código fonte do decompilador.

\section{Melhorar a cobertura do benchmark.}

Sempre que a medida de adequação obtida pelo benchmark definido não seja satisfatória pode-se adicionar novos casos de teste que aumentem essa medida. Esses novos casos de teste podem ser gerados usando as técnicas descritas para a definição do benchmark inicial, ou podem ser elaborados após uma revisão do código fonte do compilador. Os novos casos de teste procurarão cobrir especificamente aquelas partes do código identificadas como não executadas segundo o critério eleito. Também é conveniente separar do benchmark aqueles casos de teste que não produzem aumento na cobertura com a finalidade de obter um conjunto de casos de teste mínimo para atingir essa cobertura.

\section{- Passo 2. Teste e validação de software decompilado}

Este passo é aplicado aos pares de programas $\left(P_{O}, P_{L}\right)$ determinados no Passo 1, e está composto de 4 etapas descritas a seguir:

\section{Re-compilação do código decompilado}

O código fonte decompilado $\left(P_{L}\right)$ deve ser compilado, utilizando preferencialmente o mesmo compilador que gerou ou compilou o programa $P_{O}$. Isso, é claro, se o compilador for conhecido previamente ao processo de decompilação ou reconhecido pclo próprio decompilador, e estiver disponível.

O fato de que o compilador usado para gerar o programa binário original não seja conhecido ou não esteja disponível pode impactar negativamente esta ctapa considerando, entre outros:

- que podem existir chamadas a bibliotecas proprietárias do compilador original as quais poderiam não ser reconhecidas por algum outro compilador; ou

- que poderiam existir diferenças na definição do intervalo de valores para um mesmo tipo de dado.

\section{Verificação básica da funcionalidade (teste aleatório)}

Atendendo às considerações assinaladas na Seção 4.2 e com base nos trabalhos de 
Menzies e Cukic (2000) e de Rothermel et al. (1999), propõe-se a realização de uma seleção preliminar de casos de teste, oriundos do uso do software, escolhidos de forma aleatória.

Se o código fonte do programa $P_{L}$ é compilado novamente com sucesso, gera-se o executável do programa $P_{L}$, que se chamará de $P_{L b i n}$, sobre o qual tenta-se executar um ou alguns casos de teste conhecidos que correspondam a casos de uso do programa $P_{O}$, eleito(s) de forma aleatória, para descobrir eventuais defeitos grosseiros na cxecução do programa $P_{L}$. Somente os programas que não apresentarem erros que impeçam a sua execução ou então que não mostrarem desde já erros que afetassem a sua funcionalidade passarão a ser testados segundo critérios de teste mais rigorosos.

Dado que os programas que apresentam erros nesta etapa revelam a presença de defeitos no decompilador, do ponto de vista do desenvolvedor, o decompilador deveria ser corrigido com a finalidade de eliminar tais defeitos e o processo deveria ser iniciado novamente com os casos de teste que falharam.

O número de casos de teste, e o tempo e recursos utilizados nesta elapa não devem ser muito grandes, pois a técnica de teste aleatório ou teste por aproximação, segundo o estudo empírico de Menzies e Cukic (2000) é inadequada para uns 25\% dos casos que eles pesquisaram. Além disso, Menzies e Cukic apontam que os seus estudos não consideraram casos de sistemas críticos, e para cles, alternativas ao teste aleatório deveriam ser procuradas.

\section{Determinação de casos de teste adequados a diversos critérios}

Sendo que o programa $P_{L}$ apresenta um comportamento similar com o original para um conjunto inicial de casos de teste, procede-se a determinar um conjunto de casos de teste $T_{P L}$ adequado para vários critérios de teste, tais como os critérios de teste estrutural e o critério Análise de Mutantes. Cabe destacar, que para a aplicação de tais critérios requer-se que os programas $P_{L}$ a serem testados exijam dados de entrada para determinar o scu comportamento. Caso contrário, outras alternativas deverão ser procuradas.

A ordem em que são aplicados os critérios está determinada pelo custo computacional de cada um deles. Na medida em que é atingida uma medida de adequação considerada satisfatória para cada um dos critérios, outros critérios mais onerosos podem ser aplicados.

Um dos maiores problemas que se apresenta quanto a isto é determinar qual medida de adequação é satisfatória para cada critério, isto é, qual o critério de parada para a geração de novos casos de teste que incrementem a adequação do conjunto ao critério sendo aplicado. Com base na literatura, como é indicado no procedimento de 
teste para o próprio decompilador, podem-se identificar alguns critérios de parada, mas vale a pena lembrar que esses estudos empíricos não são definitivos e somente servem como guia inicial para facilitar ao testador a tomada da decisão.

(a) Critérios de teste estrutural

São vários os critérios de teste estrutural que podem ser aplicados, tal c como mostrado na Seção 3.3.2. No entanto, a escolha de qual dos critérios aplicar não ć muito simples, pois vai depender de diversos fatores, especialmente da disponibilidade de ferramentas automatizadas que possam apoiar as atividades de teste.

Recomenda-se que a escolha do(s) critério(s) seja realizada levando em consideração a relação de inclusão entre os diferentes critérios (Maldonado, 1991). Vale destacar que na literatura (Frankl e Weiss, 1993) apresenta-se o critério Todos-Usos como sendo mais efetivo na detecção de erros que o critério Todos-Arcos, para a maioria dos casos.

Sendo $C$ o critério escolhido para medir a adequação, após finalizada a tarefa de gerar um conjunto de casos de teste $T_{C-\text { adequados }}$ procede-se à verificação da equivalência funcional dos programas $P_{O}$ e $P_{L}$ em relação a $T$, segundo se descreve na etapa 4. Posteriormente pode-se medir a adequação de $T$ para um critério $C^{\prime}$ mais rigoroso e, se for o caso, adicionar casos de teste que façam com que $T$ seja $C^{\prime}$ - adequado.

(b) Análise de Mutantes

Esse critério, embora seja um dos critérios mais efetivos na deteç̧ão de erros, apresenta o problema de ser altamente oneroso $\mathrm{em}$ termos computacionais (Mathur e Wong, 1993). A literatura não determina um critério de parada para cste critério de teste, como mencionado para o teste do próprio decompilador. Tal e como se fez na etapa $3(a)$, determinado o conjunto de casos de teste $T$ que atinge algum critério de parada determinado com anterioridade, procede-se a verificar, para cada par de programas $\left(P_{O}, P_{L}\right)$, a equivalência funcional entre cles em relação a $T$ segundo se descreve na etapa 4 .

\section{Avaliação da funcionalidade com relação ao "oráculo" $P_{O}$}

Determinado um conjunto de casos de teste adequado ao critério $C$ aplicado para o programa $P_{L}\left(T_{P_{L}}\right)$, deve-se avaliar se a funcionalidade do programa $P_{L}$ é semelhante com a funcionalidade do executável original $P_{O}$, isto é, se $P_{L \text { bin }}{ }^{*}\left(T_{P L}\right) \stackrel{m}{=} P_{O}{ }^{*}\left(T_{P L}\right)$.

O processo de teste de um decompilador pode não se limitar à aplicação de um único critério de teste $\mathrm{c}$ poderia requerer a aplicação, em testes sucessivos, de outros critérios, cada um mais 
rigoroso que o anterior, para aumentar a confiança no decompilador até atingir um nível que seja considerado adequado. Isso faria com que o procedimento aqui apresentado fosse iterativo.

\subsection{Estudo de caso - Linguagem C}

Nesta seção relata-se a experiência realizada com o objetivo de testar e validar um decompilador segundo o procedimento descrito na Seção 4.3. Para isso, primeiramente detcrminou-se um conjunto de casos de teste, que constituem um benchmark para testar o decompilador, sobre o qual, num segundo momento, aplicou-se o procedimento de teste e validação de programas decompilados para avaliar se as saídas geradas pelo decompilador com esses casos de teste eram funcionalmente equivalentes às saídas esperadas.

Para se realizar o teste e validação de uma ferramenta de decompilação testaram-se algumas das ferramentas descritas na Seção 2.3. Entre as ferramentas testadas (REC, Dcc, e a experimental DisC), selecionou-se, para realizar o processo de decompilação, o decompilador Dcc porque este, considerando as comparações feitas em termos de facilidade de uso e qualidade do código gerado, demonstrou ser a ferramenta mais adequada de decompilação de arquivos binários para programas na linguagem $\mathrm{C}$ que existe atualmente.

\subsubsection{Ambiente de decompilação e configuração}

A distribuição do decompilador Dcc é livre e consta tanto de arquivos de código fonte (na linguagem () quanto de arquivos executáveis para serem usados numa plataforma de sistema operacional DOS. Devido a que o uso do código fonte era necessário para utilizar algumas técnicas e critérios de teste, compilou-se o código fonte distribuído em duas plataformas (Windows/DOS e SunOS), notando-se um comportamento diferente entre os programas compilados e os programas distribuídos. Realizaram-se tarefas de debugging para identificar os problemas que originavam tais diferenças. Os problemas encontrados foram:

- Reconhecimento do tipo de arquivo binário que era fornecido como entrada ao decompilador, o qual fazia com que o código decompilado sempre estivesse incompleto.

- Inconsistências no código dos programas decompilados (nomes de labels não coincidentes e inclusão de bibliotecas não existentes).

- Código não executável (algumas variáveis e estruturas que não eram usadas e funções que não eram chamadas). 
Identificados os problemas, procedeu-se a modificar o código fonte do decompilador para solucioná-los, resultando uma versão modificada do decompilador Dcc que postcriormente foi compilada nas duas plataformas (SunOS. e Windows) para ser utilizada neste estudo de caso.

O teste e validação da versão modificada do Dcc foi realizado inicialmente na plataforma Windows, utilizando a ferramenta CCover que apóia a aplicação do critério de Cobertura de Condição/Decisão. Planejava-se realizar, posteriormente, a avaliação de cobertura segundo critérios mais rigorosos (crilérios de teste cstrutural baseados em Fluxo de Dados c o critério Análise de Mutantes) usando as ferramentas PokeTool e Proteum, na plataforma SunOS. Não obstante, as ferramentas mostraram-se não adequadas para realizar essa avaliação devido a certa incompatibilidade entre o dialcto da linguagem $\mathrm{C}$ que as ferramentas aceitam $\mathrm{e}$ o dialcto da mesma linguagem usado pelos desenvolvedores do decompilador Dcc. Essas incompatibilidades tornaram-se limitações que não foram corrigidas e superadas no tempo de realização do presente trabalho.

As ferramentas Poketool e Proteum foram utilizadas no teste e validação dos programas decompilados, apoiando a aplicação de critérios que contribuíssem a aumentar a confiança na equivalência funcional deles com rclação aos programas originais.

Assim, o decompilador Dec foi instalado em duas plataformas: SunOS e Windows/DOS. Junto ao decompilador foram usados os arquivos de signatures dos compiladores Borland $\mathrm{C}++$ v3.0 e Turbo C v2.0, e o arquivo dcclibs. dat contendo os nomes de procedimentos e funções da linguagem $\mathrm{C}$, assim como o tipo do dado de retorno, e o número, tipos e nomes dos argumentos passados a essas funções. Esses arquivos são fornecidos junto à distribuição do decompilador Dcc.

Os arquivos binários a serem decompilados foram colocados no mesmo diretório no qual estavam os arquivos do decompilador, ou então, em sub-diretórios daquele, sendo que, no momento de começar a execução do processo de decompilação, o caminho era indicado ao decompilador. Os arquivos de saída do processo de decompilação foram gravados no caminho especificado.

Por exemplo, se os arquivos do decompilador encontravam-se no diretório C: $\backslash$ dcc, e os arquivos binários no diretório $\mathrm{C}: \backslash \mathrm{dcc} \backslash$ binfiles, a chamada ao decompilador era dec binfiles $\backslash$ arq.exe, e os arquivos de saída eram escritos em $\mathrm{C}: \backslash \mathrm{dcc} \backslash$ binfiles. 


\subsubsection{Passo 1. Determinação do conjunto de casos de teste para o decom- pilador Dec}

Durante a aplicação do Passo 1 para o presente estudo de caso foram obtidas diversas informações cstáticas sobre o decompilador Dcc, as quais, para melhor conferência são listadas a seguir:

- Linhas de código (LOC) : 15330

- Decisões $(\operatorname{arcos})$ : 3408

- Combinações (decisão/condição) : 4812

Para começar a realização do teste do decompilador elegeu-se como benchmark inicial (benchmark $_{0}$ o conjunto de casos de teste utilizado por Cifuentes (1994), o qual consta de 14 programas cujos arquivos executáveis são distribuídos junto ao código do decompilador Dcc. Avaliada a cobertura desses 14 programas com relação ao código fonte modificado do Dcc, observou-se que para o critério de Cobertura de Condição/Decisão eles atingiam uma cobertura de $62 \%$.

Num segundo momento, com o intuito de melhorar a cobertura do benchmark, procuraram-se mais programas para serem adicionados ao benchmark. $k_{0}$. Assim sendo, coletou-se um conjunto de programas publicados como exemplos no livro "Applications Programming in ANSI C" (Johnsonbaugh e Kalin. 1996), totalizando 53 programas que foram compilados usando o compilador BorlandC ++ v.3.0 para gerar os arquivos binários a serem decompilados no estudo de caso. Dentre esses programas, três (host.c; child.c e vonkoch.c) năo foram utilizados, pois não foi possível compilar o código apresentado no livro. Obtidos os programas binários (50), caracterizou-se o benchmar $k_{1}$, para o qual, avaliada a cobertura em relação ao decompilador, atingiu-se uma porcentagem de cobertura de $72 \%$.

Dentre os programas adicionados identificaram-se 5 que além de produzir erros ao serem decompilados, não melhoravam a cobertura, de modo que foram trocados por outros 5 programas de maior complexidade escolhidos de forma aleatória (identifiexe, prepdisc.exe, sample4.exe, menu2.exe, cc8700.exe), caracterizando assim o benchmark. Avaliada a cobertura de esse benchmark, atingiu-se uma porcentagem de cobertura de $74 \%$.

Na Tabela 4.1 mostra-se com detalhes a evolução do benchmark usado no presente estudo de caso.

Cabe destacar que para a formação do becnhmark $k_{1}$ tentou-se utilizar um gerador automático de programas baseado na gramática da linguagem $\mathrm{C}$, ou programas que fizeram parte de um 
Tabela 4.1: Evolução do benchmark para validar o decompilador Dcc - Estudo de caso C

\begin{tabular}{|c|c|c|c|c|c|}
\hline Programa & $\%$ Cobertura & Melhora $(\%)$ & Programa & $\%$ de Cobertura & Melhora \\
\hline benchfn & 32,15 & & infix & 69,29 & 1,75 \\
\hline benchlng & 45,70 & 13,55 & jump & 69,41 & 0,12 \\
\hline benchmul & 47,11 & 1,41 & kinder & 69,41 & 0,00 \\
\hline benchmus & 47,90 & 0,79 & length & 69,43 & 0,02 \\
\hline benchsho & 49,31 & 1,41 & line_ed & 69,49 & 0,06 \\
\hline byteops & 50,02 & 0,71 & line_len & 69,53 & 0,04 \\
\hline dhamp & 59,56 & 9,54 & matmult & 69,56 & 0,03 \\
\hline fibol & 59.60 & 0,04 & $\max$ & 69,62 & 0,06 \\
\hline fibos & 59,60 & 0,00 & page & 69,64 & 0,02 \\
\hline longops & 61,08 & 1,48 & perc & 69,97 & 0,33 \\
\hline matrixmu & 61,68 & 0,60 & phone & 70,10 & 0,13 \\
\hline $\max$ & 61,70 & 0,02 & primes & 70,12 & 0,02 \\
\hline strlen & 61,97 & 0,27 & queue1 & 70,47 & 0,35 \\
\hline testlong & 61.97 & 0,00 & queue2 ${ }^{1}$ & 70,47 & 0,00 \\
\hline benchmark $k_{0}$ & 61,97 & & random & 70,64 & 0,17 \\
\hline assert & 63,84 & 1,87 & resistor & 71,86 & 1,22 \\
\hline astar & 65,36 & 1,52 & reverse & 71,86 & 0,00 \\
\hline average & 65,79 & 0,43 & sales & 72,03 & 0,17 \\
\hline bargraf1 & 66,08 & 0,29 & sched & 72,05 & 0,02 \\
\hline bargraf2 & 66,14 & 0,06 & $\operatorname{size}^{1}$ & 72,05 & 0,00 \\
\hline bargrph 1 & 66,16 & 0,02 & stack 1 & 72,07 & 0,02 \\
\hline bargrph2 & 66,16 & 0,00 & stack2 & 72,07 & 0,00 \\
\hline bfs_adj & 66,29 & 0,13 & stat & 72,11 & 0,04 \\
\hline bfs_link ${ }^{1}$ & 66,29 & 0,00 & taxes 1 & 72,11 & 0,00 \\
\hline calendar & 66,75 & 0,46 & $\operatorname{taxes} 2$ & 72,11 & 0,00 \\
\hline cars 1 & 66,87 & 0,12 & timer & 72.19 & 0,08 \\
\hline $\operatorname{cars} 2$ & 66,87 & 0,00 & tower & 72,22 & 0,03 \\
\hline chk_sort & 67,12 & 0,25 & tromino & 72,24 & 0,02 \\
\hline convert & 67,25 & 0,13 & walk_nr & 72,40 & 0,16 \\
\hline dice $^{l}$ & 67,25 & 0,00 & walk_r & 72,42 & 0,02 \\
\hline elephnt l & 67,33 & 0,08 & benchmark $_{1}$ & 72,42 & \\
\hline elephnt2 & 67,35 & 0,02 & identifi & 72,55 & 0,13 \\
\hline fact & 67,37 & 0,02 & prepdisc & 73,05 & 0,50 \\
\hline films & 67,48 & 0,11 & sample4 & 73,25 & 0,20 \\
\hline \multirow[t]{2}{*}{ grade } & 67,54 & 0,06 & menu2 & 73,57 & 0,32 \\
\hline & & & $\operatorname{cc} 8700$ & 73,88 & 0,31 \\
\hline & & & benchmark 2 & 73,88 & \\
\hline
\end{tabular}

${ }^{1}$ retirado

benchmark de teste para compiladores da linguagem C. Essa tentativa não foi bem sucedida, pois não puderam ser achados geradores e/ou benchmarks de domínio público, mas pertencentes a companhias que ofcreciam o serviço de teste de compiladores. 
Durante a avaliação da cobertura do conjunto total de casos de teste observaram-se dois fatos interessantes:

- Os primeiros 14 programas, ainda que não muito complexos, conseguiram $62 \%$ de cobertura, enquanto 50 programas adicionais somente conseguiram cobrir $12 \%$ adicionais.

- Alguns dos 50 programas coletados de (Johnsonbaugh e Kalin, 1996) não melhoraram a cobertura ou conseguiram melhorá-la $\mathrm{cm}$ apenas $0,02 \%$.

Sendo assim, considerou-sc que a geração ou identificação de novos casos de teste cfetivos em forma alcatória, cmbora sejam consideradas diferentes produções da gramática da linguagem, tal como se fe $\iota$ no caso do benchmark ${ }_{1}$, seria muito custosa e provavelmente não muito bem sucedida, de modo que começou-se a analisar o código reportado como não executado para, com base nele, projetar novos casos de teste.

Enquanto se analisava o código identificou-se que uma parte do código não executado correspondia a rotinas de gerenciamento de erros entanto outra era executada quando se utilizavam como entrada arquivos binários .COM. Forçou-se a execução de Dcc com dados de entrada inválidos (usando arquivos e caminhos inexistentes, argumentos crrados, entre outros) e utilizaram-se alguns arquivos .COM como entrada (10 arquivos, entre eles o arquivo de sistema command.com), atingindo-se uma porcentagem de cobertura de $76 \%$. A maioria de arquivos .COM não apresentaram uma melhora substancial na cobertura do código, e nenhum deles conseguiu gerar código C compilável.

Continuando com a análise do código não executado, observou-se que 3,70\% das combinações Condição/Decisão (critério segundo o qual se fez a análise de cobertura) representavam porções de código que eram executadas por alguma outra condição, como por exemplo um grupo de condições de uma estrutura switch ... case que levam à execução de um único conjunto de instruções.

Observou-se também que 7,20\% das combinações Condição/Decisão se referiam a gerenciamento de crros, alguns de difícil ocorrência mas que serviam para tentar garantir que não ocorresse nada "inesperado" durante a execução do programa (como erros na leitura de arquivos do disco rígido, por exemplo), e outros que ocorreriam somente se não se garantisse a integridade dos arquivos usados pelo decompilador (arquivos de signatures, os próprios arquivos binários decompilados, entre outros).

Outros 2,35\% das combinações, aproximadamente, não eram executadas porque eram rotinas usadas na detecção e identificação de compiladores não disponíveis para a realização do presente estudo de caso (como o decompilador proprietário da Microsoft, por exemplo). 
Nos outros $10,70 \%$ restantes foram identificadas porções de código que executariam sob condições especiais que somente poderiam ser geradas tendo-se: 1) um amplo conhecimento do programa (do código do decompilador); 2) um amplo conhecimento da linguagem assembly; 3) conhecimento do compilador usado (quais expressões idiomáticas e de otimização ele gera); e 4) a possibilidade de alterar o código de arquivos binários executávcis (código objeto dos programas) sem danificar a sua integridade.

Na Tabela 4.2 resumem-se os resultados da inspeção do código não coberto pelos casos de teste identificados para o decompilador Dcc.

Tabela 4.2: Resultados da inspeção do código fonte do decompilador Dcc - Estudo de caso C

\begin{tabular}{|l|c|}
\hline Descrição & Porcentagem \\
\hline Código que apresentava caminhos equivalentes já executados & $3,70 \%$ \\
Código de gerenciamento de erros pouco prováveis & $7,20 \%$ \\
Rotinas de verificação de compiladores não disponíveis & $2,35 \%$ \\
Código que requer testes mais elaborados e específicos e eventualmente & $10,70 \%$ \\
com caminhos não executáveis & \\
\hline
\end{tabular}

A não disponibilidade de outros compiladores, como o compilador proprictário da Microsoft por exemplo, c a dificuldade de gerar ou provocar erros de sistema operacional, fizeram com que não se conseguisse testar quase $10 \%$ do código, correspondente à identificação desses compiladores $\mathrm{c}$ ao código de gerenciamento de erros. Além disso, em cada grupo de condições que executavam caminhos equivalentes, somente uma dessas condições foi executada.

Após definido o benchmark a ser usado, procedeu-se a caracterizar os pares de programas $\left(P_{O}, P_{L}\right)$ com a finalidade de verificar que para cada par, o programa decompilado $P_{L}$ era funcionalmente equivalente ao original $P_{O}$, segundo descrito no Passo 2 do procedimento.

Dado que o decompilador tem muitas restrições sobre os tipos de dados e as estruturas lógicas que ele reconhece, esperava-se que alguns desses programas escolhidos năo fossem decompilados com sucesso, assim como foi descrito também nos testes realizados por Cifuentes (1994). Assim, dentre esses 64 programas somente alguns foram decompilados com sucesso, isto é, conseguiram gerar arquivos que continham o código fonte decompilado, enquanto outros produziram mensagens de erro ou provocaram que o decompilador parasse a sua execução antes de completar o processo de decompilação. A lista dos programas decompilados com sucesso é apresentada na Tabela 4.3.

Como pode-se observar na Tabela 4.3 são 32 dentre 64 programas os que foram decompilados com sucesso. Também pode-se observar que o mesmo programa aparece duas vezes (no caso de benchmul - benchmus e fibol-fibos, isso devido a que um mesmo programa foi compilado com "opções" de compilação (modelo de memória) diferentes dando origem a mais 
Tabcla 4.3: Programas .EXE decompilados - Estudo de caso C

\begin{tabular}{|c|c|}
\hline Programa & Descrição \\
\hline bargraph & Programa que mostra em modo texto uma barra que representa um valor ingressado \\
\hline & Programa que testa chamadas a funções \\
\hline benchmul & Programa que testa as operações de multiplicação (mod. de memória large) \\
\hline benchmus & Programa que testa as operações de multiplicação (mod. de memória small) \\
\hline benchsho & Programa que testa diversas operações, incluindo operações a nível de bytes \\
\hline byteops & Rotina que verifica operações com dados tipo byte \\
\hline calendar & Programa que imprime um calendário (requer dados de entrada) \\
\hline $\operatorname{cars} 1$ & Programa que registra stock, quantidade de vendas e fornece um reporte \\
\hline chk_sort & Rotina que verifica se uma sequiencia fornecida através do teclado está ordenada \\
\hline convert & Rotina que converte uma entrada em jardas para pés, e polegadas \\
\hline elephnt 1 & Rotina que imprime na tela três mensagens \\
\hline elephnt2 & Rotina que imprime na tela três mensagens incluindo texto ingressado pelo teclado \\
\hline fact & Rotina recursiva para calcular o fatorial de um número \\
\hline fibol & Rotina para calcular a série de Fibonacci até um número n (mod. de memória large) \\
\hline fibos & Rotina para calcular a série de Fibonacci alé um número n (mod. de memória small) \\
\hline identifi & Programa que determina se um identificador é válido ou não \\
\hline intops & Programa que testa diversas operações com tipos de dados inteiros \\
\hline jump & Rotina que divide dos valores ingressados pelo teclado \\
\hline kinder & Rotina que imprime uma mensagem na tela \\
\hline length & Rotina que calcula o cumprimento \\
\hline line_len & Programa que formata o texto a uma linha de comprimento definido \\
\hline matrixmu & Rotina que realiza multiplicação de matrizes \\
\hline $\max$ & Rotina para calcular o máximo de dois valores \\
\hline prepdisc & Programa que auxilia o decompilador DisC \\
\hline primes & Rotina que imprime a seqüencia de números primos até n \\
\hline reverse & Programa que inverte a ordem dos caracteres de uma cadcia ingressada pelo teclado \\
\hline sample4 & Programa que testa o uso de exit() \\
\hline strlen & Calcula o cumprimento de uma cadeia de caracteres \\
\hline taxes 1 & Rotina que calcula um imposto para um valor fornecido pelo usuário \\
\hline testlong & Rotina que testa o uso de variáveis de tipo long \\
\hline tromino & Programa que calcula a posição de um quadrado num tabuleiro de $n \times n$ quadrados \\
\hline walk_r & Rotina recursiva que utiliza a definição de Fibonacci \\
\hline
\end{tabular}

de um programa executável. Esses 32 programas decompilados, junto aos programas originais correspondentes, formaram os pares $\left(P_{O}, P_{L}\right)$ para serem testados segundo o Passo 2 do procedimento. 


\subsubsection{Passo2. Teste e validação dos programas decompilados pelo decom- pilador Dec}

Após ser definido o conjunto de casos de teste $T_{\text {Decomp }}=\left\{\left(P_{O}, P_{L}\right)\right\}$ para o decompilador Dcc, procedeu-se a verificar se as saídas fornecidas (os programas decompilados $P_{L}$ ) eram equivalentes as saídas esperadas. Para isso, cada par $\left(P_{O}, P_{L}\right)$ foi submetido ao Passo 2 do procedimento descrito.

\subsubsection{Re-compilação do código fonte decompilado}

Seguindo o procedimento, nesta etapa, avaliou-se se o arquivo decompilado (o código fonte gerado) $P_{L}$ podia ser compilado novamente para produzir um outro arquivo executável $P_{L b i n}$. Não considerou-se permissível o fato de fazer modificações no código decompilado, sendo que qualquer diferença ou erro nesse código com relação ao código inicial não poderia ser detectado em casos reais nos quais o código original não existisse.

Os arquivos binários do tipo .EXE que foram decompilados e compilados novamente com sucesso, completando assim a primeira etapa do Passo 2, são apresentados na Tabela 4.4 junto com o(s) compilador(es) usado(s).

Tabela 4.4: Programas .EXE decompilados e recompilados com sucesso - Estudo de caso C

\begin{tabular}{|c|c|c|}
\hline Programa & Compilador Unix & Compilador DOS \\
\hline byteops & GNU gcc & Borland $\mathrm{C}++3.0$ \\
\hline calendar & GNU gcc & Borland $\mathrm{C}++3.0$ \\
\hline cars l & GNU gcc & Borland $\mathrm{C}++3.0$ \\
\hline chk_sort & GNU gcc & Borland C++ 3.0 \\
\hline convert & GNU gcc & Borland $\mathrm{C}++3.0$ \\
\hline fact & GNU gec & Borland C ++3.0 \\
\hline fibos & GNU gec & Borland C ++3.0 \\
\hline identifi & GNU gec & Borland $\mathrm{C}++3.0$ \\
\hline intops & GNU gcc & Borland $\mathrm{C}++3.0$ \\
\hline kinder & GNU gcc & Borland $\mathrm{C}++3.0$ \\
\hline $\max$ & GNU gcc & Borland C ++3.0 \\
\hline primes & GNU gcc & Borland C ++3.0 \\
\hline strlen & GNU gec & Borland $\mathrm{C}++3.0$ \\
\hline taxes 1 & GNU gcc & Borland $\mathrm{C}++3.0$ \\
\hline testlong & GNU gec & Borland $\mathrm{C}++3.0$ \\
\hline walk_r & GNU gcc & Borland $\mathrm{C}++3.0$ \\
\hline
\end{tabular}




\subsubsection{Verificação básica da funcionalidade}

Para a execução desta etapa e das seguintes foram utilizados os programas decompilados que gcraram um novo executável. Para apresentar uma visão gcral da complexidade desses "novos" programas, aponta-se que eles tinham uma complexidade que medida em termos de linhas de código (LOC) variava entre 10 e 60 LOC. Além disso, sendo feita uma análise estática dos programas, em relação ao grafo de fluxo de controle de cada um deles, notou-sc que o número de nós variava entre 1 c 23, o número de arcos variava entre 0 (aqueles programas que tinham somente um nó) e 29, c o número de associações entre uma definição de variável e seu posterior uso era no máximo 54 e no mínimo 0 .

Durante esta etapa, os programas foram executados em ambas as plataformas, tendo-se como entrada para cles, casos de teste selecionados ad hoc dentre os dados que constituem o uso diário deles. Os programas que foram identificados como errados nesta etapa apresentaram diversos "tipos" de crros, desde aqueles que ocasionaram saídas erradas dos programas decompilados, comparadas às saídas fornecidas pelos programas originais com os mesmos casos de teste (bytcops, primes, testlong, calendar), até erros que ocasionaram que os programas nem completasscm a sua execução (carsl, taxes l, identifi).

Tabela 4.5: Resultados da verificação de funcionalidade com teste aleatório - Estudo de caso C

\begin{tabular}{|l|l|l|}
\hline Programa & Estado & Caso(s) de Teste \\
\hline byteops & falhou & - \\
calcndar & falhou & $\{(1,1)\}$ \\
carsl & falhou & - \\
chk_sort & falhou & $\{(1,2)\}$ \\
convert & passou & $\{(1),(3),(-1)\}$ \\
fact & passou & $\{(3),(0)\}$ \\
tibos & passou & $\{(1,2)\}$ \\
identifi & falhou & $\{(\mathrm{a} 1)\}$ \\
intops & passou & - \\
kinder & passou & - \\
max & passou & $\{(0,4)\}$ \\
primes & falhou & $(10)$ \\
strlen & falhou & - \\
taxes 1 & falhou & - \\
testlong & falhou & $\{(1,2,3,4)\}$ \\
walk_r & passou & $\{(0),(2)\}$ \\
\hline
\end{tabular}

A Tabela 4.5 mostra os resultados da execução da segunda etapa do Passo 2 do procedimento, em ambas as plataformas, para os programas decompilados que cumpriram as restrições impostas na primeira etapa. Cabe destacar que não se faz distinção entre os resultados obtidos 
em cada uma das plataformas porque eles foram os mesmos. Na tabela, os valores de entrada dos casos de teste com que se executaram os programas são representados por n-tuplas entre parênteses (dependendo do número $n$ de dados de entrada que cada programa requer). Em alguns casos, não foram requeridos dados de entrada, e em outros foram usados um ou mais de um.

Nesta etapa, observou-se que alguns dos programas $P_{L}$ (kinder e intops) que mostraram um comportamento equivalente aos programas originais $P_{O}$ não precisavam de dados de entrada para sua execução. Esses programas não preenchiam os requisitos para serem testados segundo os critérios descritos pelo procedimento e usados no estudo de caso, e sobre eles não poder-se-ia afirmar nada scm antes testá-los integrados em diferentes ambientes. No entanto, neste estudo de caso, encontrando-se disponíveis os códigos fonte dos programas originais, conseguiu-se comparar o código fonte dos programas $P_{L}$ e $P_{O}$, determinando-se que eles eram funcionalmente equivalentes.

Os demais programas decompilados que cumpriram as restrições da presente ctapa nas duas plataformas, e por tanto considerados potencialmente corretos, isto ć, funcionalmente equivalentes aos seus pares originais, continuaram sendo testados segundo as instruções da terceira etapa.

\subsubsection{Aplicação de critérios estruturais e de análise de mutantes}

Os 5 arquivos que foram decompilados com sucesso, e não apresentaram erros nas etapas anteriores, foram testados, seguidamente, de maneira que pudesse ser vcrificado se cles realmente mantinham a funcionalidade daqueles executáveis que thes deram origem. Para isso, foram usadas técnicas de teste estruturais e o critério de Análise de Mutantes, para determinar conjuntos de casos de teste adequados a cada um dos critérios escolhidos para cada caso, segundo o que foi definido no procedimento proposto. Após a identificação de um conjunto adequado para cada critério, aplicou-se, a cada par de programas (original e decompilado), o processo descrito para a quarta etapa, com a finalidade de verificar a equivalência da funcionalidade cntre ambos.

\section{Critérios de teste estrutural}

O teste estrutural foi realizado na plataforma SunOS utilizando a ferramenta PokeTool e na plataforma Windows/DOS utilizando a ferramenta CCover, aplicando num primeiro momento os critérios Todos-Nós, Todos-Arcos, e Todos-Usos (PokeTool), e posteriormente os critérios Todos-Nós, Todos-Arcos e Cobertura de Decisão/Condição (CCover). Segundo csses critérios foram avaliados casos de teste para os programas que cumpriram os requisitos da ctapa anterior e casos de teste adicionados a esses como resultado 
da inspeção do código fonte de cada um dos programas. Os resultados da aplicação dos critćrios de teste estrutural encontram-se na Tabela 4.6.

Tabela 4.6: Porcentagens de adequação a critérios de tcste estrutural - Estudo de caso C

\begin{tabular}{|c|c|c|c|c|c|}
\hline \multicolumn{6}{|c|}{ Ferramenta PokeTool (SunOS) } \\
\hline Programa & Função & Todos-Nós & Todos-Arcos & Todos-Usos & Conj. de Casos de Teste \\
\hline convert $^{a}$ & main & - & - & - & - \\
\hline fact & $\begin{array}{l}\text { main } \\
\text { proc_l }\end{array}$ & $\begin{array}{l}100 \% \\
100 \%\end{array}$ & $\begin{array}{l}100 \% \\
100 \%\end{array}$ & $\begin{array}{l}100 \% \\
80 \%\end{array}$ & $\begin{array}{l}\{(1),(-1)\} \\
\{(1),(2)\}\end{array}$ \\
\hline fibos & $\begin{array}{l}\text { main } \\
\text { proc_l }\end{array}$ & $\begin{array}{l}0 \% \\
80 \%\end{array}$ & $\begin{array}{c}\mathbf{0 \%} \% \\
50 \%\end{array}$ & $\begin{array}{l}0 \% \\
40 \%\end{array}$ & $\begin{array}{l}\{(1,1),(1,2),(1,5)\} \\
\{(1,1)\}\end{array}$ \\
\hline $\max$ & $\begin{array}{l}\text { main } \\
\text { proc_l }\end{array}$ & $\begin{array}{l}100 \% \\
100 \%\end{array}$ & $\begin{array}{l}100 \% \\
100 \%\end{array}$ & $\begin{array}{l}100 \% \\
100 \%\end{array}$ & $\begin{array}{l}\{(0,1),(0,0)\} \\
\{(0,1),(12,2)\}\end{array}$ \\
\hline walk_r & $\begin{array}{l}\text { main } \\
\text { proc_l }\end{array}$ & $\begin{array}{l}0 \% \\
80 \%\end{array}$ & $\begin{array}{l}\mathbf{0 \%} \\
50 \%\end{array}$ & $\begin{array}{l}0 \% \\
50 \%\end{array}$ & $\begin{array}{l}\{(0),(1),(3)\} \\
\{(0),(1)\}\end{array}$ \\
\hline \multicolumn{6}{|c|}{ Ferramenta CCover (Windows/DOS) } \\
\hline Programa & Função & Todos-Nós & Todos-Arcos & Decisão/Condição & Conj. de Casos de Teste \\
\hline convert & main & $100 \%$ & $100 \%$ & $100 \%$ & $\{(1),(3),(-1)\}$ \\
\hline fact & $\begin{array}{l}\text { main } \\
\text { proc_1 }\end{array}$ & $\begin{array}{l}100 \% \\
100 \%\end{array}$ & $\begin{array}{l}100 \% \\
100 \%\end{array}$ & $\begin{array}{l}100 \% \\
100 \%\end{array}$ & $\begin{array}{l}\{(1),(2),(-1)\} \\
\{(1),(2),(-1)\}\end{array}$ \\
\hline fibos & $\begin{array}{l}\text { main } \\
\text { proc_l } 1\end{array}$ & $\begin{array}{l}100 \% \\
100 \%\end{array}$ & $\begin{array}{l}100 \% \\
100 \%\end{array}$ & $\begin{array}{l}100 \% \\
100 \% \\
\end{array}$ & $\begin{array}{l}\{(1,1),(1,2),(1,5)\} \\
\{(1,1),(1,2),(1,5)\}\end{array}$ \\
\hline $\max$ & $\begin{array}{l}\text { main } \\
\text { proc_1 }\end{array}$ & $\begin{array}{l}100 \% \\
100 \%\end{array}$ & $\begin{array}{l}100 \% \\
100 \%\end{array}$ & $\begin{array}{l}100 \% \\
100 \%\end{array}$ & $\begin{array}{l}\{(0,1),(0,0),(12,2)\} \\
\{(0,0),(0,1),(12,2)\}\end{array}$ \\
\hline walk_r & $\begin{array}{l}\text { main } \\
\text { proc_l }\end{array}$ & $\begin{array}{l}100 \% \\
100 \%\end{array}$ & $\begin{array}{l}100 \% \\
100 \% \\
\end{array}$ & $\begin{array}{l}100 \% \\
100 \%\end{array}$ & $\begin{array}{l}\{(0),(1),(3),(-1)\} \\
\{(0),(1),(3)\}\end{array}$ \\
\hline
\end{tabular}

${ }^{a}$ para esse programa não se conseguiu determinar um conjunto de casos de teste

Analisando-se os resultados individualmente para cada um dos programas, determinou-se que:

- Os conjuntos de casos de teste para os programas fact e max, determinados a partir dos casos de uso oriundos do programa e de uma inspeção do código decompilado, mostraram-se adequados aos critérios considerados, de modo que deverão scr submetidos à verificação da sua equivalência funcional com os programas originais em relação a esses casos de teste (Etapa 4);

- Os conjuntos de casos de teste para os programas convert, fibos e walk_r não conseguiam melhorar a cobertura indicada pela ferramenta PokeTool, ainda que adicionados vários outros casos de teste (inclusive os conjuntos de casos de teste usados com a ferramenta CCover). No entanto, usando conjuntos de casos de teste com 
pequenas modificações, a ferramenta CCover indicou cobertura de $100 \%$ para todos esses programas.

Após realizada a avaliação de adequação dos casos de teste de cada programa em duas plataformas diferentcs com ferramentas de teste diferentes, as diferenças apresentadas na cobertura de critérios equivalentes resultaram estranhas, portanto, procedcu-se a pesquisar o por quê dessas diferenças.

A resposta à questão pendente foi achada na verificação de equivalência funcional, descrita na última etapa do Passo 2, cujos resultados se resumem na Tabela 4.7.

Tabela 4.7: Resultados da verificação de funcionalidade com casos de teste adequados a critério(s) de teste estrutural - Estudo de caso C

\begin{tabular}{|l|c|c|}
\hline Programa & Plataforma DOS & Plataforma SunOS \\
\hline convert & passou & falhou \\
fact & passou & passou \\
fibos & passou & falhou \\
max & passou & passou \\
walk_r & passou & falhou \\
\hline
\end{tabular}

Durante a verificação da equivalência funcional dos programas decompilados e originais, em relação aos casos de teste adequados aos critérios de teste estrutural mencionados, identificaram-se programas que apresentavam comportamento diferente nas duas plataformas consideradas no estudo de caso. Na plataforma SunOS, os programas convert, fibos e walk_r apresentavam funcionalidade não equivalente com a dos seus pares originais, entanto que na plataforma DOS apresentavam comportamento similar aos programas originais. Scndo assim, foram considerados programas com erros numa perspectiva geral.

Os programas que se mostraram funcionalmente equivalentes aos seus pares originais em relação ao conjunto de casos de teste identificado para cada um deles nesta etapa, continuaram sendo testados segundo o procedimento que cstá sendo aplicado.

\section{Critério análise de mutantes}

Para realizar as tarefas de teste segundo o critério Análise de Mutantes utilizou-se a ferramenta de teste PROTEUM (Delamaro, 1993) para a plataforma SunOS.

A ferramenta PROTEUM foi escolhida para a condução deste estudo de caso, pois é a única ferramenta existente atualmente que apóia a aplicação do critério Análise de $\mathrm{Mu}$ tantes no teste de programas $\mathrm{C}$. 
A ferramenta PROTEUM foi utilizada para apoiar na determinação de um conjunto de casos de teste adequado ao critério análise de mulantes para os programas para os quais não foram identificados erros nas etapas anteriores. A Tabela 4.8 mostra os resultados obtidos da aplicação do critério Análise de Mutantes aos programas, e os respectivos casos de teste utilizados. Os casos de teste são conjuntos de teste AM-adequados (considerados todos os operadores de mutação) que contêm apenas casos de teste efetivos (que mataram ao menos um mutante).

Tabela 4.8: Resultados da aplicação do critério Análise de Mutantes - Estudo de caso C

\begin{tabular}{|l|c|c|l|}
\hline Programa & Mutantes Gerados & Score de Mutação & Conj. de Casos de Teste \\
\hline fact & 19 & 1 & $\{(1),(0),(-1),(2),(5)\}$ \\
$\max$ & 20 & 1 & $\{(0,1),(0,0),(12,2),(-1,0)\}$ \\
\hline
\end{tabular}

Dado que para alcançar a adequação ao critério análise de mutantes teve-se que gerar novos casos de teste, mediante a inspeção do código decompilado, realizou-se novamente a avaliação do comportamento dos programas em ambas as plataformas consideradas. Os testes foram bem sucedidos, incrementando a confiança nos programas decompilados $\mathrm{e}$ no decompilador que os gerou.

\subsubsection{Resultados}

O processo de teste e validação do decompilador Dcc foi realizado em duas etapas: 1) determinação do conjunto de casos de teste, e 2) teste e validação dos programas decompilados.

Durante a etapa de determinação do conjunto de casos de teste, identificou-se um benchmark inicial (benchmar $k_{0}$ ), o qual foi evoluindo sucessivamente até atingir uma cobertura próxima ao adequado para o critério Cobertura de Condição/Decisão. Na Tabela 4.9 resume-se a evolução do benchmark identificado.

Tabela 4.9: Resumo da evolução do benchmark para o teste e validação do decompilador Dcc

\begin{tabular}{|c|c|c|}
\hline Conj. de Casos de Teste & Nro. de programas & Cobertura atingida \\
\hline benchmark $k_{0}$ & 14 & $62 \%$ \\
\hline benchmarkin & 64 & $72 \%$ \\
\hline benchmark:" & 64 & $74 \%$ \\
\hline
\end{tabular}

"neste benchmark, cinco (5) dos programas que não contribuiam a melhorar a cobertura foram retirados e substituídos por outros, mantendo invariável o número total de programas

Complementando a avaliação da cobertura do benchmark em relação ao código fonte do decompilador Dcc, realizou-se uma inspeção do código não coberto pelos casos de teste do bench- 


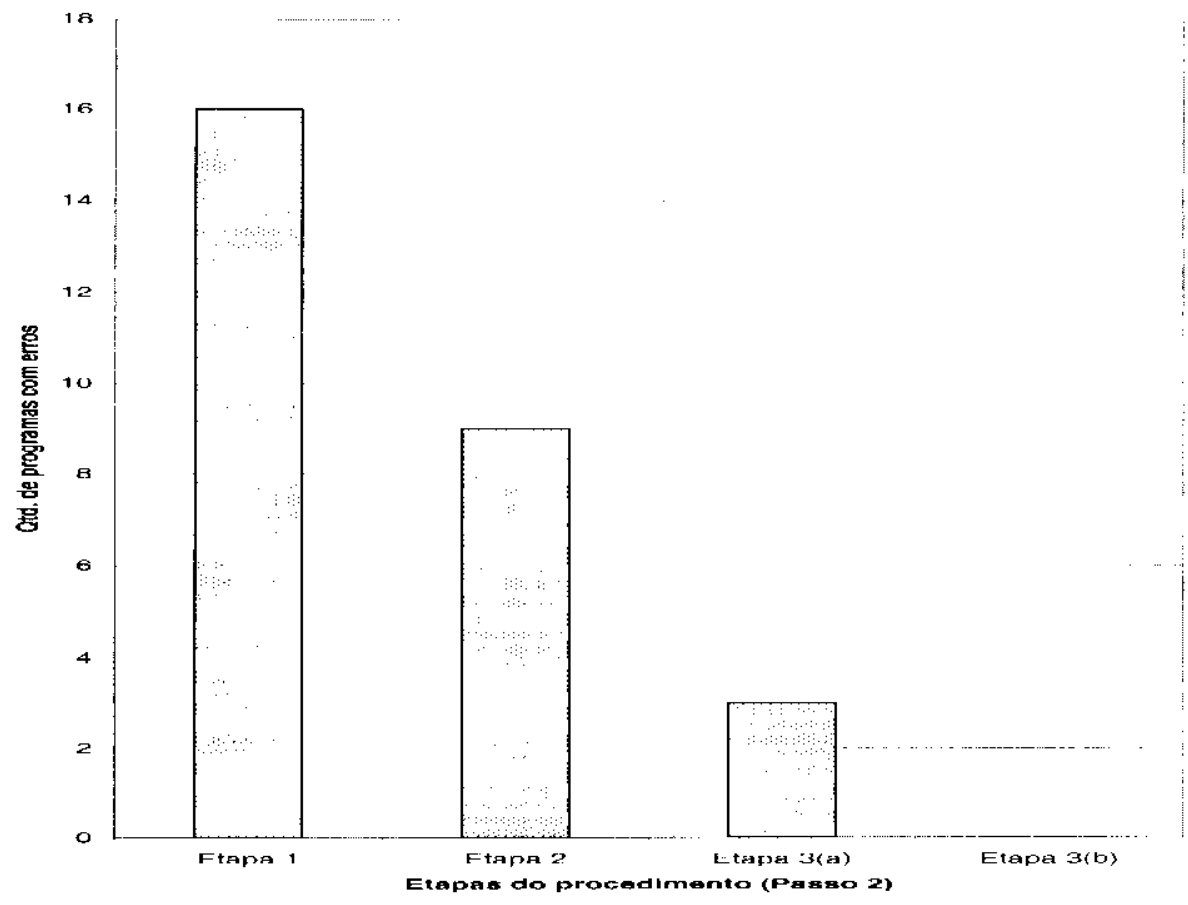

Figura 4.2: Programas com erros detectados em cada etapa do Passo 2 - Estudo de caso C

mark, obtendo-se como resultado: $3,70 \%$ do código do decompilador correspondia a condições que executavam caminhos equivalentes; $7,20 \%$ a código de gerenciamento de erros; $2,35 \%$ a rotinas de verificação e identificação de compiladores não disponíveis; e $10,70 \%$ a código que requer de testes mais elaborados e eventualmente poderia conter caminhos não execuláveis.

Definido o benchmark, do total de 64 programas que o compõem e que representam algumas, mas não todas, as combinações de instruções permitidas pela gramática padrão da linguagem $\mathrm{C}$, apenas 32 (representando $50 \%$ ) conseguiram ser decompilados pelo decompilador Dcc. Esses 32 programas são os que foram considerados para a aplicação do procedimento de teste e validação de programas decompilados.

A evolução do processo de teste e validação dos programas decompilados considerando os passos diretamente relacionados à deteç̧ão de erros nesses programas se ilustra na Figura 4.2.

A primeira etapa do procedimento de teste e validação de software decompilado , isto é, a recompilação do código fonte gerado revelou que somente 16 dos 32 programas decompilados (representando 50\%) puderam ser compilados novamente e geraram novos arquivos binários exccutáveis, tanto na plataforma SunOS quanto na plataforma original DOS.

A ctapa de verificação da funcionalidade mediante teste aleatório permitiu identificar erros em $9(56,25 \%)$ dos 16 programas restantes após a primeira etapa, sendo que alguns dos erros 
foram tais que impediram a completa execução dos programas enquanto outros foram erros que faziam com que os programas apresentassem respostas ou saídas de dados incorretas, ou então, não compatíveis com as respostas do programa original tomado como "oráculo".

Na terceira etapa, de teste e validação segundo diversos critérios, que incluiu a etapa de verificação da equivalência funcional, os 7 programas restantes foram testados em duas sub-etapas, a primeira considerando casos de teste adequados a critério(s) de teste estrutural, e a segunda considerando casos de teste adequados ao critério Análise de Mutantes. Cabe destacar que 2 dos 7 programas foram considerados funcionalmente equivalentes aos seus respectivos pares originais e não continuaram sendo testados, resultando, o conjunto de casos de teste para csta etapa, reduzido a 5 programas. Na primeira sub-etapa, 3 programas apresentaram crros numa das plataformas consideradas. Já na segunda sub-etapa, nenhum programa errado foi identificado.

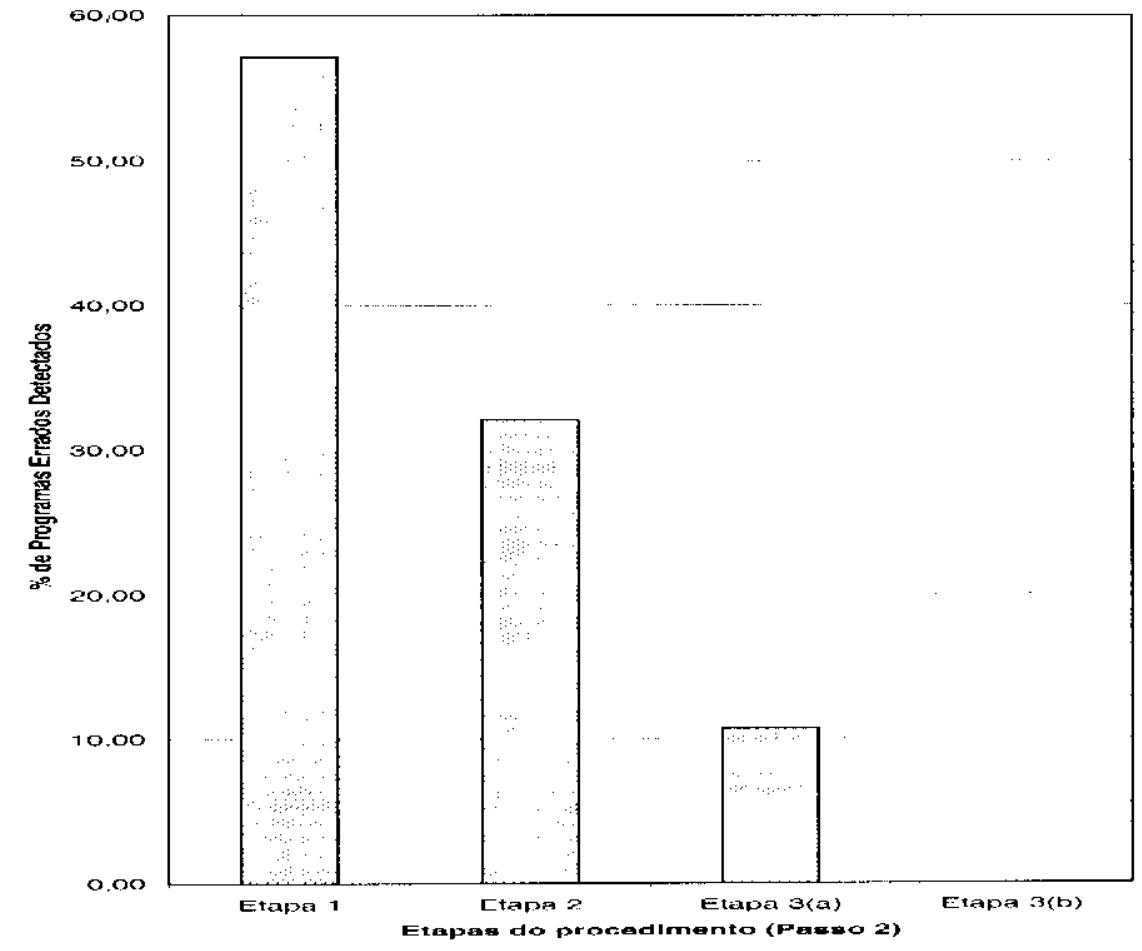

Figura 4.3: Porcentagem de programas errados detectados em cada etapa do Passo 2 - Estudo de caso $\mathrm{C}$

Em síntese, dos 32 programas decompilados que foram usados no estudo de caso, 28 apresentaram erros quando compilados novamente na plataforma SunOS, e somente 25 quando compilados na plataforma DOS (desde uma perspectiva geral foram 28 os programas errados). $\mathrm{Na}$ Figura 4.3 mostra-se a porcentagem de programas errados que cada passo do procedimento conseguiu identificar. 
Os resultados empíricos do procedimento completo de teste do decompilador Dcc, considerando as duas etapas, mostraram que Dcc consegue decompilar com sucesso, somente uns $11 \%$ dos programas usados neste estudo de caso, considerando o melhor cenário (conhecido e usado novamente o compilador original) e apenas $6,25 \%$ no outro cenário apresentado.

\subsection{Estudo de caso - Linguagem Java}

Para realizar um outro estudo de caso que contribuísse para melhorar a compreensão do procedimento descrito na Seção 4.3 decidiu-se testar a decompilação de arquivos binários.CLASS gerados pela linguagem Java. Entre as ferramentas testadas (Mocha, Jasmine, DeCafe, JAD, DJ Java Decompiler), selecionou-se, para realizar esse novo processo de decompilação, o decompilador JAD porque:

- dentre os decompiladores de uso livre, segundo uma avaliação empírica, mostrou-sc como o mais adequado para decompilar arquivos binários. CLASS para programas na linguagem Java, em termos de qualidade do código fonte gerado, facilidade de uso, c ausência de erros; e

- dentre os decompiladores proprietários testados, DeCafe e DJ Java Decompiler o usam como "motor" de decompilação, implementando sobre ele uma interface gráfica.

\subsubsection{Ambiente de decompilação e configuração}

Este cstudo de caso se realizou num computador com sistema operacional Windows, contando com o seguinte software instalado:

- JDK (Java Development Kit) e JRE (Java Runtime Environment) versão 1.3.0, instalados com as opções predefinidas na distribuição de SUN Microsystems.

- JAD e FrontEnd, instalados sem nenhuma consideração especial exccto de que FrontEnd (interface visual para o decompilador JAD) estivesse no mesmo diretório do que JAD.

- Jester e JUnit, sendo que os diretórios dos arquivos .JAR que contêm as classes executáveis estavam indicados na variável de sistema CLASSPATH. 


\subsubsection{Passo 1. Determinação do conjunto de casos de teste para o decom- pilador JAD}

Infelizmente, a não disponibilidade do código fonte do decompilador tornou impossível a determinação de um conjunto de casos de teste $T$ adequado ao decompilador, segundo algum critério de teste estrutural ou baseado cm crros. Tal como se fez no estudo de caso anterior na Seção 4.4. Assim, aplicou-se somente a etapa de determinação do conjunto de casos de teste mediante seleção de diversos programas, levando em consideração as recomendações assinaladas no procedimento.

O uso das classes de um framework de teste para as bibliotecas da linguagem como benchmark para testar o decompilador pode reforçar a confiança nos resultados do estudo de caso . Sendo assim, utilizaram-se as classes do framework do projeto Mauve (2000) e outras selecionadas de forma ad hoc tal como se indica a seguir.

\subsubsection{O projeto MAUVE}

O Projeto MAUVE é um projeto de software livre que visa a coletar um conjunto de testes para verificar o comportamento das bibliotecas da linguagem JAVA inseridas em diversas distribuições.

Esse projeto é uma iniciativa da Cygnus Solutions, apoiada por RedHat e por Hewlett Packard, que pode ser usado e distribuído segundo a licença GNU-GPL.

Mauve contém:

- duas classes principais que realizam os testes, TestHarness e SimpleTestHarness;

- uma interface de configuração, Config;

- uma interface a ser implementada pelas classes que implementam os testes das bibliotecas, Testlet;

- uma classe para o tratamento de erros, ResourceNotFoundException; e

- 274 classes que implementam os testes das bibliotecas, distribuídas numa árvore de diretórios (chamados de packages na linguagem JAVA).

As classes do projeto Mauve apresentaram uma complexidade (medida em LOC) que variava entre 20 c 150 LOC. 


\subsubsection{Outros programas na linguagem Java}

Para complementar os casos de teste a serem usados no estudo de caso foram coletadas de forma ad hoc, levando em consideração aspectos da gramática da linguagem Java, um conjunto de 20 classes (arquivos .CLASS). Essas classes apresentavam uma complexidade, medida em termos de LOC, que variava entre 40 e 300 LOC. Na Tabela 4.10 listam-se essas classes com as suas respectivas descrições.

Tabcla 4.10: Arquivos binários .CLASS a serem decompilados - Estudo de caso Java

\begin{tabular}{|l|l|}
\hline Programa & Descrição \\
\hline Blink & Applet que faz aparecer um texto que muda de cor aleatóriamente \\
Calendar & Programa que mostra a data e identifica se ć dia útil ou fim de semana \\
Counter3 & Classe que implementa um contador \\
Counter3Test & Applet que faz executar dois threads que exccutam um contador cada \\
DateTest & Programa que mostra a data c hora do sistema em três formatos \\
DialogTest & Programa que testa o uso de caixas de diálogo em Java \\
DigitalClock & Applet que mostra a data e hora do sistema (modo gráfico) \\
FilelnputStreamTest & Programa que conta caracteres e espaços num texto \\
FileReaderTest2 & Programa que conta caracteres e espaços num texto (usa outras classes) \\
HashtableTest & Programa que testa o funcionamento da classe Hashtable \\
Item & Classe que implementa uma estrutura com dois campos \\
LineNumberReaderTest & Programa que procura um caracter num arquivo \\
NewFileTest & Programa que cria um arquivo especificado como argumento \\
RandomAccessTest & Programa que mostra o valor de um dado inteiro lido desde um arquivo \\
TestContinue & Programa que mostra os anos bissextos entre dois anos fornecidos \\
TestConditionalOperator & Programa que calcula o maior de dois números \\
TestLabelledBreak & Programa que testa o uso de labels \\
TestSwitch2 & Programa que testa o uso da estrutura switch...case \\
VectorCapacityTest & Programa que testa o comportamento da classe Vector \\
Veiovis & Programa que testa a realização de diversas operações \\
\hline
\end{tabular}

\subsubsection{A decompilação}

Para a formação do conjunto de casos de teste $T$ para o decompilador JAD, numa primeira etapa, foram decompilados os programas principais que realizam os testes no projeto Mauve, sendo que todos foram decompilados com sucesso.

Numa segunda etapa, foram decompiladas (todas com sucesso) as classes que implementam os testes das bibliotecas no projeto Mauve. Essas classes não precisam de entrada de dados fornecidos pelo usuário, de maneira que não precnchem os requisitos para serem testadas segundo os critérios aplicados na terceira etapa do Passo 2 do procedimento. No entanto, na 
segunda etapa do Passo 2, pode-se comprovar se as classes decompiladas são funcionalmente compatíveis com as originais para o contexto específico em que estão sendo testadas, e, excepcionalmente no presente caso de estudo, encontrando-se disponível o código fonte das classes, pode-se realizar uma comparação que permita verificar melhor a cquivalência funcional.

Finalmente, foram decompiladas as outras classes que foram escolhidas de forma aleatória como casos de teste para a realização do estudo de caso. Dentre essas classes foram também identificadas aquelas que não requeriam mais do que um único caso de teste, sendo testadas segundo determinou-se para as classes do projeto Mauve.

Cabe destacar, que todas as classes $\left(P_{O}\right)$ coletadas para este estudo de caso (totalizando 296) foram decompiladas com sucesso, isto é, não provocaram que o decompilador travasse a sua execução nem gerasse mensagens de erro.

A identificação dos programas que precisam de entrada de dados fornecida pelo usuário e daqueles que não a precisam foi útil para economizar recursos computacionais na fase de testes, especialmente nas ctapas 3 e 4 do Passo 2 do procedimento.

\subsubsection{Passo 2. Teste e validação das classes Java geradas}

A seguir se relata em forma detalhada a aplicação do procedimento de teste e validação de software decompilado para as classes que compõem o benchmark identificado para o teste do decompilador JAD.

\subsubsection{Recompilação do código fonte decompilado}

Após realizado o processo de recompilação dos arquivos com código fonte gerado pelo decompilador os resultados mostraram que a grande maioria das classes decompiladas conseguiram gerar novamente arquivos binários .CLASS. Em números, 19 das 20 classes selecionadas aleatóriamente, as 2 classes principais de Mauve e 262 das 274 classes de teste de Mauve foram recompiladas com sucesso.

Na Tabela 4.11 mostram-se as classes que não puderam ser recompiladas.

As classes que foram decompiladas e recompiladas com sucesso foram testadas com casos de teste aleatórios para tentar descobrir a presença de erros grosseiros. 
Tabela 4.11: Classes não recompiladas - Estudo de caso Java

\begin{tabular}{|l|l|}
\hline Package & Classe \\
\hline gnu.testlet.java.io.BufferedInputStream & ProtectedVars \\
gnu.testlet.java.io.ByteArraylnputStream & ProtectedVars \\
gnu.testlet.java.io.CharArrayReader & MarkReset \\
gnu.testlet.java.io.CharArrayReader & ProtectedVars \\
gnu.testlet.java.io.PushbackInputStrcam & ProtectedVars \\
gnu.testlet.java.io.StringBufferlnputStream & ProtectedVars \\
gnu.testlet.java.lang.String & hash \\
gnu.testlet.java.net.MulticastSocket & MulticastClient \\
gnu.testlet.java.net.URL & URLTest \\
gnu.testlet.java.text.ACIAttribute & Test \\
gnu.testlet.java.text.AttributedString & Test \\
gnu.testlet.java.util.Properties & AcuniaPropertiesTest \\
\hline
\end{tabular}

\subsubsection{Verificação básica da funcionalidade}

Para a realização desta fase do estudo de caso, os programas que não precisavam de dados de entrada fornecidos pelo usuário, e por tanto, tinham um único comportamento previamente definido para o contexto no qual se realizava o estudo de caso, foram testados comparando o comportamento do programa decompilado $P_{L \text { bin }}$ com o do programa original $P_{O}$, para seguidamente realizar a comparação do código fonte decompilado com o código fonte original. É esse o caso das 262 classes que realizam os testes de bibliotecas no projeto Mauve, e que foram recompiladas, e de $9(45 \%)$ dos demais programas que foram escolhidos.

No caso das classes de testes do projeto Mauve, elas não são executáveis exceto quando chamadas desde as classes principais do projeto. Sendo assim, o teste funcional dessas classes teve que ser realizado usando as classes principais originais do projeto Mauve (não decompiladas) e com auxílio da ferramenta JUnit. Para isso teve que ser criada uma classe de teste de unidade ${ }^{2}$ que comparava o comportamento das classes de teste decompiladas com o comportamento das classes originais em termos de número de testes realizados, número de falhas não esperadas identificadas, número de falhas esperadas identificadas e número de testes que se esperava falharem mas apresentaram resultados corretos. Além disso, teve que se criar uma função que substituísse a função main da classe SimpleTestHarness e que retornasse os valores requeridos quando chamada desde a classe de teste de unidade. Na Tabela 4.12 mostram-se as classes que apresentaram resultados diferentes aos do seu par original.

\footnotetext{
${ }^{2}$ Classe que implementa o framework de teste da ferramenta JUnit
} 
Tabela 4.12: Classes decompiladas do projeto Mauve que apresentaram erros funcionais

\begin{tabular}{|l|l|}
\hline Package & Classe \\
\hline gnu.testlet.java.lang.Float & FloatTest \\
gnu.testlet.java.lang.Float & new_Float \\
gnu.testlet.java.lang.Math & max \\
gnu.testlet.java.lang.Math & min \\
gnu.testlet.java.lang.String & hash \\
\hline
\end{tabular}

Assim também, no caso das demais classes que não precisavam de dados de entrada fornecidos pelo usuário, realizou-se o teste manualmente verificando o comportamento delas contra o do seu "oráculo", c scguidamente comparando o código fonte decompilado com o código fonte original. Cabe destacar que nenhuma dessas classes decompiladas apresentou erros funcionais.

Por outro lado, as classes principais do projeto Mauve foram testadas usando um subconjunto das classes de teste originais, também com auxílio da ferramenta JUnit e da classe SimpleTestHarnessTest, classe de teste de unidade criada para o estudo de caso. As classes principais do projeto Mauve também não apresentaram erros funcionais.

Finalmente, o restante das classes usadas no estudo de caso foram testadas com casos de teste aleatórios, obtendo-se os resultados mostrados na Tabela 4.13.

Tabela 4.13: Resultados do teste aleatório - Estudo de caso Java

\begin{tabular}{|l|l|l|}
\hline Classe & Estado & Caso(s) de Teste \\
\hline Calendar & passou & $\{(10 / 01 / 2001)\}$ \\
DateTest & passou & $\{(10 / 01 / 2001)\}$ \\
FileInputStreamTest & passou & $\{($ myfile.dat $)\}$ \\
FileReaderTest2 & passou & $\{($ myfile.dat $)\}$ \\
LineNumberReaderTest & passou & $\{($ myfile.dat,"k"),(...,"8") $\}$ \\
RandomAccessTest & passou & $\{(0),(1)\}$ \\
NewFileTest & passou & $\{($ ("'),(“d:/myfile.dat") $\}$ \\
TestContinue & passou & $\{(10,20),(-2000,1500)\}$ \\
TestConditionalOperator & passou & $\{(0,(1900,2000)\}$ \\
TestSwitch2 & passou & $\{(0,(2),(7)\}$ \\
\hline
\end{tabular}

Após a realização desta etapa do procedimento de testc aqui aplicado, o conjunto de testc para as seguintes ctapas foi reduzido às classes principais do projeto Mauve e às classes com entradas de dados externas que passaram no teste aleatório (mostrados na Tabela 4.13), totalizando 12 classes. Para as demais classes que passaram a fase de teste aleatório (aquelas que não precisavam de entrada de dados) somente pode-se afirmar que são funcionalmente equivalentes às classes originais devido à disponibilidade do código fonte dessas últimas, que permitiu re- 
alizar a comparação entre o código fonte original e o decompilado. Cabe destacar que num caso real não poderia-se afirmar a equivalência funcional de tais classes com os seus pares originais sem a realização de outro tipo de testes (testes cm contextos diferentes, por exemplo).

\subsubsection{Teste e verificação dos arquivos decompilados}

Um grupo reduzido (12) das classes que foram decompiladas com sucesso foram testadas. seguidamente, usando as ferramentas JCover e Jester-JUnit quc auxiliam na aplicação de critérios de teste estrutural e do critério Análise de Mutantes, respectivamente. Esses testes visavam a identificar casos de teste adequados a tais critérios com a finalidade de verificar que as classes decompiladas fossem funcionalmente equivalentes aos seus pares originais e assim aumentar a confiança nelas.

\section{Critérios de teste estrutural}

O teste estrutural foi realizado utilizando a ferramenta JCover que apóia a aplicação dos critérios Todos-Nós e Todos-Arcos para programas na linguagem Java. Embora esses critérios sejam considerados os mais fracos dos critérios de teste estrutural, a expcriência demonstra que pelo menos são mais efetivos do que o teste aleatório.

Deve-se deixar bem claro que o principal motivo da escolha dos critérios aqui aplicados foi a disponibilidade da ferramenta. Além do mais, a simplicidade do código das classes decompiladas fez com que se considerassem adequados esses critérios.

Na Tabela 4.14 mostram-se os resultados da realização da etapa 3(a) do Passo 2. Quasc todas as classes, pela sua simplicidade, atingem $100 \%$ de adequação aos critérios considerados. No entanto, as duas classes principais do projeto Mauve, dada a complexidade delas, atingem porcentagens aceitáveis para o critério Todos-Nós e porcentagens menores para o critério Todos-Arcos. O critério de parada considerado para considerar adequadas essas porcentagens de cobertura foi o custo computacional de gerar novos casos de teste que incrementassem consideravelmente as porcentagens, e o custo computacional, ainda maior, de verificar a funcionalidade da classe decompilada comparada com a do oráculo usando um conjunto maior de casos de teste.

Identificados os casos de teste adequados aos critérios selecionados, procedeu-se a verificar a equivalência funcional das classes decompiladas $\left(P_{L}\right)$ com relação as classes originais $\left(P_{O}\right)$, não sendo identificados erros nesta ctapa.

2. Critério análise de mutantes 
Tabcla 4.14: Porcentagens de adequação a critérios estruturais - Estudo de caso Java

\begin{tabular}{|c|c|c|c|}
\hline Classe & Todos-Nós & Todos-Arcos & Caso(s) de Teste \\
\hline Calendar & $100 \%$ & $100 \%$ & $\{(10 / 01 / 2002),(12 / 01 / 2002)\}$ \\
\hline DateTest & $100 \%$ & $100 \%$ & $\{(10 / 01 / 2001)\}$ \\
\hline FileInputStreamTest & $100 \%$ & $100 \%$ & $\{($ myfile.dat $),()\}$ \\
\hline FileReaderTest 2 & $100 \%$ & $100 \%$ & $\{($ myfile.dat $),()\}$ \\
\hline LineNumberReaderTest & $100 \%$ & $100 \%$ & $\{($ myfile.dat,"k"),(...,"b"),()\} \\
\hline RandomAccessTest & $100 \%$ & $100 \%$ & $\{(0),(1)\}$ \\
\hline NewFileTest & $100 \%$ & $100 \%$ & $\{(),($ d:/myfilc.dat") $\}$ \\
\hline TestContinue & $100 \%$ & $100 \%$ & $\{(0,(1900,2000)\}$ \\
\hline TestConditionalOperator & $100 \%$ & $100 \%$ & $\{(),(10,20),(-2000,1500)\}$ \\
\hline TestSwitch2 & $100 \%$ & $100 \%$ & $\{(),(2),(7)\}$ \\
\hline SimpleTestHarness & $94,23 \%$ & $75 \%$ & classes.txt $t^{a}$ \\
\hline TestHarness & $89,29 \%$ & $62,50 \%$ & classes.txt \\
\hline
\end{tabular}

${ }^{a} \mathrm{O}$ arquivo classes.txt contém o nome das classes do framework de Mauve que se desejam usar para testar as classes principais ( 19 das 274 classes), na forma:

gnu.testlet.java.beans. DescriptorTest

gnu.testlet.java.lang.lang Test

‥

gnu.testlet.java.util.zip.ZipInputStream.close

Para realizar as tarefas de teste segundo o critério Análise de Mutantes, foram usadas as ferramentas: Jester (que realiza a geração dos mutantes) e JUnit (que realiza a avaliação da execução dos mutantes comparada à execução do programa original).

Durante a preparação desta etapa do estudo de caso notou-se que a natureza dos programas a serem testados, somada ao custo que representava usar as ferramentas Jester e JUnit nesses programas ${ }^{3}$ tornavam inconveniente a aplicação do critério Análise de $\mathrm{Mu}$ tantes, exceto para as classes principais do projeto Mauve, SimpleTestHarness e TestHarness. Para as classes que não foram testadas aplicando o critério de Análise de Mutantes realizou-se uma inspeção do código fonte decompilado, sendo que a sua simplicidade assim o permitia.

Como se mostra na Tabela 4.15, o conjunto de casos de teste próximo ao adequado para os critérios de teste estrutural aplicados anteriormente (critérios Todos-Nós e Todos-Arcos) mostrou-se mais adequado ao critério Análise de Mutantes com um númcro reduzido de operadores de mutação, isso após ter identificado mutantes equivalentes c mutantes gerados a partir de alterações em porções de código "não sensíveis" ao teste realizado pela ferramenta JUnit. As porções de código que foram identificadas como "não sensíveis" e

\footnotetext{
${ }^{3}$ JUnit precisa da criação de classes de teste derivadas do seu framework, as quais poderiam ser ainda mais complexas do que as classes a serem testadas
} 
Tabela 4.15: Resultados da aplicação do critério Análise de Mutantes - Estudo de caso Java

\begin{tabular}{|l|c|c|l|}
\hline Programa & Mutantes Gerados & Score de Mutação & Conj. de Casos de Teste \\
\hline SimpleTestHarness & 80 & 1,00 & classes.txt \\
TestHarness & 26 & 1,00 & classes.txt ${ }^{a}$ \\
\hline
\end{tabular}

"para se obter esse resultado adicionou-se, às classes já contidas na lista, uma nova classe que forçava a execução do código não exccutado pelas classes originais de Mauve

eliminadas foram aquelas que se limitavam a imprimir mensagens na saída padrão do sistema.

Cabe destacar que a identificação de mutantes equivalentes e a verificação manual das saídas não testadas pela ferramenta JUnit não foi uma tarefa trivial, $\mathrm{c}$ representou tempo e esforço razoável.

\subsubsection{Resultados}

Neste estudo de caso foi caracterizado um benchmark para o teste do decompilador JAD, a partir de um outro benchmark para o teste de bibliotecas da linguagem Java, $\mathrm{c}$ alguns outros programas escolhidos aleatoriamente. A adequação desse benchmark em relação ao decompilador JAD não foi medida devido à não disponibilidade do código fonte do decompilador.

$\mathrm{O}$ estudo de caso mostrou que num primeiro momento, em contraste com o decompilador Dcc, usado no primeiro estudo de caso, o decompilador JAD atingiu $100 \%$ de efetividade ao decompilar todas as 296 classes escolhidas como casos de teste para a decompilação.

Todas as classes escolhidas e decompiladas, então, foram submetidas ao Passo 2 do procedimento para testar e validar os programas decompilados. Na Figura 4.4 se apresenta gráficamente a evolução do estudo de caso considerando as etapas diretamente relacionadas a detecção de erros nos programas decompilados.

A primeira etapa do procedimento para testar software decompilado, ou seja, o processo de recompilação do código fonte das classes decompiladas revelou crros $\mathrm{em} 13$ das classes decompiladas (representando 4,4\%), sendo a maioria delas classes de teste do projeto Mauve.

Já na segunda etapa, quando testadas as classes que não precisavam de entrada de dados fornecida pclo usuário e comparados os resultados da sua execução com os resultados da exccução dos respectivos "oráculos", se revelaram erros em 5 das classes restantes (representando $1,75 \%)$. 


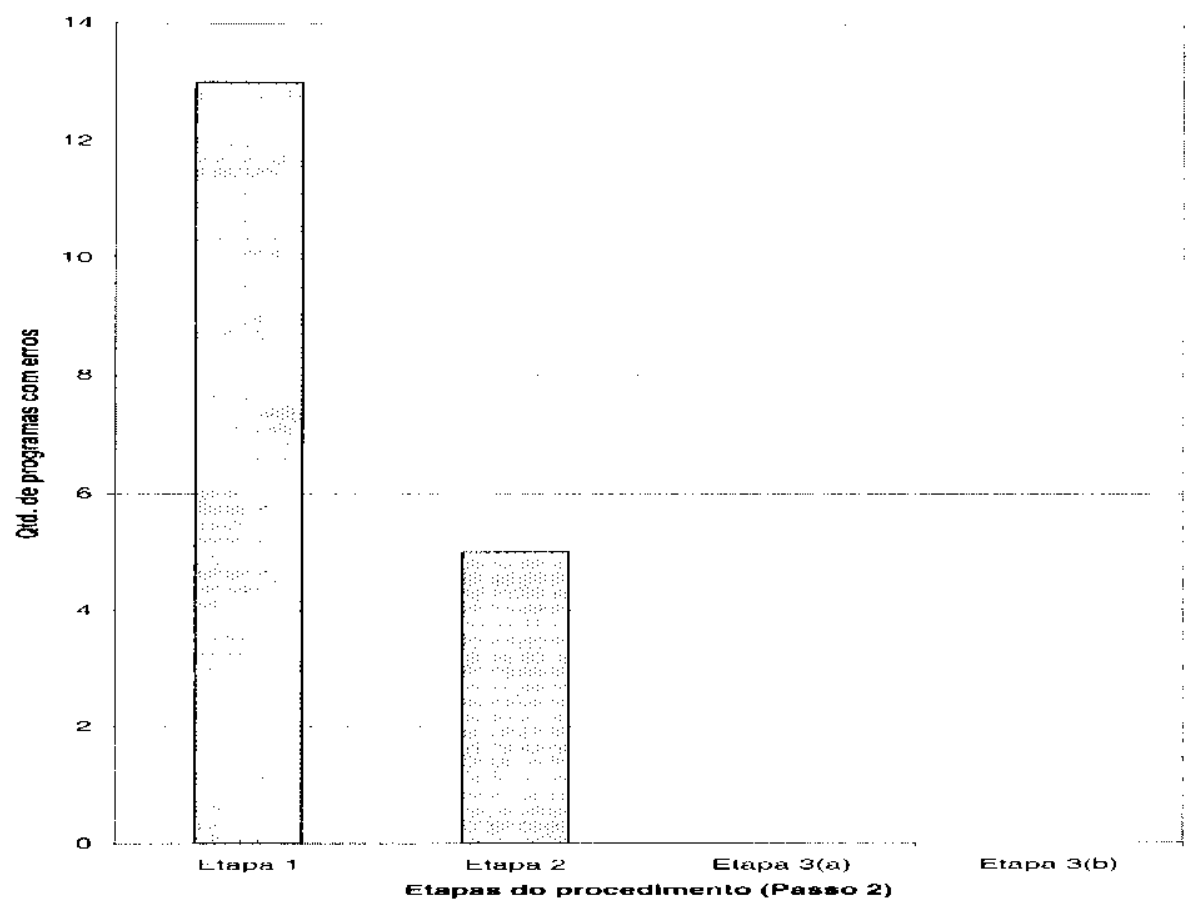

Figura 4.4: Classes com erros detectados em cada etapa do Passo 2 - Estudo de caso Java

Na etapa 3(a) não foram identificados erros em nenhuma das classes decompiladas, e na etapa 3(b), a natureza e simplicidade da maioria das aplicações fe $\%$ com que se considerasse impraticável a aplicação do critério Análise de Mutantes usando as ferramentas Jester e JUnit (as únicas disponíveis até quando fora realizado o estudo de caso). No lugar da aplicação do critério de Análise de Mutantes foi realizada uma inspeção do código fonte decompilado. Somente as classes principais do projeto Mauve, pela sua complexidade, foram submetidas a essas ferramentas. Neste passo também não foram identificados erros nas classes decompiladas.

Em resumo, de 296 classes decompiladas que foram usadas no estudo de caso, 18 apresentaram erros. Na Figura 4.5 mostra-se a porcentagem dessas 18 classes erradas que cada etapa do procedimento conseguiu identificar.

\subsection{Considerações finais}

Neste capítulo definiram-se as considerações que devem ser levadas em conta quando se define uma estratégia de teste para software decompilado, descreveu-se de maneira geral um procedimento para teste e validação de ferramentas de decompilação e de software decompilado, e apresentaram-se dois estudos de caso aplicando esse procedimento, observando-se, como resultado da avaliação de tais experiências, aspectos positivos e negativos que se detalham a seguir. 


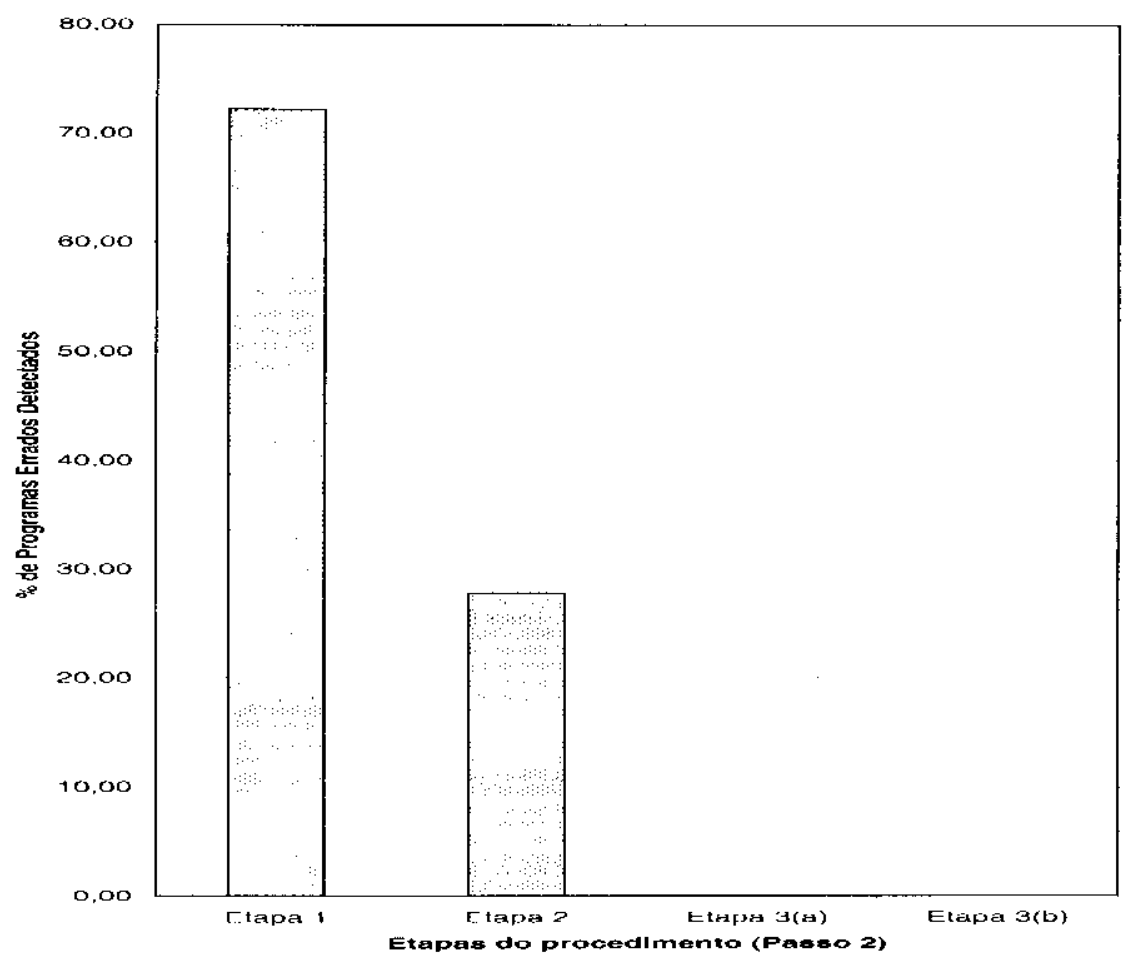

Figura 4.5: Porcentagem de classes erradas detectadas em cada etapa do Passo 2 - Estudo de caso Java

Mesmo com os critérios básicos aplicados no Passo 1 no primeiro estudo de caso, podem-se observar os benefícios de se utilizar uma forma sistemática para a atividade de teste e validação do decompilador. Por exemplo, conseguiu-se determinar que o conjunto de casos de teste caracterizado por Cifuentes (1994) não era adequado e podia ser mclhorado. Conseguiu-se melhorar a cobertura desse conjunto com a inclusão de novos casos de teste, e determinaram-se características do código que dificultavam uma melhora de cobertura ainda maior.

A avaliação da adequação dos casos de teste do segundo estudo de caso não foi possível devido à não disponibilidade do código fonte do decompilador.

Durante a aplicação do Passo 2 no primeiro estudo de caso, pôde-se observar que a aplicação sistemática dos diversos critérios, especialmente em diversos contextos, contribuiu à detecção de erros nos produtos gerados pclo decompilador, mostrando assim, uma certa relação de dependência do decompilador Dcc com respeito ao ambiente original no qual foi criado o programa executável.

Em ambos os casos de teste, a aplicação de critérios mais básicos nas primeiras etapas do procedimento permitiu, potencialmente, economizar recursos computacionais.

Em se tratando de avaliar o desempenho dos decompiladores, cabe destacar que as diferenças entre os tipos de programas binários usados nos dois experimentos influem muito nos 
resultados. Daí, analisando os resultados de ambos, e baseados no conhecimento que se tem de cada um desses tipos de arquivos, pode-se concluir que os programas binários do tipo.CLASS (programas bytecode) têm maiores probabilidades de gerar código fonte decompilado correto do que os programas binários de tipo .EXE (programas binários na linguagem de máquina). Isto devido principalmente à grande quantidade de informação simbólica contida nos arquivos .CLASS.

No entanto, ainda que não possam ser comparados, as experiências mostraram um desempenho bastante promissor por parte do decompilador JAD, cnquanto que o decompilador Dcc apresentava alguns problcmas. 


$\overleftarrow{5}$

\section{Conclusões e Trabalhos Futuros}

\subsection{Considerações iniciais}

Neste capítulo são apresentadas as conclusões derivadas dos assuntos, tanto teóricos quanto práticos, tratados no presente trabalho de pesquisa. Ressaltam-se também, levando-se em consideração os objetivos definidos inicialmente, as contribuições contidas neste trabalho. Finalmente, são mencionados alguns potenciais trabalhos de pesquisa relacionados ou complementares a este.

\subsection{Conclusões e contribuições}

No tempo presente a decompilação não é mais um assunto somente acadêmico ou de reduzidos círculos de pesquisa. O crescente interesse de companhias privadas em financiar projetos de pesquisa na área, e a inclusão de regras para a sua aplicação nas legislações pertinentes de diversos países, fazem com que seja necessário acompanhar o seu desenvolvimento.

Os usos da decompilação são diversos, desde a migração de sistemas legados de uma plataforma de software/hardware para outra, até auditoria de software, segurança, entre outros. Essa diversidade de usos, e a inclusão da decompilação como parte do Processo de Soft- 
ware (no contexto da Engenharia Reversa) fazem com que surjam cada vez mais ferramentas automatizadas e, portanto, mais produtos daquelas (software decompilado).

Falando em software, uma das maiores preocupaçōes é sempre tentar garantir, com o maior grau de confiança possível, que o software desempenhe aquilo para o qual foi projetado. No caso das ferramentas de decompilação, é tentar garantir que o software decompilado que elas produzem seja funcionalmente equivalente à aquele que lhe deu origcm. As atividades de teste de software contribuem a aumentar a confiança nas ferramentas de decompilação e nos produtos gerados, no entanto, não existe na literatura nenhuma menção específica sobre o teste dessas ferramentas nem de software decompilado.

$\mathrm{Na}$ área de teste e validação de software muitas pesquisas apresentam como resultados diversas técnicas e critérios de teste que visam a medir quão adequado a um programa $P$ é um determinado conjunto de casos de teste $T$.

Para a realização das atividades de teste no contexto de decompilação definiu-se uma estratégia que oferece ao testador a vantagem de definir o grau de qualidadc c confiabilidade que se quer atingir, e o tempo e recursos a serem investidos, deixando a ele o poder de decidir quais critérios aplicar e quando parar. A definição dessa estratégia bascou-se na literatura da área que mostrava comparações de custo e eficácia de alguns critérios, critérios de parada para diversos critérios de teste, graus de equivalência do software, entre outros.

Uma vez definida a estratégia de teste a ser usada para o teste e validação de decompiladores e do software por eles gerado, dois estudos de caso, realizados com diferentes decompiladores, mostraram que ela era, para esses casos, eficaz em revelar erros do decompilador ainda nos primeiros estágios (os de menor custo computacional). O primeiro estudo de caso foi realizado usando o decompilador Dec para a linguagem $\mathrm{C}$ em duas plataformas de software/hardware, e o segundo, usando o decompilador JAD para a linguagem Java numa única plataforma de soltware/hardware.

A aplicação sistemática de diversas técnicas e critérios de teste, realizada no primeiro estudo de caso, mostrou que o conjunto de programas (casos de teste) para o teste do decompilador Dcc, caractcrizado por Cifuentes, mostrava um nível de adequação não muito alto. Esse estudo de caso também permitiu caracterizar, de forma empírica, um benchmark para o teste de decompiladores para a linguagem $\mathrm{C}$, o qual, quando aplicado ao decompilador Dcc, mostrou um nível de adequação maior. No entanto, o decompilador Dcc não mostrou um desempenho destacável em relação a csse benchmark.

No segundo estudo de caso, o decompilador JAD mostrou-se bastante efetivo cm relação ao benchmark de teste caracterizado para decompiladores que têm a linguagem Java como linguagem alvo. 
Devido à grande quantidade de informação simbólica contida no bytecode dos arquivos .CLASS, pode-se considerar que a decompilação de programas a partir de arquivos .CLASS é mais viável do que a decompilação a partir de código na linguagem de máquina. Com essa consideração explicam-se as diferenças entre o desempenho do decompilador Dcc e o desempenho do decompilador JAD.

Em síntese, como resultado do presente trabalho, definiu-se uma estratégia incremental de teste para ferramentas de decompilação e para programas decompilados, e conseguiu-se determinar de forma empírica um benchmark para o teste e validação do decompilador Dcc e outro para o decompilador JAD, os quais podem ser usados como benchmarks iniciais no teste e validação de decompiladores similares para as linguagens C e Java, respectivamente. Assim sendo, considera-se que, com tais resultados, os objetivos definidos inicialmente foram atingidos.

\subsubsection{Trabalhos futuros}

Finalmente, espera-se que os resultados obtidos despertem o interesse de outros pesquisadores que desenvolvam trabalhos relacionados ou complementares. Algumas das linhas de pesquisa, nas quais podem-se visualizar potenciais trabalhos são:

- Definição de novos operadores de mutação. Conhecidos os problemas que apresenta a decompilação de arquivos binários, e considerando que o critério de Análise de Mutantes é um dos que apresenta maior eficácia na deteç̧ão de erros, podem ser definidos novos operadores de mutação específicos para a decompilação de uma determinada linguagem. Operadores de mutação que mudem os tipos de dados nas definições das variáveis, ou que façam "casting" dos valores de uma variável de um tipo para outro, poderiam ser úteis.

- Geração de casos de teste para ferramentas de decompilação. A adoção de conjuntos de programas usados para o teste de compiladores incrementa a confiabilidade dos testes, mas para muitas linguagens eles não são de domínio público. A geração automática de casos de teste partindo de uma definição da gramática da linguagem alvo seria de muita utilidade para a realização de atividades de teste e validação de decompiladores. 


\section{Referências Bibliográficas}

Barbosa, E. F.; Maldonado, J. C.; Vincenzi, A. M. R.; Delamaro, M. E.; Souza, S. R. S.; JINO, M. Introdução ao teste de software. Minicurso apresentado no SBES'2000 - Simpósio Brasileiro de Engenharia de Software, 2000.

Beck, K.; Gamma, E. Test infected: Programmers love writing tests, Java Report, v. 3, n. 7, p. 51-56, 1998.

BECK, K.; Gamma, E. Junit: A cook`s tour, disponível na Internet http://www.junit.org em 22 fev. $2002,2001$.

BEIZER, B. Software testing techniques. Van Norstrand Reinhold Electrical/Computer Science and Engineering Series, 2 ed. New York: Van Nostrand Reinhold Company, 1990.

Budd, T. A. Computer program testing, cáp. Mutation Analysis: Ideas, Examples, Problems and Prospects Sogesta: North-Holland Publishing Company, p. 129-148, 1981.

Budd, T. A.; Acree, A. T.; DeMillo, R. A.; Lipton, R. J.; SAYward, F. G. Mutation analysis. Technical Report GIT-ICS-79 08, Georgia Institute of Technology, 1979.

CAPRINO, G. Reverse engineering compiler. Disponível na Internet http://www.backerstreet.com/rec/rec.htm em 22 fev. 2002, 1997.

CHAIM, M. L. Poke-tool - uma ferramenta para suporte ao teste estrutural de programas baseado em fluxo de dados. Dissertação de Mestrado, DCA/FEEC/UNICAMP, Campinas, SP, Brasil, 1991.

Chaim, M. L.; Jino, M.; Maldonado, J. C. Poke-tool - estado atual de uma ferramenta para teste estrutural de software baseado em análise de fluxo de dados. In: Caderno de Ferramentas do XII SBES, Maringá, PR, Brasil: SBC, 1998, p. 37-45. 
Chaim, M. L.; Maldonado, J. C.; Jino, M. Poke-tool - uma ferramenta para suporte ao teste estrutural de programas baseado em análise de fluxo de dados. In: V Simpósio Brasileiro de Engenharia de Software, Ouro Preto, MG, Brasil, 1991, p. 10.

Cifuentes, C. Reverse compilation techniques. Tese de Doutoramento, Queensland University of Technology, School of Computer Science, 1994.

Cifuentes, C. An environment for the reverse engineering of executable programs. In: Proceedings of the Asia-Pacific Software Engineering Conference (APSEC), Brisbane, Australia: IEEE Computer Society Press, 1995, p. 410-419.

Cifuentes, C. The impact of copyright on the development of cutting-edge reverse engineering technology. In: Proceedings of the Sixth Working Conference on Reverse Engineering, Atlanta, USA: IEEE Computer Society Press, 1999, p. 66-76.

Cifufntes, C.; Fitzgerald, A. Reverse engineering of computer programs: Comments on the copyright law review committee's final report on computer software protection. Journal of Law and Information Science, v. 6, n. 2, p. 241-276, 1995.

CoRnett, S. Code coverage analysis. Disponível na Internet http://www.bullseye.com/coverage.html em 22 fev. 2002, 1998.

Delamaro, M. E. Proteum: Um ambiente de teste baseado na análise de mutantes. Dissertação de Mestrado, ICMC/USP, São Carlos - SP, 1993.

Delamaro, M. E.; Maldonado, J. C.; Nakagawau, E. Y. Proteum/im: Uma ferramenta de apoio ao teste de integração. In: Anáis do XI Simpósio Brasileiro de Engenharia de Software, Fortalcza, Brasil: SBC, 1997, p. 487-490.

DeMillo, R. A.; Lipton, R. J.; Sayward, F. G. Hints on test data selection: Help for the practicing programmer. IEEE Computer, v. 11, n. 4, p. 34-41, 1978.

Demillo, R. A.; McCracken, W. M.; Martin, R. J.; Passafiume, J. F. Software testing and evaluation. The Benjamin/Cummings Publishing Company Inc., 1987.

DYER, D. Java decompilers compared. JavaWorld, n. 7, disponível na Internet http://www.javaworld.com/javaworld/jw-07-1997/jw-07-decompilers.html cm 22 fev. 2002, 1997.

EMmerik, M. V. Signatures for library functions in executable files. Technical Report 2/94, Faculty of Information Technology, University of Queensland, GPO Box 2434, Brisbane 4001, Austrália, 1994. 
FRANKL, P. G.; WEISS, S. N. An experimental comparison of the effectiveness of branch testing and data flow testing. Software Engineering, v. 19, n. 8, p. 774-787, disponível na Internet http://citcseer.nj.nec.com/frank193experimental.html em 22 fev. 2002, 1993.

Halstead, M. H. Elements of sofiware science. New York: Elsevier North-Holland Inc., 1977.

Herman, P. M. A data flow analysis approach to program testing. Australian Computer Journal, v. 8, n. 3, 1976.

Housel III, B. C. A study of decompiling machine languages into high-leve machine independent languages. Tese de Doutoramento, Computer Science, Purdue University, 1973.

Johnsonbaugh, R.; Kalin, M. Applications programming in ANSI C. 3 ed. Englewood Cliffs, N.J.: Prentice Hall, 1996.

Kouznetsov, P. Jad. Disponível na Internet http://kpdus.tripod.com/jad.html em 22 fev. $2002,1997$.

LASKI, J. W.; KORLL, B. A data flow oriented program testing strategy. IEEE Transactions on Software Engineering, v. 9, n. 3, p. 347-354, 1983.

Maldonado, J. C. Critérios potenciais usos: Uma contribução ao teste estrutural de software. Tese de Doutoramento, DCA/FEE/UNICAMP, Campinas, SP, Brasil, 1991.

Maldonado, J. C.; Vergílio, S.; Chaim, M. L.; Jino, M. Critérios potencias usos: Análise de aplicação de um benchmark. In: VI Simpósio Brasileiro de Engenharia de Software, Gramado, RS, Brasil, 1992, p. 357-371.

Maldonado, J. C.; Vincenzi, A. M. R.; Barbosa, E. F.; Solza, S. R. S.; Delamaro, M. E. Aspectos teóricos e empíricos de teste de cobertura de software. Rel. Téc. 31, Instituto de Ciências Matemáticas e de Computação - ICMC-USP, 1998.

Mathur, A.; WONG, W. An empirical comparison of mutation and data flow-based test adcquacy criteria. Disponível na Internet http://citeseer.nj.nec.com/mathur93empirical.html em 22 fev. 2002, 1993.

Mathur, A. P. Performance, efectiveness, and reliability issues in software testing. In: Proceedings of the Fifteenth Annual International Computer Software and Applications Conference, Tokyo, Japan, 1991, p. 604-605.

MENZIES, T. J.; CUKIC, B. Handbook of sofiware engineering and knowledge engineering, v. 2, cáp. How Many Tests are Enough? World Scientific Pub. Co., 2000.

Disponível em http: //Www. ksi.edu/seke/hand.html 
Mishra, R. Reverse engineering in japan and the global trend towards interoperability. E-Law - Murdoch University Electronic Journal of Law, v. 4, n. 2, disponível na Internet http://www.murdoch.edu.au/claw/issues/v4n2/mishra42.html em 22 fev. 2002, 1997.

MOORe, I. Jester - a junit test tester. In: Second International Conference on eXtreme Programming and Flexible Processes in Software Engineering, Sardinia, Itália: Adisson-Wesley, 2001, p. 84-87.

OfFUTT, A. J.; CRAFT, W. M. Using compiler optimizaton techniques to detect equivalent mutants. The Journal of Software Testing, Verification, and Reliability, v. 4, n. 3, p. 131-154, 1994.

OFfutt, A. J.; PAn, J. Auomatically detecting equivalent mutants and infeasible paths. The Journal of Software Testing, Verification, and Reliability, v. 7, n. 3, p. 165-192, 1997.

O'Gorman, J. J. Systematic decompilation. Tese de Doutoramento, Departament of Computer Science and Information Systems, University of Limerick, Ireland, 1991.

PRESSMAN, R. S. Software engineering: A practioner's approach. McGraw-Hill Series in Computer Science, 5 ed. London: McGraw-Hill, 2000.

Projeto MAUVE. Disponível na Internet http://sources.redhat.com/mauve/ em 22 fev. 2002, 2000.

RAMSEY, N.; FERNÁNDFZ, M. Automatic checking of instruction specifications, 1997 International Conference of Software (submitled), disponível em http://www.eecs.harvard.edu/nr/pubs/checker.ps, 1997.

RAPPS, S.; WEYUKER, E. J. Data flow analysis techniques for program test data selection. In: 6th International Conference on Software Engineering, Tokyo, Japan, 1982, p. 272-278.

Rapps, S.; WeYukfr, E. J. Selecting software test data using data flow information. IEEE Transactions on Software Engineering, v. 11, n. 4, p. 367-375, 1985.

Rothermel, G.; Untch, R. H.; Chu, C.; Harrold, M. J. Testcase priorization: An empirical study. In: Proceedings of the International Conference on Software Mainteinance, Oxford, UK: IEEE, 1999.

SCHNEIDER, A. Junit best practices. Java World, n. 12, disponível na Internet http://www.javaworld.com/javaworld/jw-12-2000/jw-1221-junit.html em 22 fev. 2002, 2000.

VAN VLIET, H. Mocha, the java decompiler. Disponível na Internet http://www.brouhaha.com/ eric/computers/mocha.html em 22 fev. 2002, 1997. 
WLODARSKI, P. Analysing code coverage with c-cover by bullseye. STQE Magazine, p. 66-68, disponível na Internet http://www.bullseye.com/stqe-toollook-MarApr2001 .pdf em 22 fev. 2002, 2001.

Wong, W. On mutation and data flow. Tese de Doutoramento, Purdue University, West Lafayette, IN, disponível na Internet http://citeseer.nj.nec.com/wong93mutation.html em 22 fev. $2002,1993$. 


$\bar{A}$

\section{Código fonte de programas}

Neste apêndice é apresentado o código fonte de dois programas decompilados e o código fonte dos scus respectivos programas originais. Na Seção A.1 apresenta-se o programa fact escrito na linguagem $\mathrm{C}$ e decompilado pelo decompilador Dcc, e na Seção A.2 apresenta-se a classe SimpleTestHarness escrita na linguagem Java e decompilada pclo decompilador JAD.

\section{A.1 O programa fact}

O programa fact foi decompilado com sucesso pelo decompilador Dcc. Esse programa tinha 20 LOC, e quando testado segundo critérios de teste estrutural usando a ferramenta PokeTool apresentou 9 nós c 9 arcos no seu grafo de fluxo de controle; quando testado usando a ferramenta Proteum, gerou 19 mutantes. 
Tabela A.1: Código fonte original do programa fact

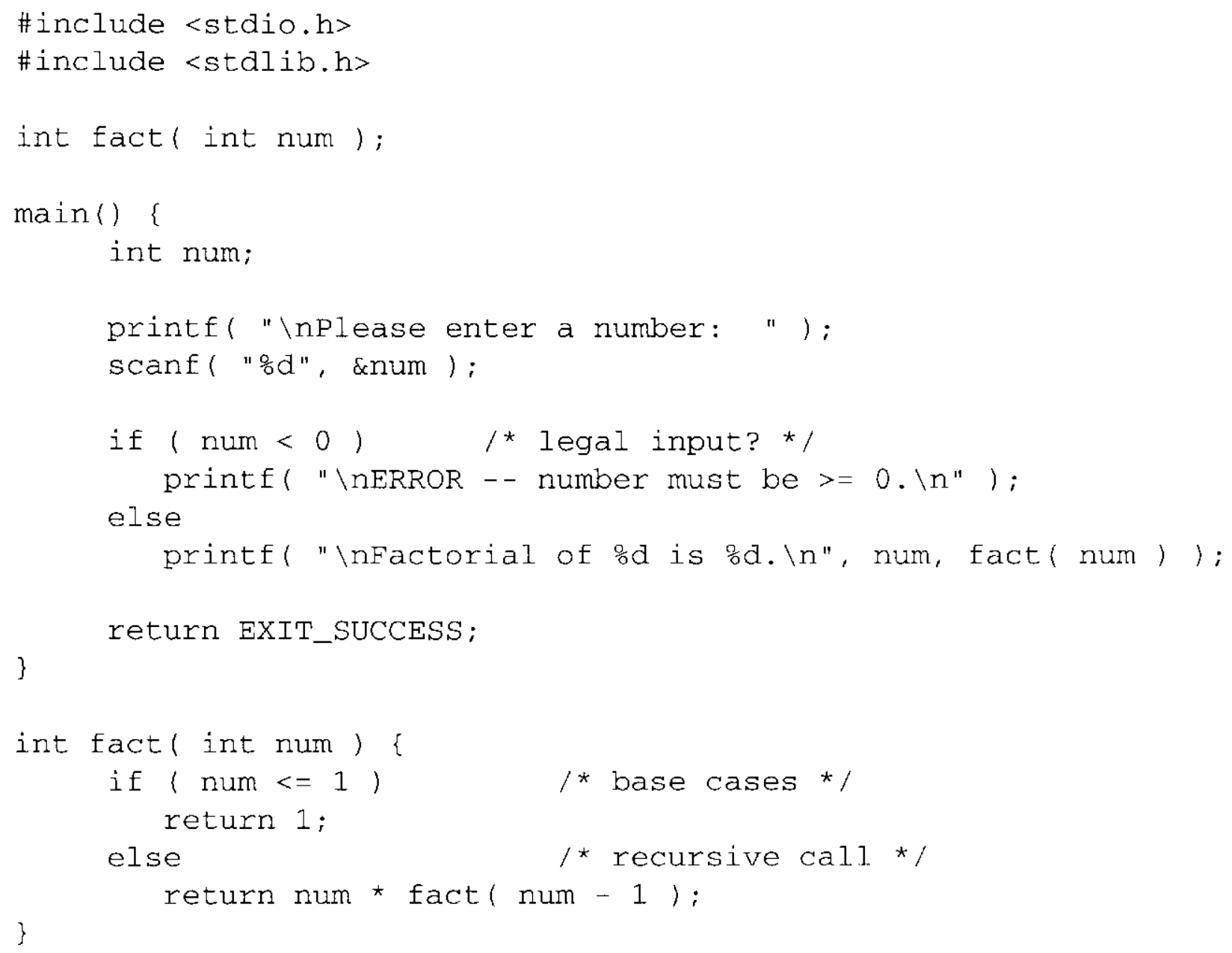


Tabela A.2: Código fonte decompilado do programa fact

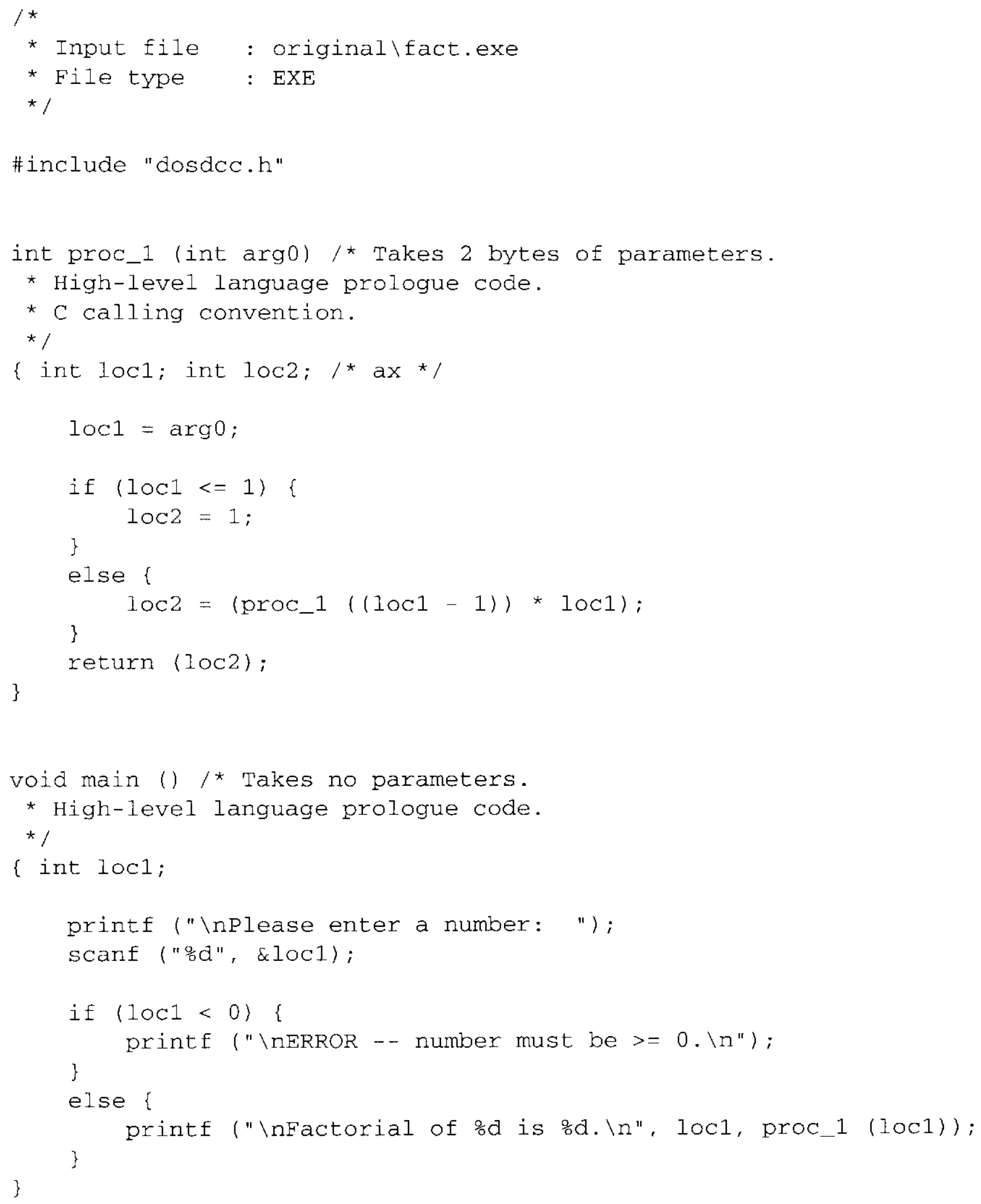




\section{A.2 A classe SimpleTestHarness}

A classe SimpleTestHarness é a classe principal do projeto Mauve, a qual se encarrega de realizar os testes das bibliotecas executando as outras classes.

\section{Código fonte original da classe SimpleTestHarness}

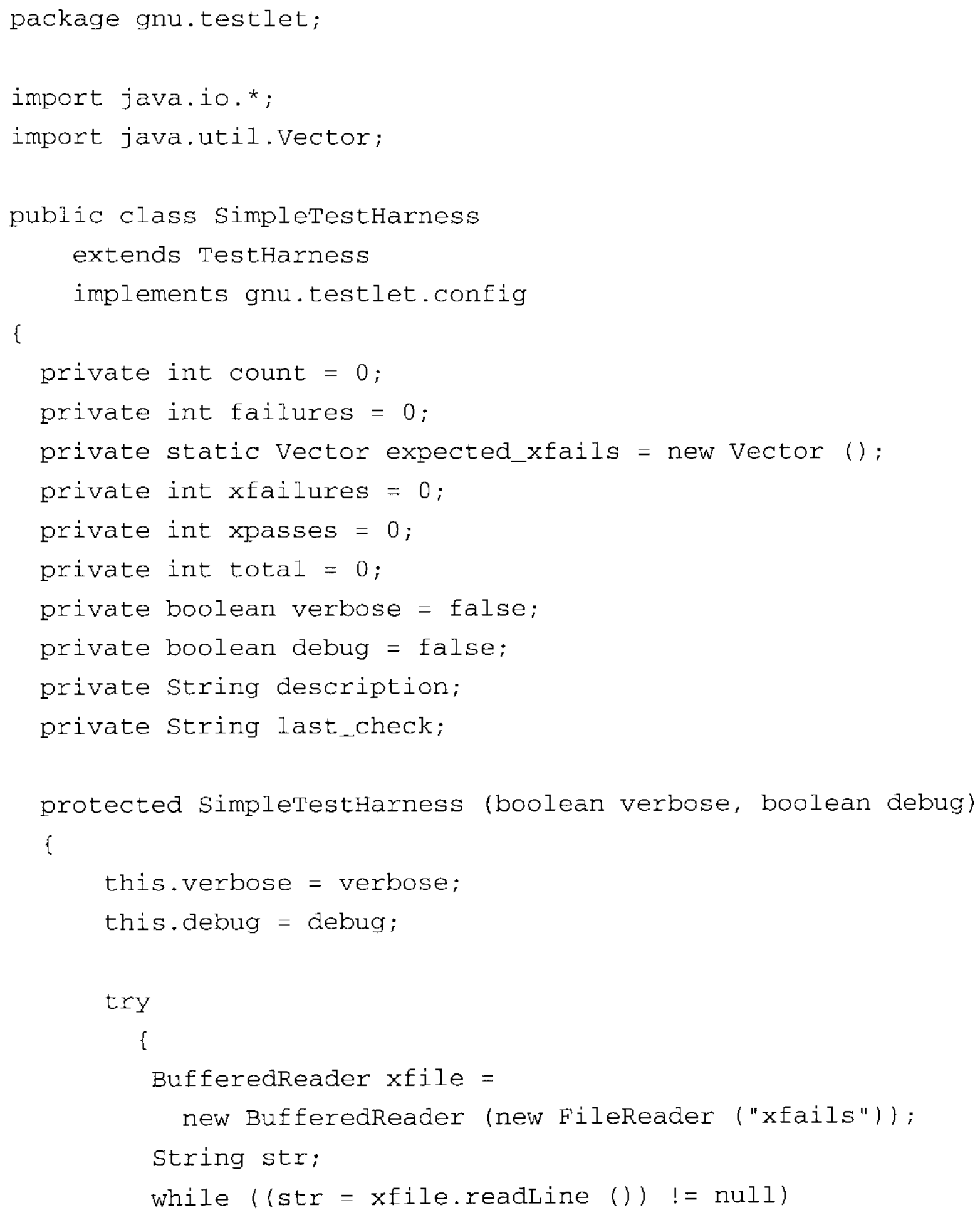




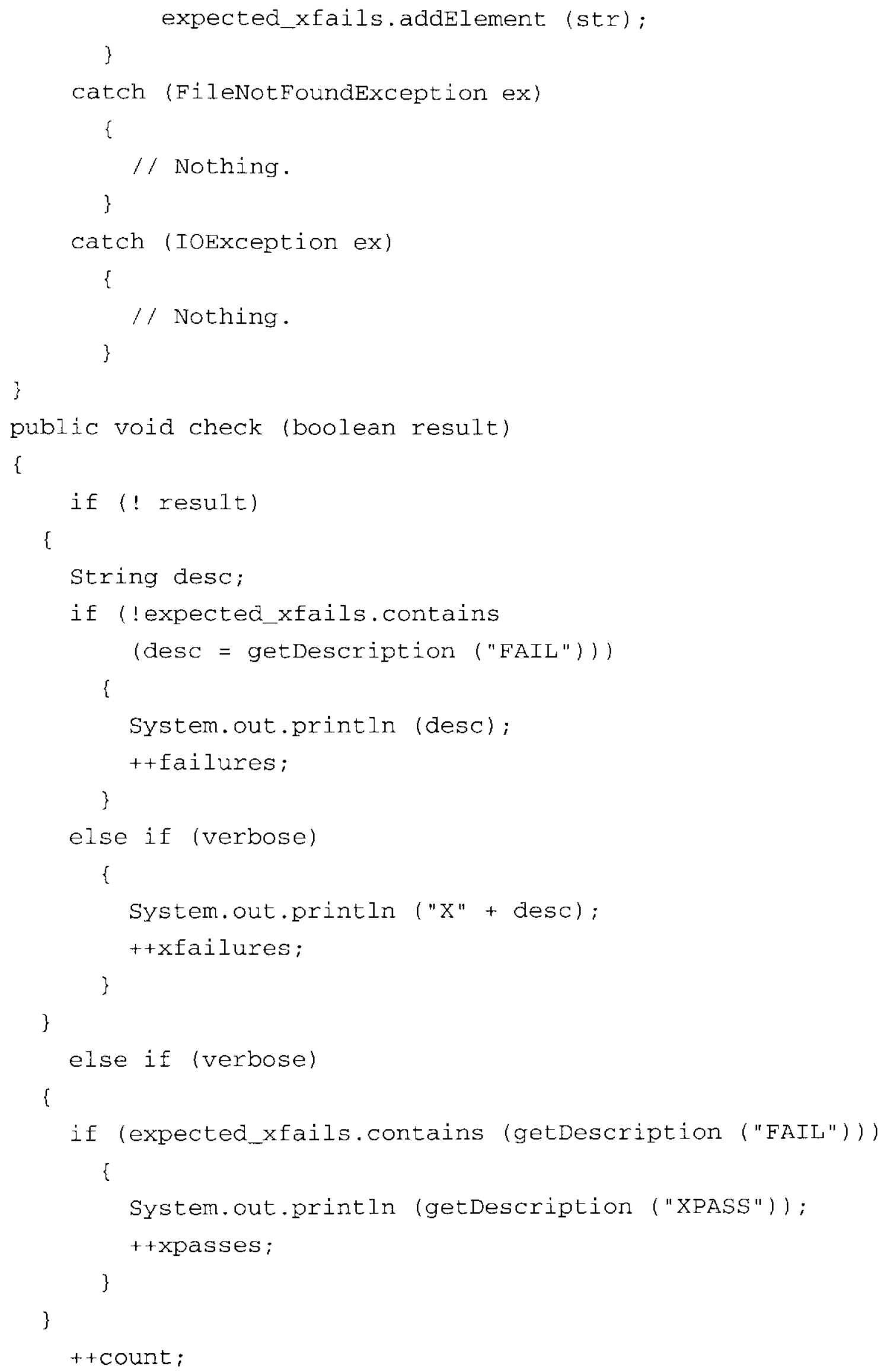




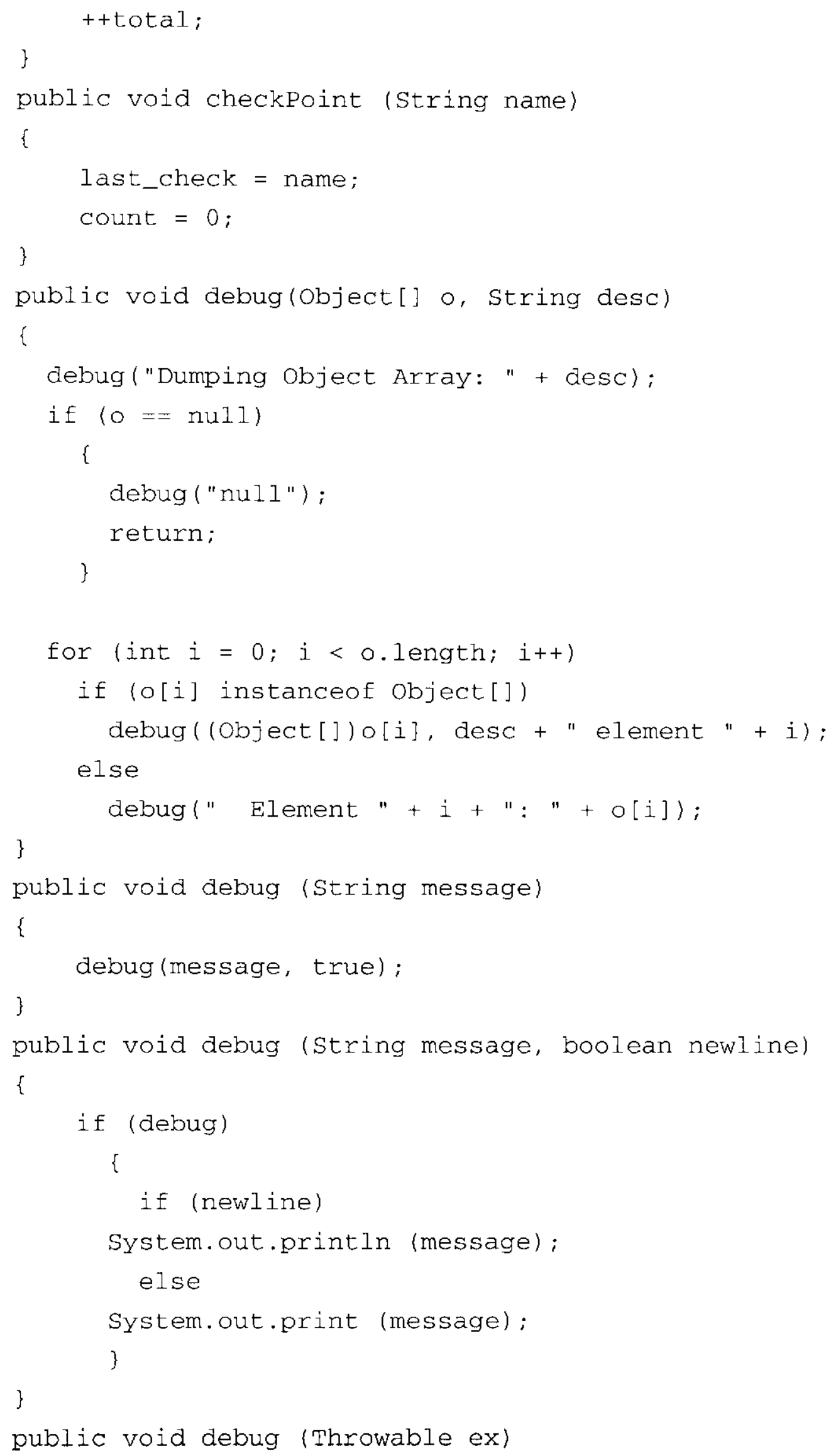




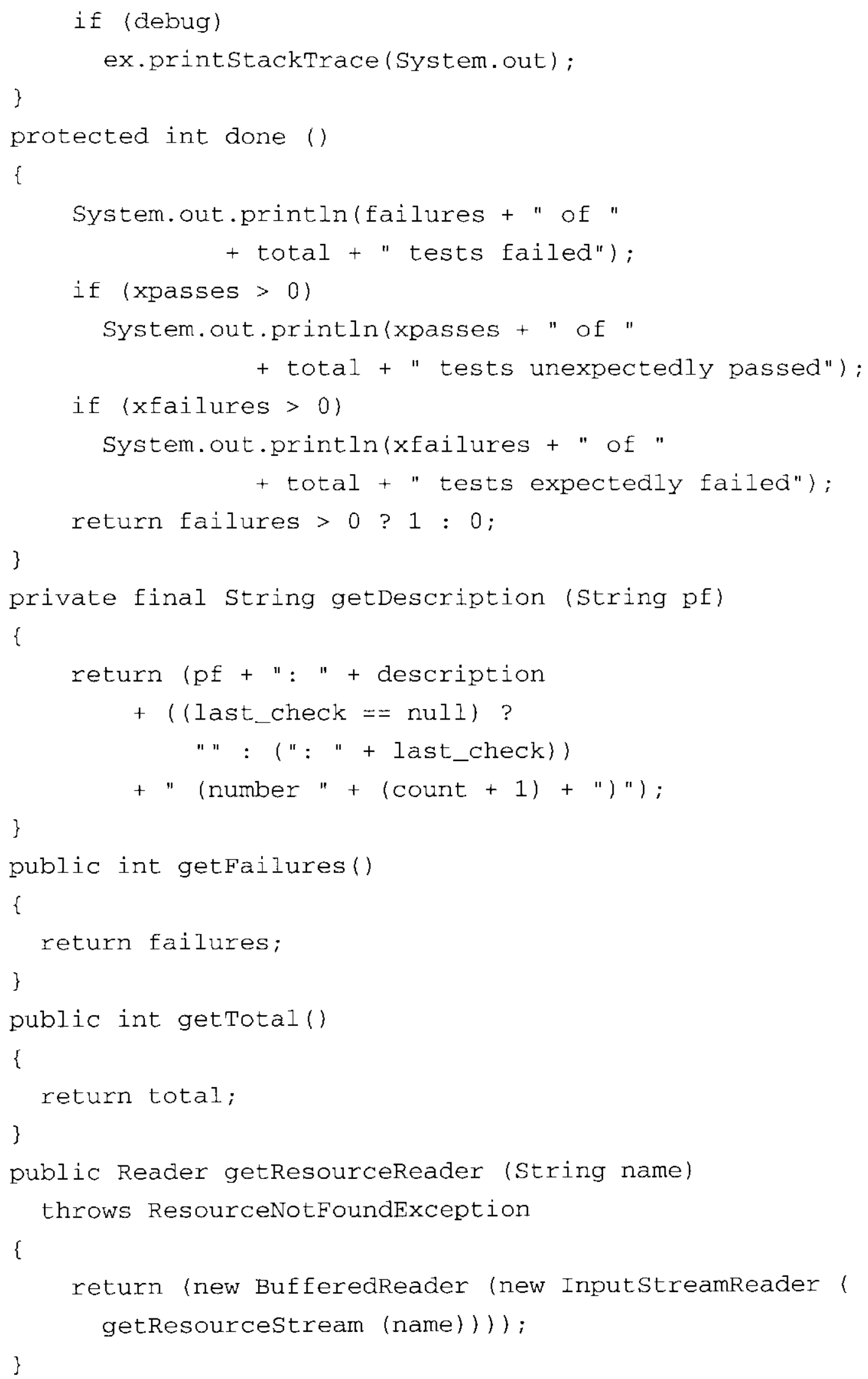




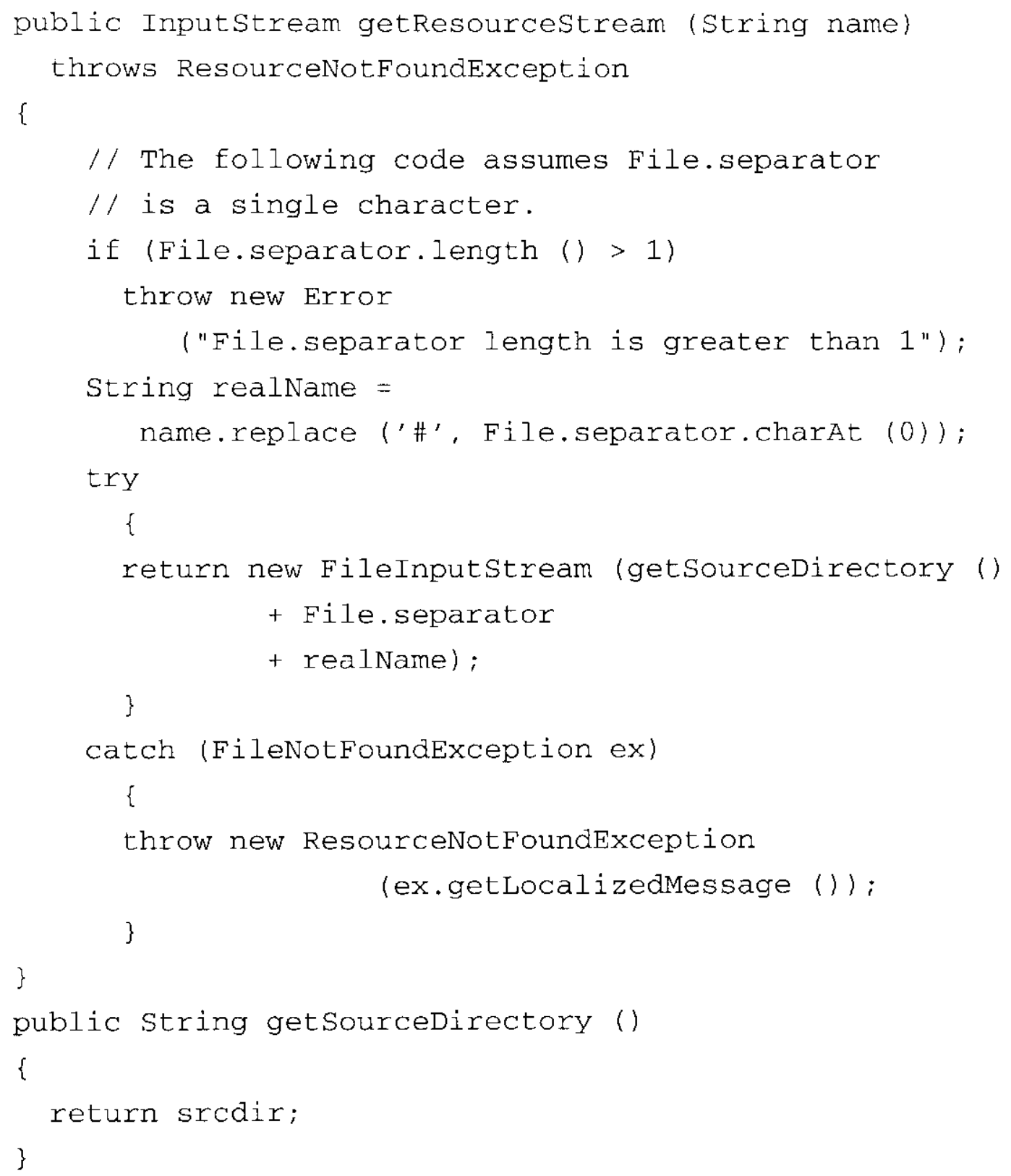




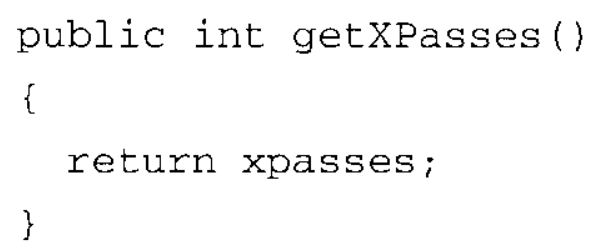




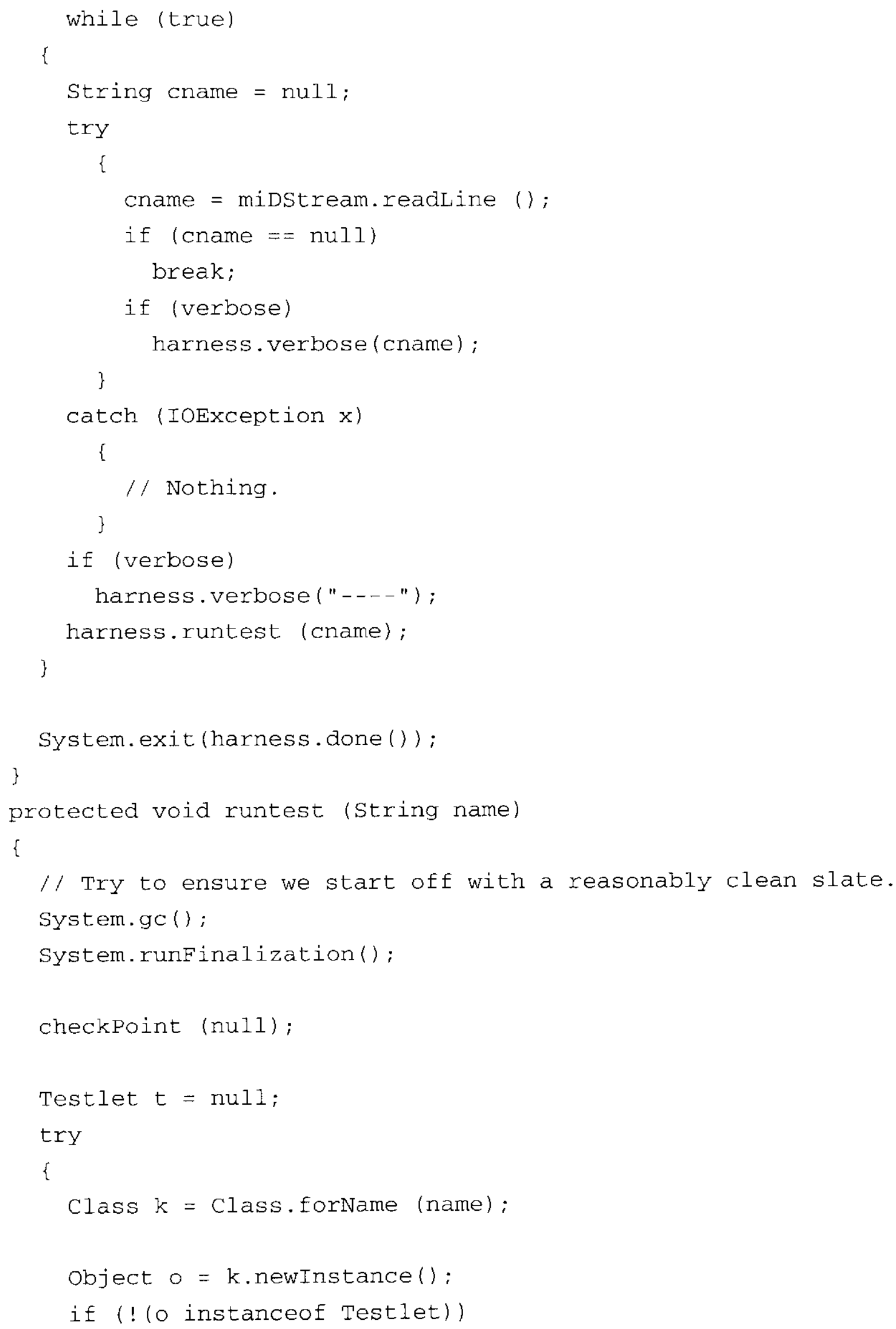




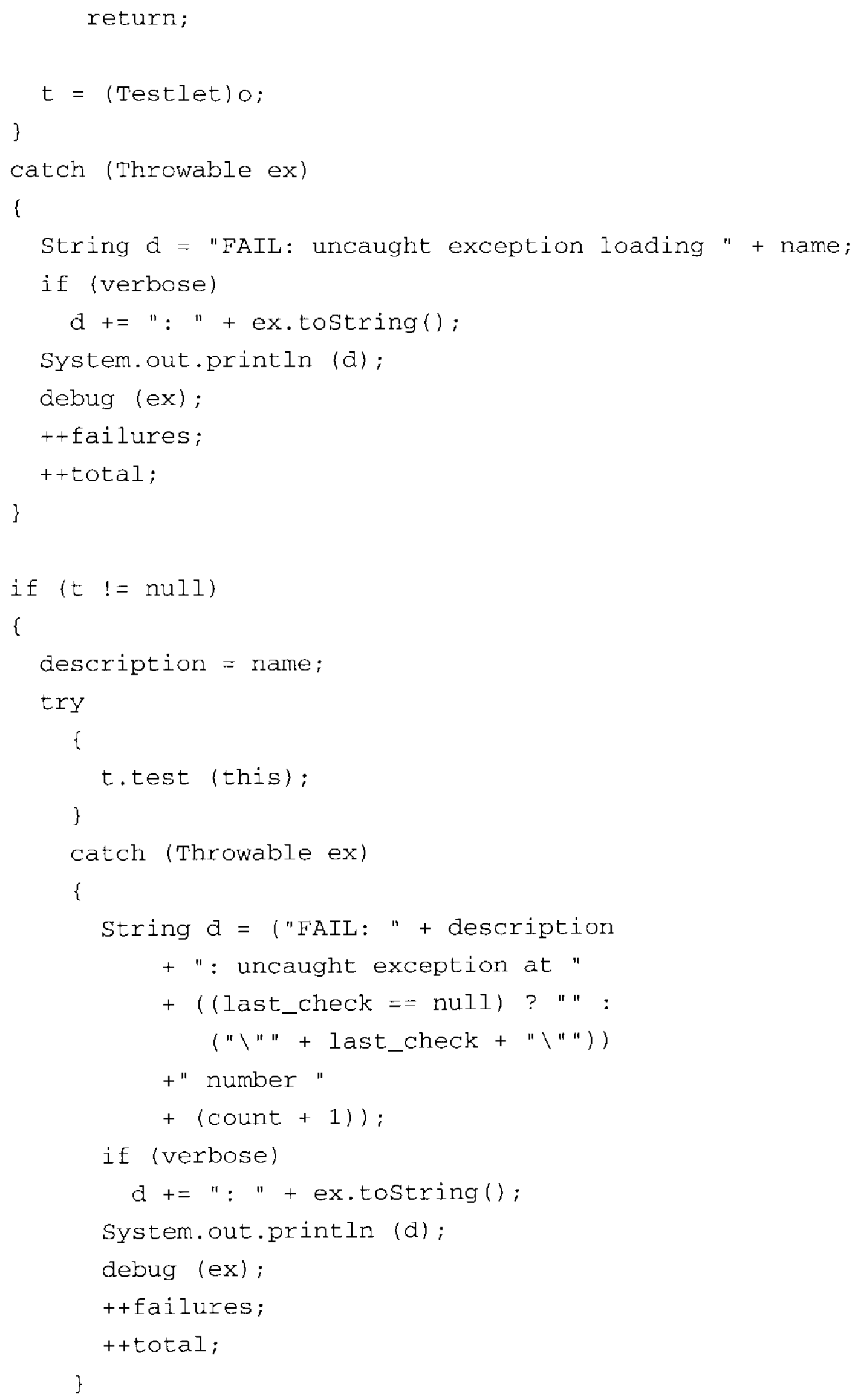




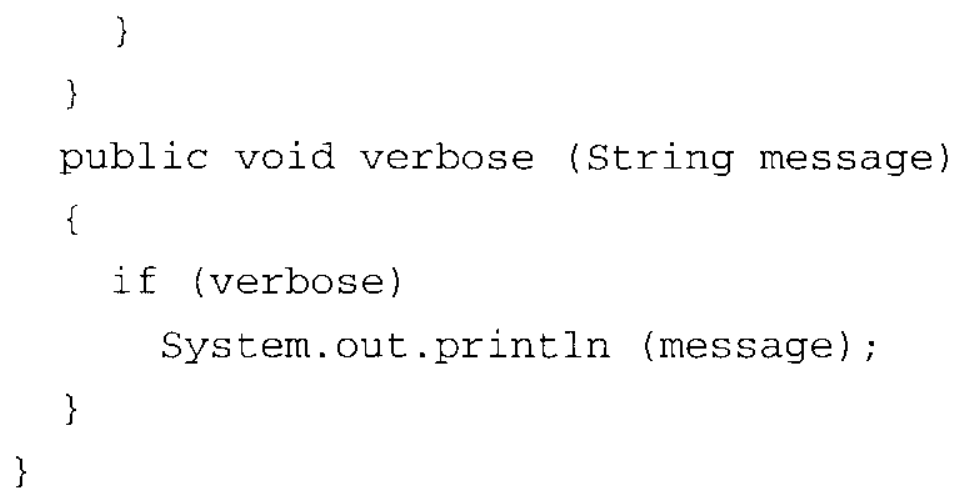

Código fonte decompilado da classe SimpleTestHarness

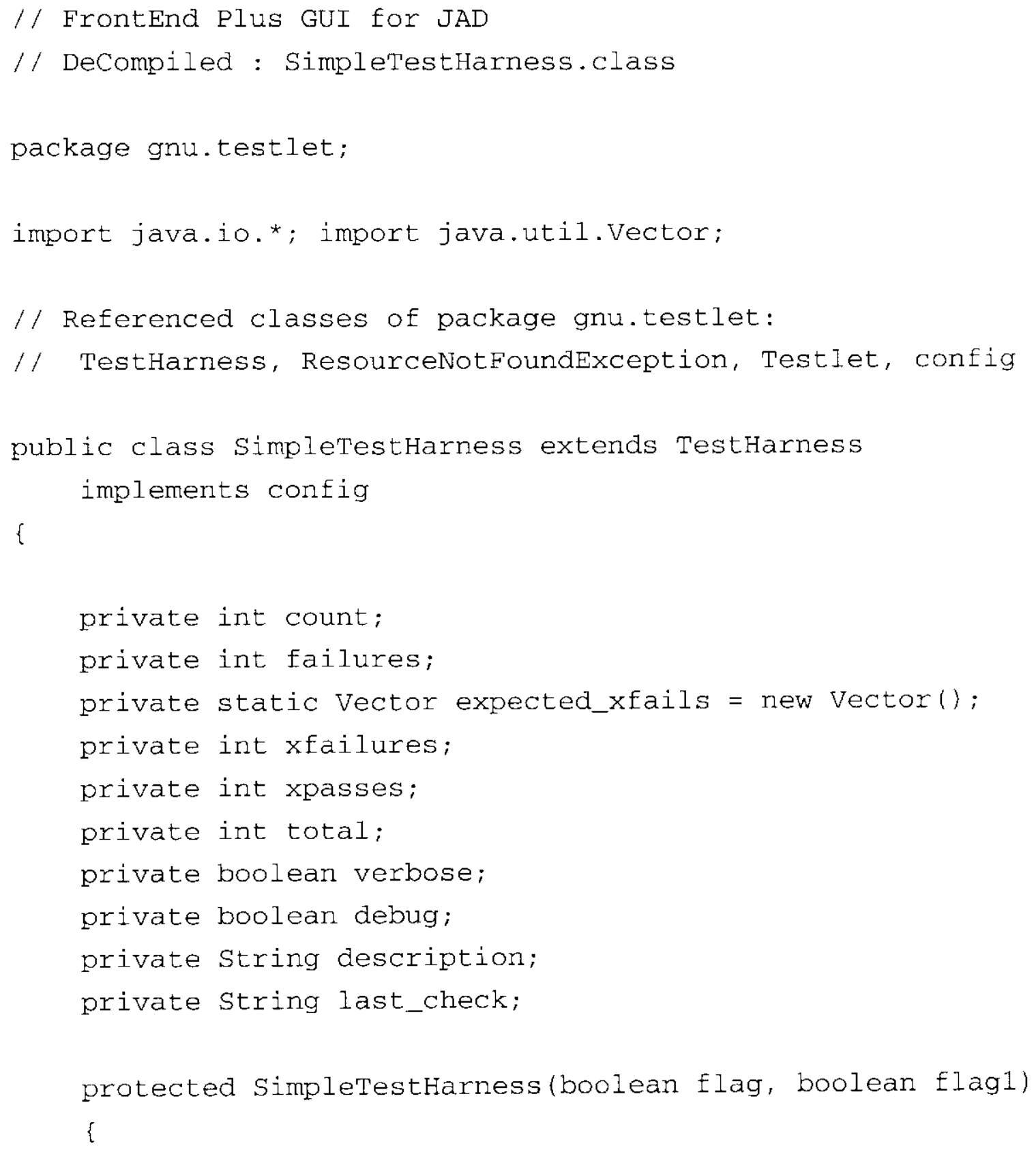




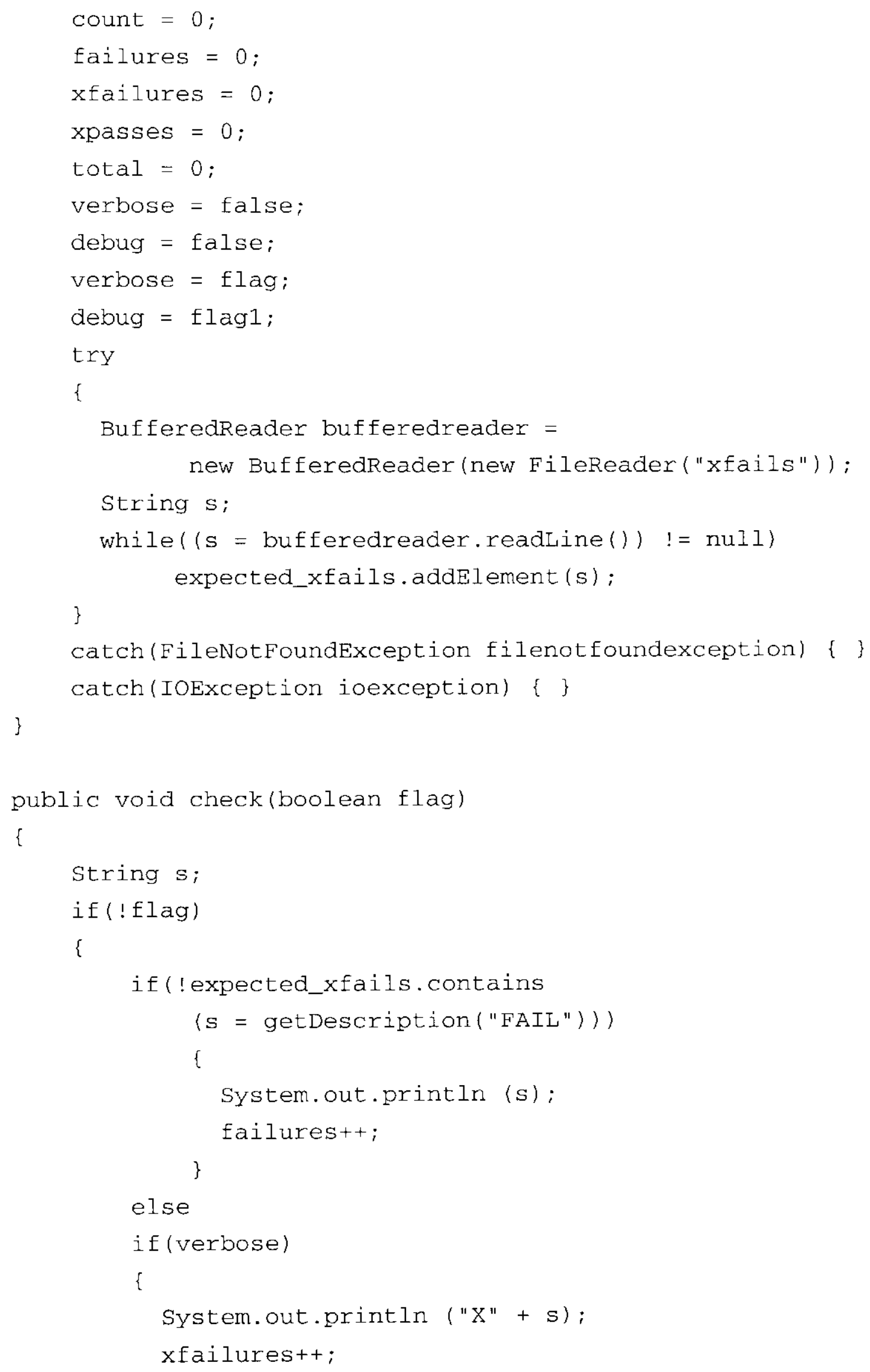




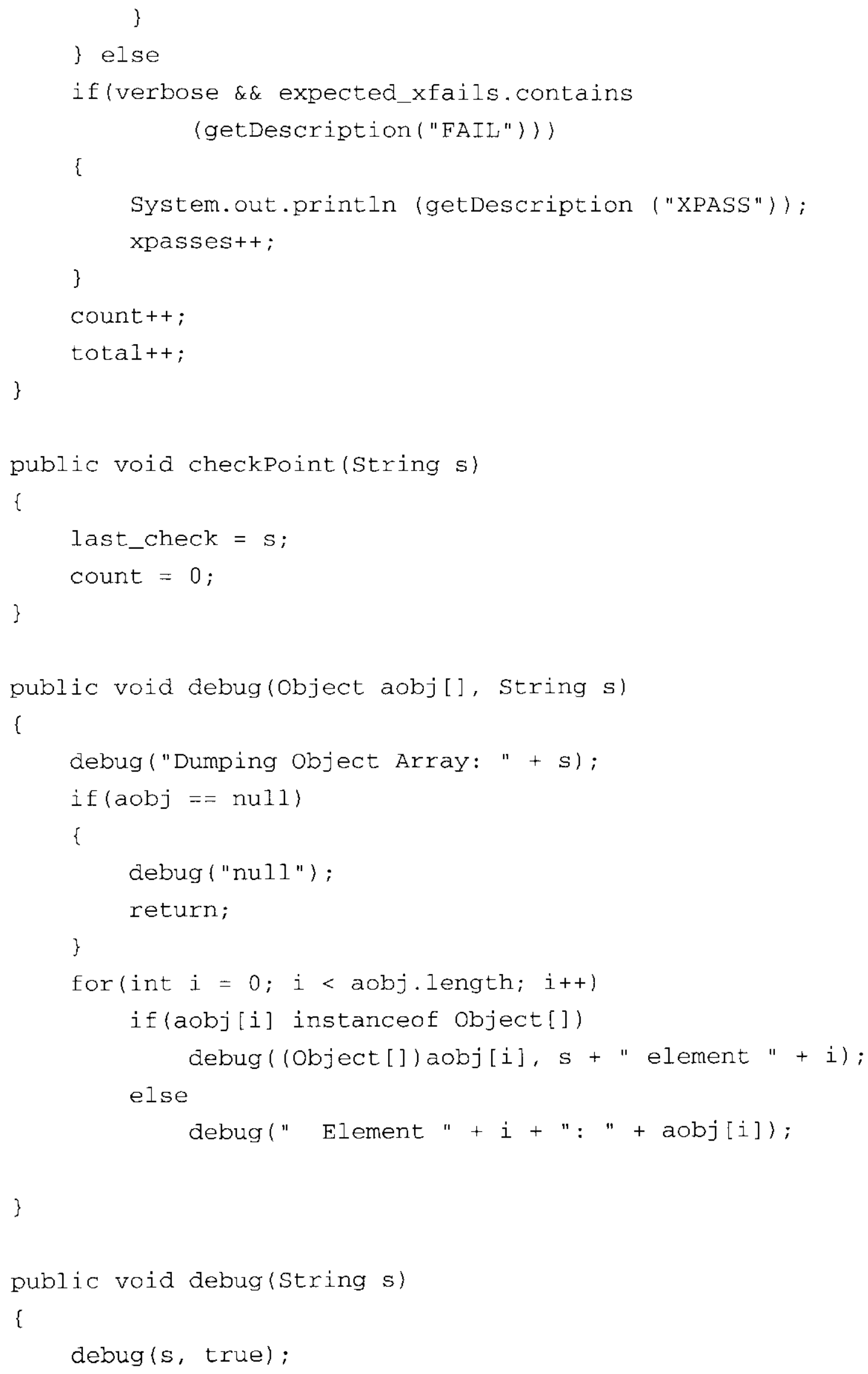


\}

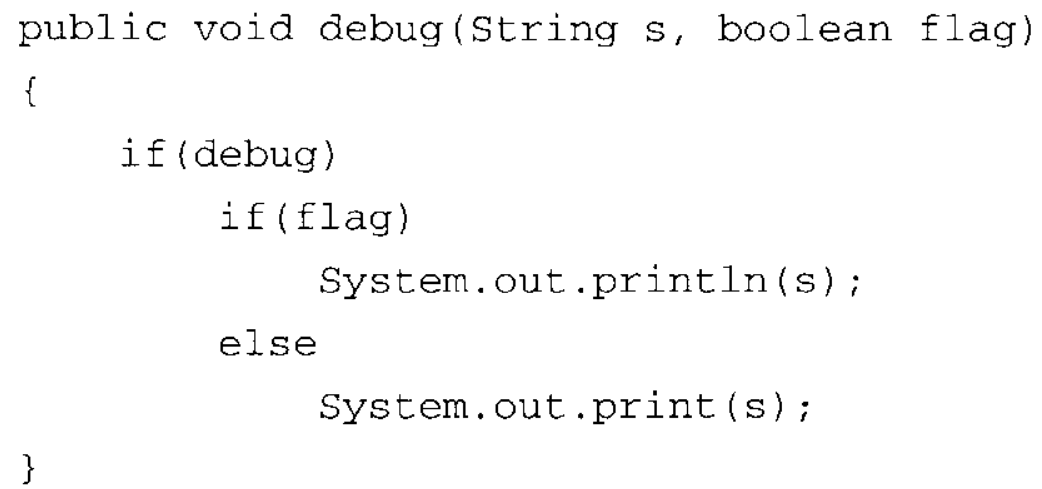




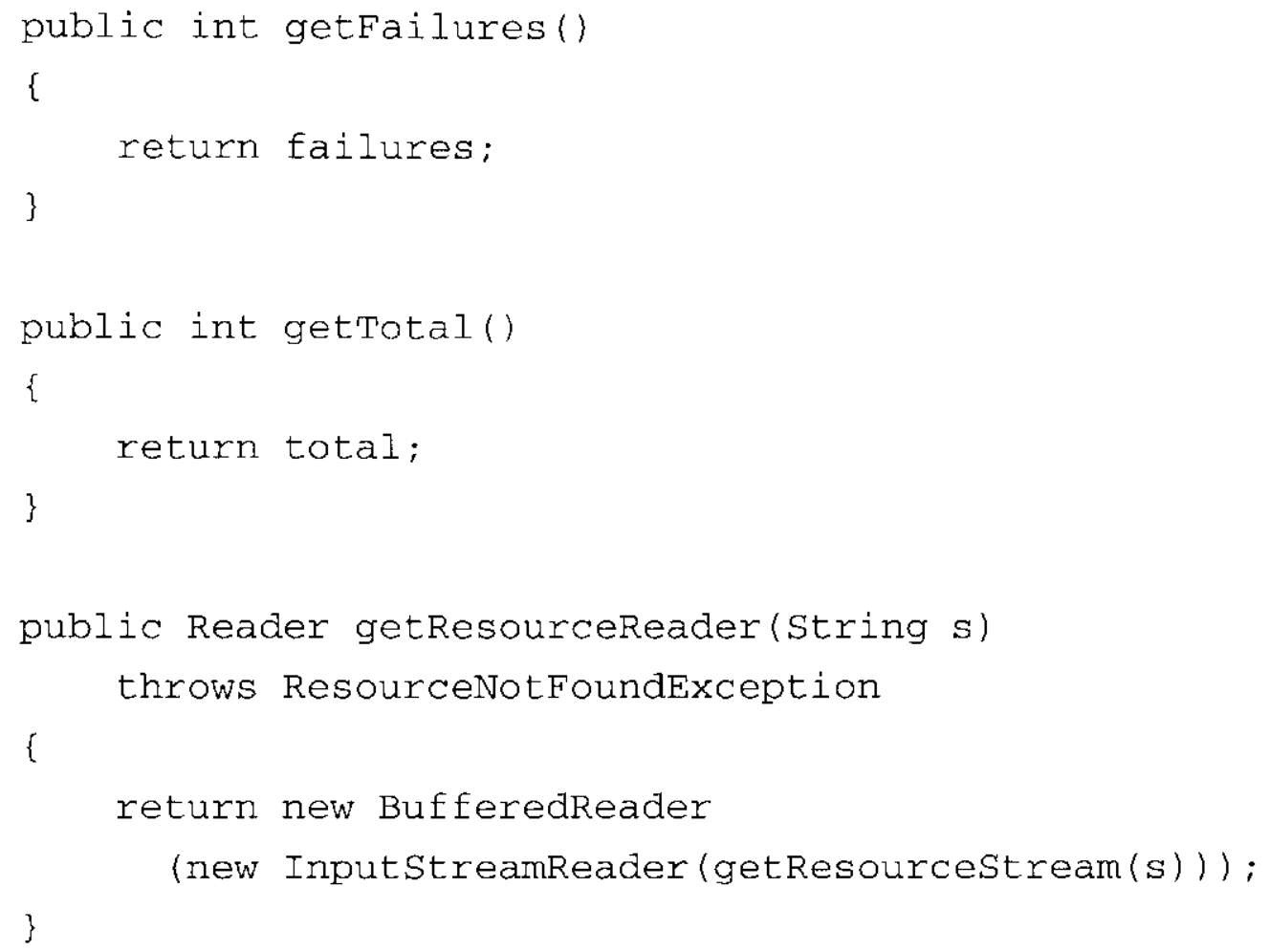




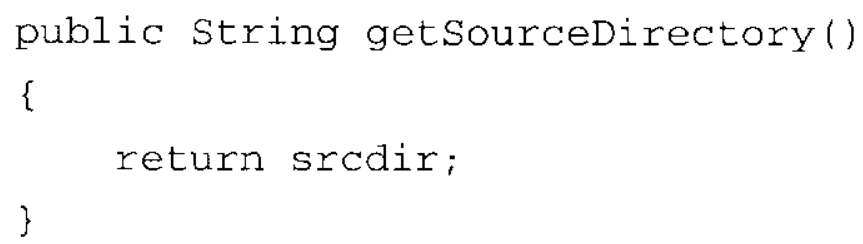


new SimpletestHarness (verbose, debug);

DataInputstream miDstream = null;

FileInputStream miFstream = null;

try

miFStream = new FileInputStream("C: \\classes.txt");

midstream = new DataInputstream (miFstream);

\}

catch(FileNotFoundException e)

\{

System.out.println("Archivo classes.txt no encontrado..."); miDStream = new DataInputStream (nul1);

System.exit (0);

\}

while (true)

\{

String cname = null;

try

\{

cname = midstream. readLine ();

if (cname $==$ null)

break;

if (verbose)

harness.verbose (cname) ;

\}

catch (IOException $\mathrm{x}$ )

\{

// Nothing .

\}

if (verbose)

harness.verbose("---");

harness.runtest (cname);

\}

System.exit (harness.done ()) ;

\} 


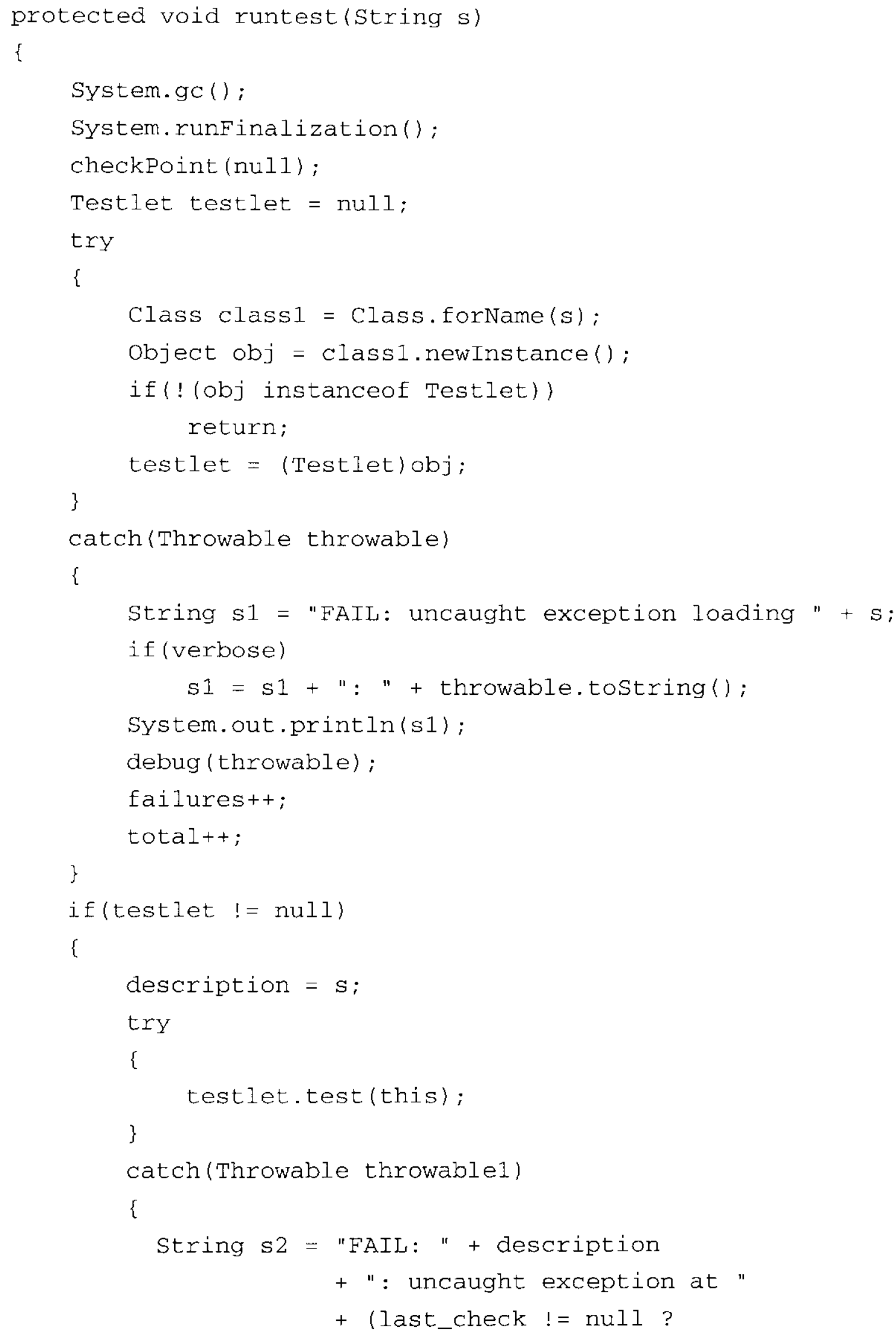




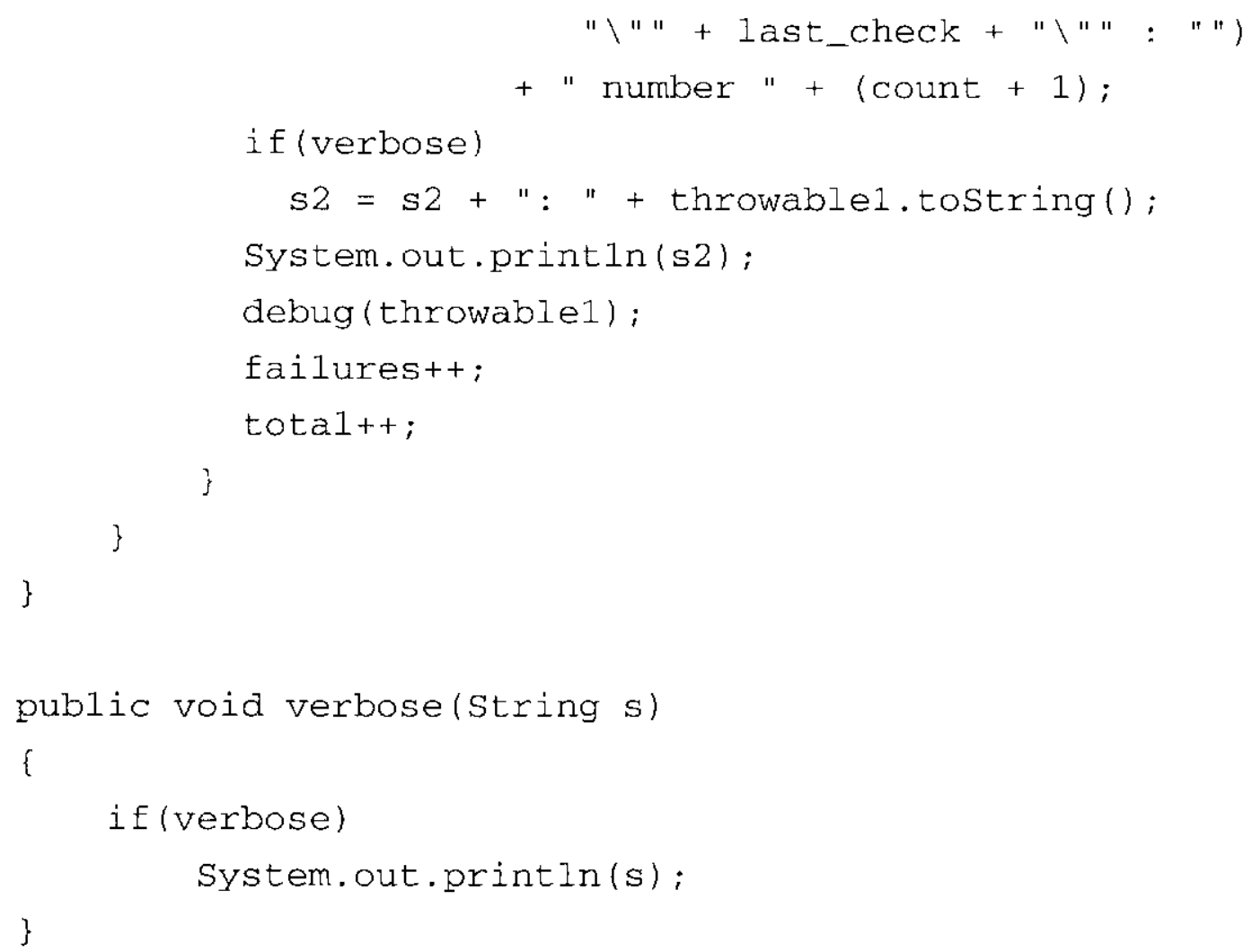

